San Jose State University

SJSU ScholarWorks

Master's Theses

Master's Theses and Graduate Research

1997

\title{
Age and growth of the Pacific Grenadier (Family Macrouridae, Coryphaenoides acrolepis) with age estimate validation using an improved radiometric ageing technique
}

Allen Hia Andrews

San Jose State University

Follow this and additional works at: https://scholarworks.sjsu.edu/etd_theses

\section{Recommended Citation}

Andrews, Allen Hia, "Age and growth of the Pacific Grenadier (Family Macrouridae, Coryphaenoides acrolepis) with age estimate validation using an improved radiometric ageing technique" (1997). Master's Theses. 1549.

DOI: https://doi.org/10.31979/etd.3sh3-yuan

https://scholarworks.sjsu.edu/etd_theses/1549

This Thesis is brought to you for free and open access by the Master's Theses and Graduate Research at SJSU ScholarWorks. It has been accepted for inclusion in Master's Theses by an authorized administrator of SJSU ScholarWorks. For more information, please contact scholarworks@sjsu.edu. 


\section{INFORMATION TO USERS}

This manuscript has been reproduced from the microfilm master. UMI films the text directly from the original or copy submitted. Thus, some thesis and dissertation copies are in typewriter face, while others may be from any type of computer printer.

The quality of this reproduction is dependent upon the quality of the copy submitted. Broken or indistinct print, colored or poor quality illustracions and photographs, print bleedthrough, substandard margins, and improper alignment can adversely affect reproduction.

In the unlikely event that the author did not send UMI a complete manuscript and there are missing pages, these will be noted. Also, if unauthorized copyright material had to be removed, a note will indicate the deletion.

Oversize materials (e.g., maps, drawings, charts) are reproduced by sectioning the original, beginning at the upper left-hand corner and continuing from left to right in equal sections with small overlaps. Each original is also photographed in one exposure and is included in reduced form at the back of the book.

Photographs included in the original manuscript have been reproduced xerographically in this copy. Higher quality 6" $\times 9$ " black and white photographic prints are available for any photographs or illustrations appearing in this copy for an additional charge. Contact UMI directly to order.

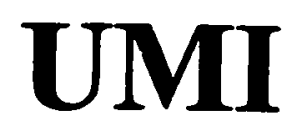

A Bell \& Howell Information Company 
AGE AND GROWTH OF THE PACIFIC GRENADIER

(FAMILY MACROURIDAE, Coryphaenoides acrolepis)

\title{
WITH AGE ESTIMATE VALIDATION USING AN IMPROVED RADIOMETRIC
}

\section{AGEING TECHNIQUE}

\author{
A Thesis \\ Presented to \\ The Faculty of Moss Landing Marine Laboratories \\ In Partial Fulfillment \\ of the Requirements for the Degree \\ Master of Science
}

By

Allen Hia Andrews

December, 1997 
UMI Number: 1388167

UMI Microform 1388167

Copyright 1998, by UMI Company. All rights reserved.

This microform edition is protected against unauthorized copying under Title 17, United States Code.

\section{UMI \\ 300 North Zeeb Road \\ Ann Arbor, MI 48103}




\section{O 1997}

Allen Hia Andrews

ALL RIGHTS RESERVED 
APPROVED FOR MOSS LANDING MARINE LABORATORIES

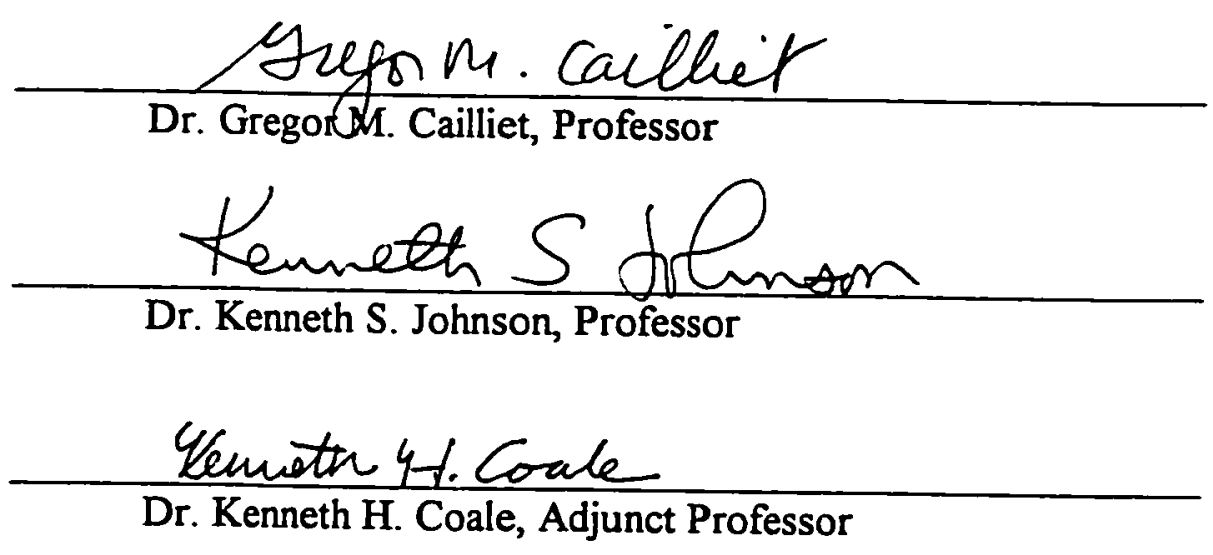

APPROVED FOR THE UNIVERSITY

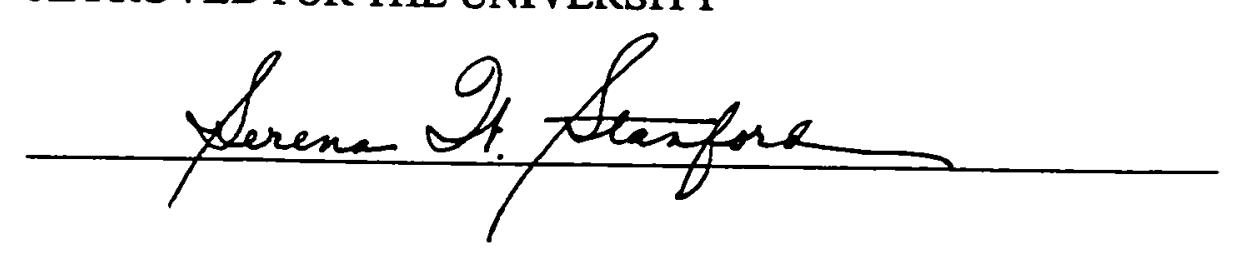




\title{
ABSTRACT \\ AGE AND GROWTH OF THE PACIFIC GRENADIER (FAMIL Y MACROURIDAE, Coryphaenoides acrolepis) WITH AGE ESTIMATE VALIDATION USING AN IMPROVED RADIOMETRIC AGEING TECHNIQUE
}

\author{
by Allen Hia Andrews
}

Longevity estimates for the Pacific grenadier, Coryphaenoides acrolepis, range from 6 to greater than 60 years. Age estimates in this study using growth increments in otolith sections indicate the Pacific grenadier is long-lived. Prior to this study, traditional ageing of this fish was not validated. In this study, the radioactive disequilibria of ${ }^{210} \mathrm{~Pb}$ and ${ }^{226} \mathrm{Ra}$ in otolith cores from Pacific grenadier were used to validate age estimates. Accuracy of radiometric ageing using ${ }^{210} \mathrm{~Pb}:{ }^{226} \mathrm{Ra}$ disequilibria in otoliths was improved using ion-exchange chromatography and thermal ionization mass spectrometry (TIMS) to measure ${ }^{226} \mathrm{Ra}$. Because TIMS counts atoms, the accuracy and precision of the technique is superior to $\alpha$-spectrometric methods. This procedure was applied to otoliths from three other fish species. Results indicate the procedure reduced sample size and processing time, and increased accuracy. Radiometric ages for the Pacific grenadier agree with traditional age estimates and indicate the Pacific grenadier can live at least 56 years. 


\section{ACKNOWLEDGEMENTS}

I would like to express my deepest appreciation and sincerest gratitude to Dr. Gregor Cailliet for believing in me and supporting me throughout my tenure as an undergraduate and graduate student at Moss Landing Marine Laboratories. Because of the guidance, trust and friendship he has given me, I have excelled in many areas of research and marines sciences, and have attained the ability of an independent researcher.

I have also been very fortunate to work under Dr. Kenneth Coale. Because of his expertise and guidance in biogeoradiochemistry, I have performed pioneering research in the recently developed school of radiometric age determination of fishes. His trust in me as a competent researcher has also given me to opportunity to function as an independent researcher.

I would also like to express my sincere appreciation to Dr. Ken Johnson and Dr. Gcorge Boehlert (Pacific Fisheries Environmental Laboratory) for interest in the subjects of my thesis and in me. Special thanks to Dr. George Boehlert for assistance with statistical analyses. Special thanks to Dr. Ken Johnson for rising to the occasion when I was in dire need of help.

Thanks to Mary Yoklavich of Pacific Fisheries Environmental Laboratory, Dave Woodbury of NMFS, Tiburon, and Erica Burton of MLML for assistance with data analysis and otolith section interpretation.

The late Dr. John Martin deserves a special thanks for providing me with funding to attend the First International Otolith Research and Application Symposium in Hilton 
Head, South Carolina in 1991. Because of this symposium, I firmly committed to pursuing a thesis in age and growth of fishes.

Chapter 2, Application of a new ion-exchange separation technique and isotopedilution thermal ionization mass spectrometry to ${ }^{226} \mathrm{Ra}$ determination in otoliths for radiometric age determination of long-lived fishes, was a collaborative effort that was made successful with the additional efforts of Jocelyn Nowicki, Craig Lundstrom, Zenon Palacz, and Erica Burton. Development of the new ion-exchange separation technique to measure radium using TIMS was facilitated by colleagues in the Department of Earth Sciences at University of California, Santa Cruz. Use of the thermal ionization mass spectrometer was an essential part of this research. Special thanks to Craig Lundstrom, Zenon Palacz, and Pete Holden for sample processing and teaching me how to use the instrument.

Fish specimens were procured from the following organizations; all of which have been very cooperative. In some cases, valuable ship-time was given.

- National Oceanic and Atmospheric Administration, Southwest Fisheries Science Center, National Marine Fisheries Service. Special thanks to John Butler.

- National Oceanic and Atmospheric Administration, Alaska Fisheries Science Center, National Marine Fisheries Service. Special thanks to Bob Lauth.

- Oregon Department of Fish and Wildlife. Special thanks to Mike Hosie.

- California Department of Fish and Game. Special thanks to Bob Lea and Bob Leos.

- University of California, San Diego/Scripps Institute of Oceanography. 
- Pacific Biological Station, Nanaimo, British Columbia. Special thanks to Bill Andrews and Kathy Rutherford.

Special thanks to Brown Lines Trucking Company for donating shipping supplies and expense for delivery of 1 ton of fish collected by Alaska Fisheries Science Center during their 1993 slope survey.

Thanks to the librarians of Moss Landing Marine Laboratories, past and present, Sheila Baldridge, Sandy ONeil, and Joan Parker, for assistance in acquiring references from all over the world.

Thanks to Lynn McMasters for assistance with graphics and siide production.

Thanks to the David and Lucille Packard Foundation for a grant to present my thesis at the American Society of Ichthyologists and Herpetologists meeting in Seattle, Washington in 1997. This research was funded by a grant from the National Sea Grant College Program, National Oceanic and Atmospheric Administration, U.S. Department of Commerce, under grant number NA36RG0537, project number R/F-148 through the California State Resources Agency.

A very special thanks to my closest friend, Jodi Thomas, whom has been very supportive and interested in my research and assisted me with processing more than 500 pounds of frozen fish in an unheated warehouse in December. 


\section{PREFACE}

This thesis presents results from using a novel technique used to determine ${ }^{226} \mathrm{Ra}$ activity in otolith material, with an application to the validation of Pacific grenadier age estimates using radiometric age determination. Chapter one is a comprehensive introduction which covers the history and application of radiometric age determination to many species and the age and growth of the Pacific grenadier, with documentation of the rapidly developing fishery. Chapter two details the research and development of the new technique used to determine ${ }^{226} \mathrm{Ra}$ activity in otolith material. Chapter three reveals new age estimates for the Pacific grenadier, compares them to existing estimates, and validates the new age estimates by applying the improved radiometric ageing technique. Chapter four is a comprehensive conclusion to chapters two and three that includes more details and further discussion indicating potential management strategies. Chapters two and three are prepared as complete scientific papers that will be submitted to the Canadian Journal of Fisheries and Aquatic Sciences, a refereed journal of our trade. These chapters are in the format required by this journal. 


\section{CONTENTS}

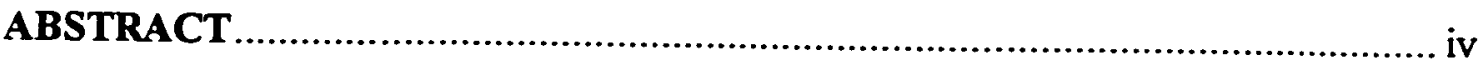

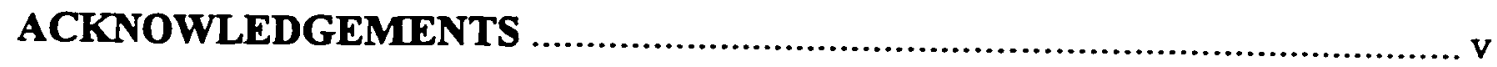

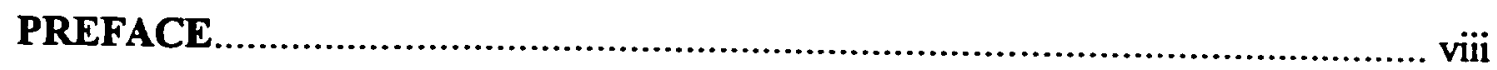

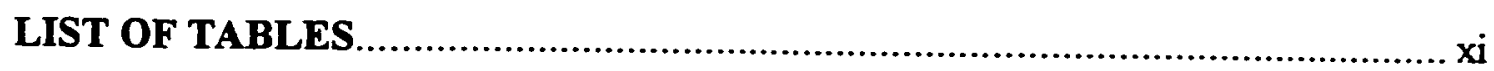

LIST OF FIGURES................................................................................

CHAPTER 1 - Introduction................................................................. 1

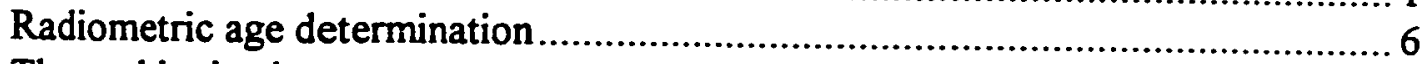

Thermal ionization mass spectrometry ................................................... 8

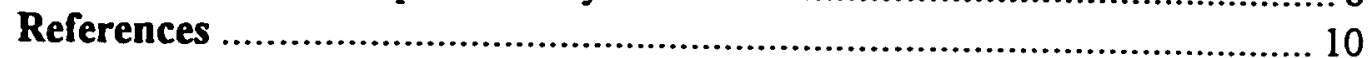

CHAPTER 2 - Application of a new ion-exchange separation technique and isotope-dilution thermal ionization mass spectrometry to ${ }^{226} \mathrm{Ra}$ determination in otoliths for radiometric age determination of long-lived fishes ................ 16

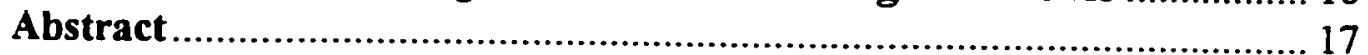

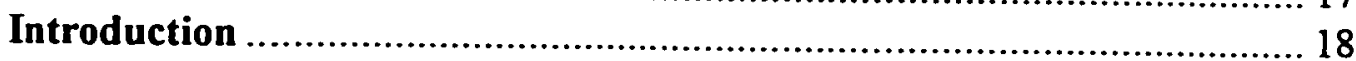

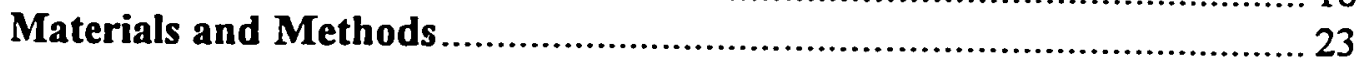

Otolith cleaning and dissolution ........................................................... 24

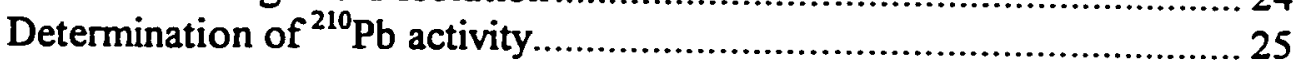

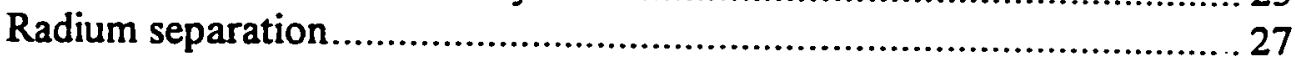

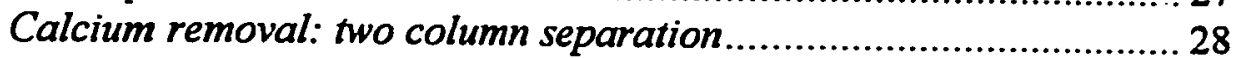

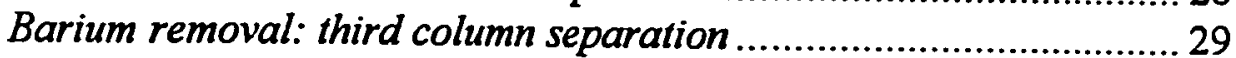

Thermal ionization mass spectrometry ................................................ 30

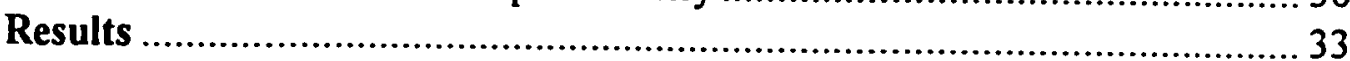

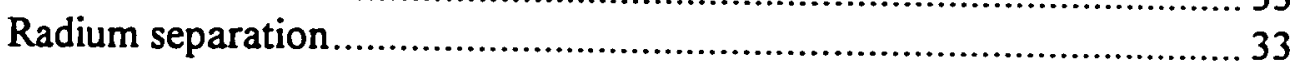

Thermal ionization mass spectrometry ............................................ 34

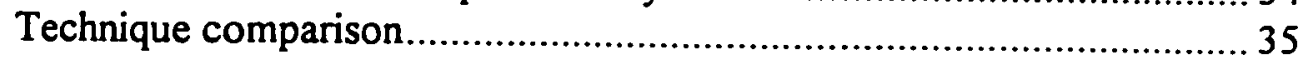

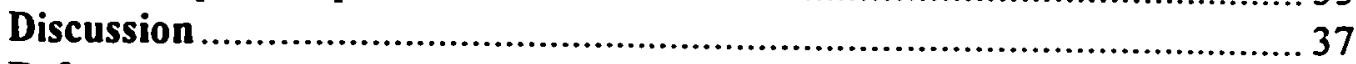

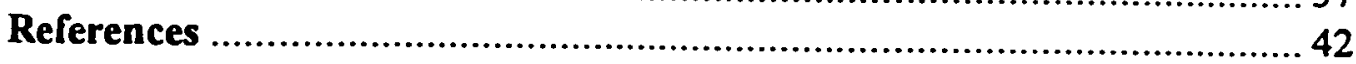

CHAPTER 3 -- Age and growth of the Pacific grenadier (Family Macrouridae, Coryphaenoides acrolepis) with age estimate validation using an improved radiometric ageing technique.

Abstract.

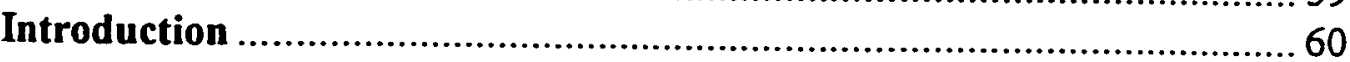




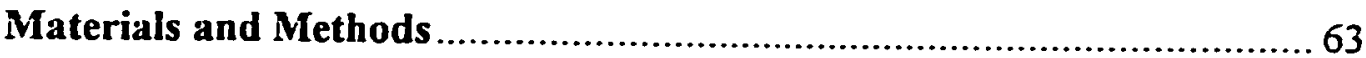

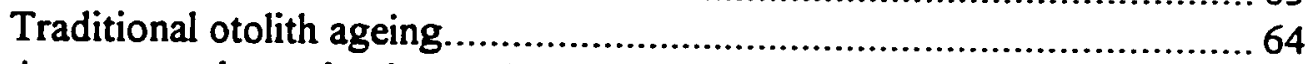

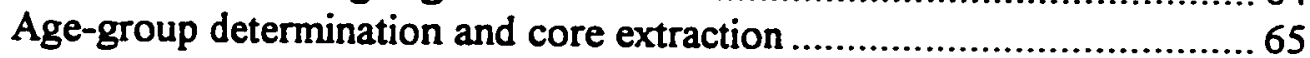

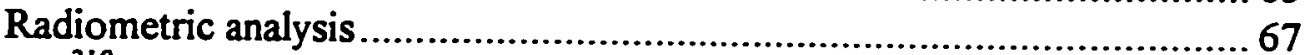

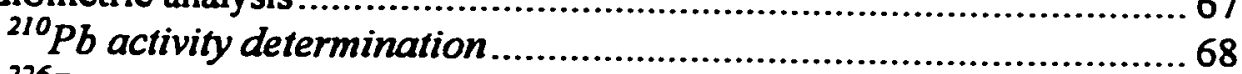

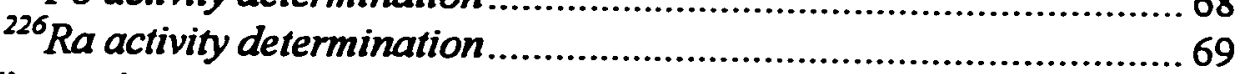

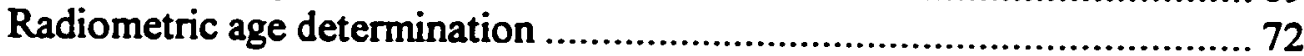

Analytical uncertainty calculation ............................................... 73

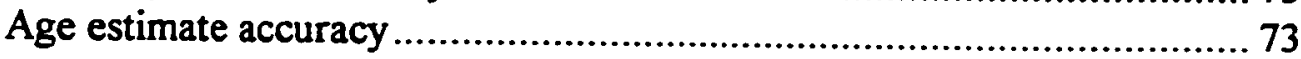

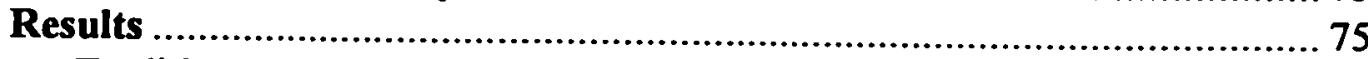

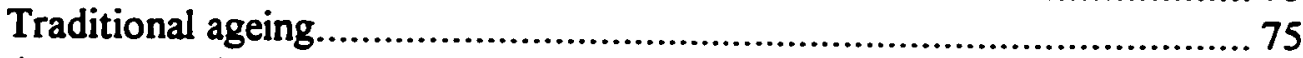

Age-group determination and core extraction ........................................ 76

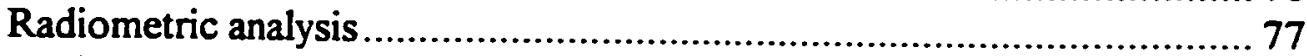

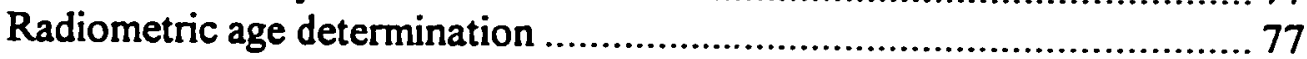

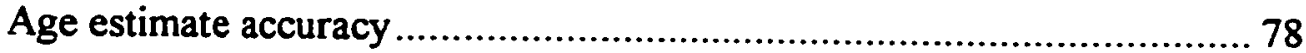

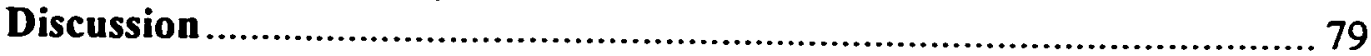

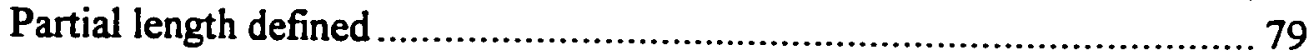

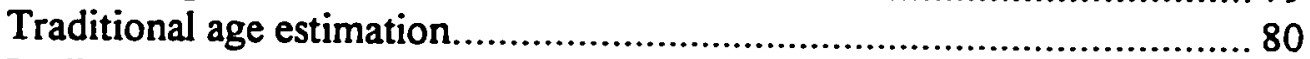

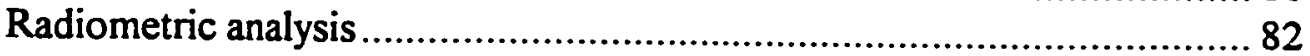

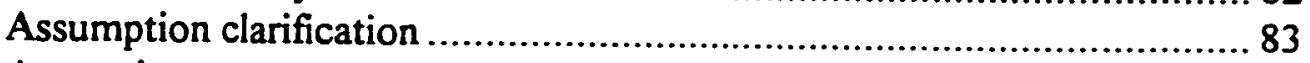

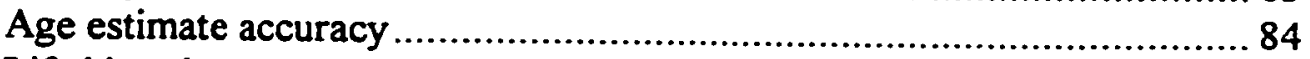

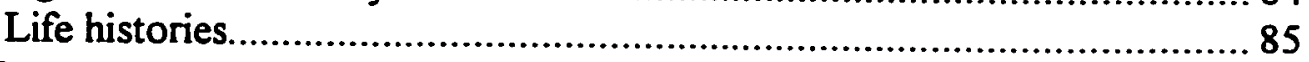

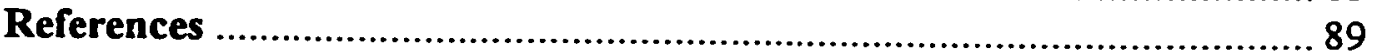

CHAPTER 4 -- Conclusions and recommendations .................................. 118

Isotope-dilution thermal ionization mass spectrometry.................................. 119

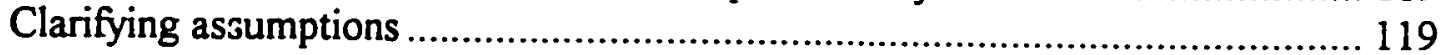

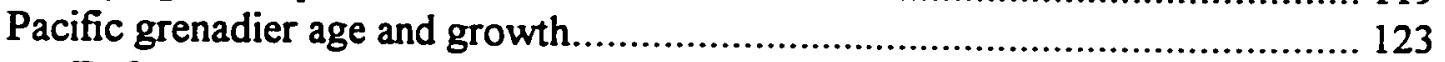

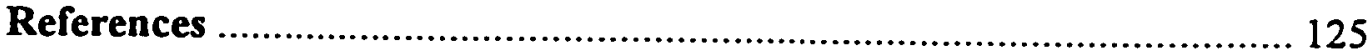




\section{LIST OF TABLES}

Figure

Page

Chapter 2

1. Cation-exchange column separation procedures 50

2. Summary of sample characteristics for each species.

3. Comparison of results for the determination of ${ }^{226} \mathrm{Ra}$ activity in otoliths from $S$. alascanus

4. Comparison of technique results for otolith-core ageing studies 53

Chapter 3

1. Comparison of reader agreement .............................................................. 100

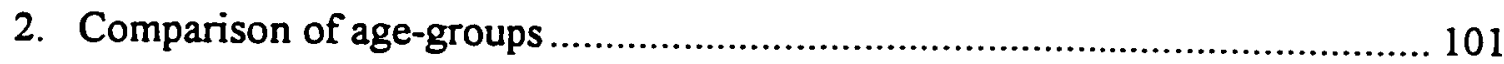

3. Radiometric results for each age-group and an otolith pair .......................... 102

4. Comparison of estimated age with radiometric age ..................................... 103

5. Comparison of von Bertalanffy growth function parameters for the Pacific grenadier 104

6. Historic and recent age estimates for Pacific grenadier 105 


\section{LIST OF FIGURES}

Figure

Page

\section{Chapter 2}

1. Elution characteristics for first column separation......................................... 55

2. Elution characteristics for second column separation....................................... 56

3. Elution characteristics for third column separation ....................................... 57

\section{Chapter 3}

1. Pacific grenadier landings for California and Oregon .................................... 109

2. Pacific grenadier landings for Monterey Bay, California................................ 110

3. Magnified transverse otolith section .................................................... 111

4. Linear relationships for three partial lengths as an indicator of total length........ 112

5. Von Bertalanffy growth functions fitted to traditional age estimates ................ 113

6. Linear relationships calculated for estimated age versus otolith weight ............. 114

7. Observed ${ }^{210} \mathrm{~Pb}:{ }^{226} \mathrm{Ra}$ activity ratios for age-groups plotted with expected

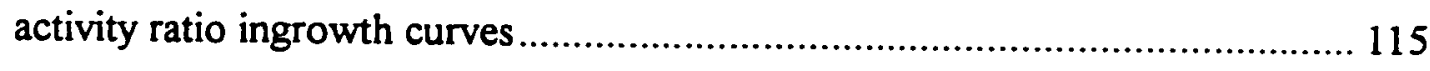

8. Comparison of estimated age versus radiometric age ..................................... 116

9. Comparison of von Bertalanffy growth functions........................................ 117 


\section{CHAPTER 1}

Introduction 
The Pacific grenadier, Coryphaenoides acrolepis, is a member of the globally important cod fishes (order Gadiformes) in the grenadier family (family Macrouridae), also known as the rattails or whiptails. Gadiform fishes composed $17 \%(13,700,000 \mathrm{t})$ of the global marine landings in 1987, of which $0.4 \%(51,000 \mathrm{t}$ ) was grenadier (Cohen et al. 1990). The grenadier is a cosmopolitan family with the exception of the Arctic Ocean and basins with a shallow sill depth (Cohen et al. 1990). The family is the most diverse of the benthopelagic fishes and consists of an ever increasing 300+ species (Tomio Iwamoto, California Academy of Sciences, San Francisco, CA, personal communication). Depth distribution ranges from the upper continental slope to abyssal depths over $6000 \mathrm{~m}$ (Marshall 1979). Most members of this family occupy the benthopelagic waters of the continental slopes between 250 and $2000 \mathrm{~m}$ (Marshall 1979, Cohen et al. 1990).

The Pacific grenadier is a benthopelagic inhabitant of the continental slopes of the northern Pacific Ocean. Its range is circum-north Pacific Ocean from Baja California, Mexico to northern Japan and into the Bering Sea (Iwamoto and Stein 1974, Cohen et al. 1990). It is one of approximately 11 grenadier species found along the central northeastern Pacific Ocean margin (Hart 1973, Iwamoto and Stein 1974, Cohen et al. 1990). Its typical depth range is from 600 to $2500 \mathrm{~m}$ (Iwamoto and Stein 1974) with a population density maximum near $1500 \mathrm{~m}$ (Stein and Pearcy 1982, Matsui et al. 1990). Historically, the Pacific grenadier fishery has been an incidental fishery where landing statistics were poorly documented. Because the Pacific grenadier has not been a targeted species, landings in most cases have been lumped into a poorly defined category. In northern Japan the grenadier catch consists of four species (C. acrolepis, C. longifilis, 
C. cinereus, and Albatrossia pectoralis). These species are not differentiated from one another and are pooled with a morid (Laemonema longipes). The landings for this group show a rapid increase from an average of approximately $3500 \mathrm{t}$ per year (1980-1989) to an average of approximately $14,000 \mathrm{t}$ per year (1990-1993), with a high of over 27,000 $\mathrm{t}$ for 1991. Increased landings are attributed to a major decrease in the landings of walleye pollock (Theragra chalcogramma), typically used in the surimi (processed white fish) market, where grenadier are used as a secondary filler (Daiji Kitigawa, Touhoku National Fisheries Institute, Hachinohe Aomori, Japan, personal communication). Russian catch per unit effort (CPUE) for Kamchatka and the Kurils indicate the highest grenadier catch success occurred in the Navarin region of the northern Bering Sea (Il'inskii 1991). Significant increases in grenadier catch occurred in the early 1980's as CPUE for other fishes decreased (i.e. sablefish (Anoplopoma fimbria)). Grenadier species composition is not described in this study.

The Pacific grenadier fishery of the northeastern Pacific Ocean began as incidental landings in the thornyhead rockfish, dover sole, and sablefish fisheries. In 1972, Eureka Fisheries (based in Fields Landing south of Eureka, California) began marketing Pacific grenadier, which has grown slowly through to the mid 1980's. In 1983, a single landing of 798 pounds at Eureka Fisheries processing plant in Coos Bay, Oregon was the beginning of the Oregon fishery, but no additional landings were made until 1987. That year, a Japanese fish buyer, Tomio Ao from Choshi, Japan began to develop an export thornyhead rockfish (Sebastolobus spp.) fishery to Japan. Thornyhead soon increased in value from approximately $\$ 0.25$ per pound in an almost exclusively United States market to over 
$\$ 1.00$ per pound in an almost exclusively Japanese market. To increase catch, many northern California and Oregon fishermen increased maximum fishing depth from approximately $800 \mathrm{~m}$ to approximately $1500 \mathrm{~m}$ by investing in larger winches and more cable at a cost of $\$ 15,000$ to $\$ 25,000$ per vessel. As a consequence, incidental landings of Pacific grenadier began to increase (Mike Hosie, Oregon Department of Fish and Game, personal communication).

Until recently, fishermen regarded the Pacific grenadier as a trash fish because the fillets were small ( $\sim 25 \%$ of the total fish weight) and had low market value ( $\$ 0.08$ to 0.16 per pound ex-vessel). In recent years the Pacific grenadier has been discovered to have desirable culinary attributes (Kremsdorf et al. 1979, Matsui et al. 1990) and has become a large commercial fishery in California and Oregon (Figure 1, Chapter 3). Landings for Monterey Bay, California have increased substantially from practically zero for 1992 to nearly $900 \mathrm{t}$ ( $\sim 2$ million pounds) for 1996 (Figure 2, Chapter 3). Prior to 1995, greater than $95 \%$ of the landings were from trawlers targeting other fish species. For 1995 and 1995, greater than $90 \%$ of the landings were from set lines targeting the Pacific grenadier (Leos 1997). Because of these landings, the Pacific grenadier is no longer in the "other" category and has become the fifth largest fishery in Monterey Bay, California and thirteenth in the state of California at $1,130 \mathrm{t}$ ( $\sim 2.5$ million pounds) for 1996 (Leos 1996, 1997).

To properly manage this rapidly developing fishery, the age structure and growth characteristics of the Pacific grenadier must be known along with other life history parameters. Some life history aspects are known (Stein and Pearcy 1982, Matsui et al. 
1990), but longevity estimates remain controversial. Recent and historical age and longevity estimates range from 6 to greater than 60 years (Kulikova 1957, Brothers et al. 1976, Mulcahey et al. 1979, Wilson 1982, Matsui et al. 1990).

Fisheries management strategies rely heavily on accurate age determinations. Age is typically determined in fishes by performing one of several techniques, but most commonly the quantification of growth increments in calcified structures (Chilton and Beamish 1982, Beamish and McFarlane 1987). The annual periodicity of growth increments in these structures is often assumed. Until recently this assumption was rarely validated (Beamish and McFarlane 1983). As a consequence, underestimation of longevity may have had serious consequences to existing fisheries; for example the decline of the Pacific ocean perch (Sebastes alutus) of the northeastern Pacific Ocean and the orange roughy (Hoplostethus atlanticus) off New Zealand (Beamish 1979, Archibald et al. 1983, Mace et al. 1990, McFarlane and Beamish 1995, Smith et al. 1995) can be attributed to inaccurate age estimates and overfishing. The problem with typical growthincrement age validation techniques is that they have limited applicability to deepwater or long-lived fishes because of slow growth, fine growth increment structure, and barotrauma upon capture (MacDonald 1987, Mace et al. 1990, McFarlane and Beamish 1995). One technique that can be used to validate age estimates for these fishes is the radiometric ageing technique which uses the disequilibria of ${ }^{210} \mathrm{~Pb}$ and ${ }^{226} \mathrm{Ra}$ in otoliths as a natural chronometer (Smith et al. 1991). 
Radiometric age determination

An essential requirement for utilizing ${ }^{210} \mathrm{~Pb}:{ }^{226} \mathrm{Ra}$ disequilibria for age determination is the capability of measuring the activity of these radioisotopes with high precision and accuracy at very low levels, from femtogram $\left(10^{-15} \mathrm{~g}\right)$ to attogram $\left(10^{-18} \mathrm{~g}\right)$ quantities. The detection of ${ }^{210} \mathrm{~Pb}$ uses the auto-deposition and alpha-spectrometric determination of its daughter proxy, ${ }^{210} \mathrm{Po}$ (Flynn 1968). Two techniques traditionally used to determine ${ }^{226} \mathrm{Ra}$ are the solid scintillation counting of its daughter proxy ${ }^{222} \mathrm{Rn}$ via radon emanation, and direct $\alpha$-spectrometry of plated ${ }^{226} \mathrm{Ra}$ samples.

The radon emanation technique has been applied to otoliths, as part of the radiometric ageing technique, of six fish species: 1) Sebastes diploproa (Bennett et al. 1982); 2) Sebastes mentella (Campana et al. 1990); 3) Anoplopoma fimbria (Kastelle et al. 1994); 4) Sebastes rufus (Watters 1995); and 5) Sebastolobus altivelis and $S$. alascamus (Kline 1996). This technique uses the $\alpha$-decay of ${ }^{222} \mathrm{Rn}$ as a proxy for ${ }^{226} \mathrm{Ra}$ determination. The first ichthyological application of this technique used whole otoliths for both ${ }^{210} \mathrm{~Pb}$ and ${ }^{226} \mathrm{Ra}$ determination (Bennett et al. 1982). However, use of whole otoliths can be imprecise and requires assumptions of constant growth which is not always a robust assumption (Francis 1995). To circumvent the need for such assumptions, a method was developed to extract the oldest part of the otolith, the core, which typically represents the first few years of growth (Campana et al. 1990). Because cores are small (approximately 0.01 to $0.05 \mathrm{~g}$ ), they must be pooled to attain measurable ${ }^{210} \mathrm{~Pb}$ activity $(\sim \mathrm{g})$. A sample size of approximately $1 \mathrm{~g}$, however, is typically too small for the radon emanation technique (Bennett et al. 1982). Therefore, ${ }^{226} \mathrm{Ra}$ determination is usually 
performed on pooled whole otoliths with the necessary assumption that ${ }^{226} \mathrm{Ra}$ uptake is in constant proportion to the otolith mass growth-rate.

To determine ${ }^{226} \mathrm{Ra}$, direct $\alpha$-spectrometry has also been used as part of the radiometric ageing technique for six fish species: 1) Hoplostethus atlanticus (Fenton et al. 1991, Smith et al. 1995); 2) Allocyttus verrucosus (Stewart et al. 1995); 3) three species of the family Lutjanidae (Milton et al. 1995); and 4) Macruronus novaezelandiea (Fenton and Short 1995). In this technique ${ }^{226} \mathrm{Ra}$ was isolated by co-precipitation with a ${ }^{133} \mathrm{Ba}$ tracer where the $\alpha$-decay of ${ }^{226} \mathrm{Ra}$ was measured directly using $\alpha$-spectrometry (Fenton et al. 1990). Because this technique is more sensitive, a lower sample size is possible $(\sim \mathrm{g})$. Therefore, this technique has been applied to otolith core samples, and whole otolith samples where cores were too small to be efficiently extracted.

Determining ${ }^{226} \mathrm{Ra}$ in otoliths using these techniques has worked well for radiometric ageing, but aspects of the technique made improvement desirable. Difficulties in developing relevant and verifiable mass growth-rate models and the uncertainty of the constant ${ }^{226} \mathrm{Ra}$ uptake assumption make the use of otolith cores preferable when possible. The large sample size typically required for radon emanation, however, make the use of cores improbable because hundreds to thousands of comparably aged fish would be necessary (>10 g; Campana et al. 1990, Watters 1995, Kline 1996). For small sample sizes typically associated with the use of otolith cores, direct $\alpha$-spectrometry is currently the most applicable. Both techniques, however, are time consuming (3-5 weeks) and can 
lead to large analytical uncertainties (range of $-4-150 \%$ from all previously cited radiometric ageing studies).

\section{Thermal ionization mass spectrometry}

In recent studies, thermal ionization mass spectrometry (TIMS) was used to measure very small quantities of ${ }^{238} \mathrm{U}$ and ${ }^{232} \mathrm{Th}$ series isotopes, including radium, in volcanic rocks with high precision and accuracy, and low detection limits (Cohen and O'Nions 1991, Volpe et al. 1991, Cohen et al. 1992, Chabaux et al. 1994). By using isotope-dilution TMS, the isotope of interest is measured directly by counting the ionized atoms. Although few thermal ionization mass spectrometers exist and processing is expensive, this technique has significant advantages over the existing radium determination techniques: 1) detection limits are at least 1000 times lower ( $\mathrm{l} \mathrm{fg}$ or 3 million atoms); 2 ) analytical precision at low concentrations is better than $1.5 \%$ (95\% conf. level); 3) measurement of radium is direct and therefore not dependent on activity or decay products; and 4) TIMS processing time requires only 1-2 hours (Volpe et al. 1991). In addition, lower detection limits would allow a smaller sample size and may make it unnecessary to pool otoliths. Given these advantages, a technique was developed to enable the application of TIMS to the measurement of ${ }^{22 \epsilon} \mathrm{Ra}$ in otoliths.

Previous applications of TIMS to the determination of ${ }^{226} \mathrm{Ra}$ in natural samples involved volcanic rocks. The elemental composition of otoliths are, however, very different from that of volcanic rocks and published methods had to be substantially modified. Of concern for the otolith analyses are high concentrations of calcium and 
barium and an organic component called otolin. Each of these constituents must be reduced to very low levels, while conserving radium, to prevent ionization suppression of the radium signal and elevated background levels during TIMS analysis (Cohen and O’Nions, 1991).

The following two chapters present the findings of two concurrent studies in journal submission format. The goals of theses studies were to: 1) develop a new technique using TIMS to determine ${ }^{226} \mathrm{Ra}$ directly in otoliths, 2) independently estimate age and growth of the Pacific grenadier using traditional ageing techniques, and 3) apply radiometric age determination and the new separation technique with isotope-dilution TIMS to age validation of the Pacific grenadier. 


\section{References}

Archibald, C.P., Fournier, D., and Leaman, B.M. 1983. Reconstruction of stock history and development of rehabilitation strategies for Pacific Ocean perch in Queen Charlotte Sound, Canada. North American Journal of Fisheries Management. 3:283-294.

Beamish, R.J. 1979. New information on the longevity of Pacific ocean perch (Sebastes alutus). J. Fish. Res. Board Can. 36:1395-1400.

Beamish, R.J. and McFarlane, G.A. 1983. The forgotten requirement for age validation in fisheries biology. Trans. Amer. Fish. Soc. 112:735-743.

Beamish, R.J. and McFarlane, G.A. 1987. Current trends in age determination methodology. In The age and growth of fish. Edited by R.C. Summerfelt and G.E. Hall. The Iowa State University Press, Ames, Iowa. pp. 15-42.

Bennett, J.T., Boehlert, G.W., and Turekian, K.K.. 1982. Confirmation of longevity in Sebastes diploproa (Pisces: Scorpaenidae) from ${ }^{210} \mathrm{~Pb} /{ }^{226} \mathrm{Ra}$ measurements in otoliths. Mar. Biol. 71:209-215.

Brothers, E.B., Mathews, C.P., Lasker, R. 1976. Daily growth increments in otoliths from larval and adult fishes. Fish. Bull. 74(1):1-8.

Campana, S.E., Zwanenburg, K.C.T., and Smith, J.N.. $1990 .{ }^{210} \mathrm{~Pb} /{ }^{226} \mathrm{Ra}$ determination of longevity in redfish. Can. J. Fish. Aquat. Sci. 47:163-165.

Chabaux, F., Othman, D.B., and Birck, J.L. 1994. A new Ra-Ba chromatographic separation and its application to Ra mass-spectrometric measurement in volcanic rocks. Chem. Geol. 119:191-197. 
Chilton, D.E. and Beamish, R.J. 1982. Age determination methods tor fishes studied by the groundfish program at the Pacific biological station. Can. Spec. Publ. Fish. Aquat. Sci. No. 60.

Cohen, A.S. and ONions, R.K. 1991. Precise determination of femtogram quantities of radium by thermal ionization mass spectrometry. Anal. Chem. 63:2705-2708.

Cohen. A.S., Belshaw, N.S., and ONions, R.K. 1992. High precision uranium, thorium and radium isotope ratio measurements by high dynamic range thermal ionisation mass spectrometry. Int. J. Mass Spec. Ion Proc. 116:71-81.

Cohen, D.M., Inada, T., Iwamoto, T., Scialabba, N. 1990. FAO species catalogue. Vol. 10. Gadiform fishes of the world (Order Gadiformes). An annotated and illustrated catalogue of cods, hakes, grenadiers and other gadiform fishes known to date.

FAO Fisheries Synopsis. No. 125, Vol. 10. Rome, FAO.

Fenton, G.E., Ritz, D.A., and Short, S.A. $1990 .{ }^{210} \mathrm{~Pb} /{ }^{226} \mathrm{Ra}$ disequilibria in otoliths of blue grenadier, Macruronus novaezelandiae; problems associated with radiometric ageing. Aust. J. Freshwater Res. 41:467-473.

Fenton, G.E., Short, S.A., and Ritz, D.A. 1991. Age determination of orange roughy, Hoplostethus atlanticus (Pisces: Trachichthyidae) using ${ }^{210} \mathrm{~Pb}:{ }^{226} \mathrm{Ra}$ disequilibria. Mar. Biol. 109:197-202.

Fenton, G.E. and Short, S.A. 1995. Radiometric analysis of blue grenadier, Macruronus novaezelandiae, otolith cores. Fish. Bull. 93:391-396.

Flynn, W.W. 1968. The determination of low levels of polonium-210 in environmental materials. Anal. Chim. Acta 43:221-227. 
Francis, R.I.C.C. 1995. The problem of specifying otolith-mass growth parameters in the radiometric estimation of fish age using whole otoliths. Mar. Biol. 124:169-176.

Hart, J.L. 1973. Pacific fishes of Canada. Bulletin 180. Fisheries Research Board of Canada. Ottawa.

Il'inskii, E.N. 1991. Long-term changes in the composition of bottom fish catches on the continental slope in the western part of the Bering Sea, along the Pacific Seaboard of Kamchatka and the Kurils. Voprosy ikhtiologii, 31(1):73-81. (Translated from Russian by Scripta Technica, Inc. 1991. p. 117-127).

Iwamoto, T., and Stein, D.L. 1974. A systematic review of the rattail fishes (Macrouridae: Gadiformes) from Oregon and adjacent waters. Calif. Acad. Sci., Occas. Pap. 111:1-79.

Kastelle, C.R., Kimura, D.K., Nevissi, A.E., and Gunderson, D.R. 1994. Using Pb210/Ra-226 disequilibria for sablefish, Anoplopoma fimria, age validation. Fish. Bull. 92:292-301.

Kline, D.E. 1996. Radiometric age verification for two deep-sea rockfish (Sebastolobus altivelis and Sebastolobus alascamus). M.S. thesis, California State University, San Jose, Moss Landing Marine Laboratories.

Kremsdorf, D.L., Josephson, R.V., Spindler, A.A., Phleger, C.F. 1979. Gross composition, sensory evaluation, and cold storage stability of underutilized deep sea Pacific rattail fish, Coryphaenoides acrolepis. J. Food Sci. 44:1044-1048. 
Kulikova, E.B. 1957. Growth and age of deep-water fishes. Trudy Inst. Okean. Akad. Nauk. 20:347-355. (Translated from Russian by Am. Inst. Biol. Soc. p. 284-290. 1959).

Leos, B. (ed.). 1996. Monterey Bay commercial fisheries report: an annual newsletter to the commercial fishing industry. California Department of Fish and Game. No. 7.

Leos. B. (ed.). 1997. Monterey Bay commercial fisheries report: an annual newsletter to the commercial fishing industry. California Department of Fish and Game. No. 8.

Mace, P.M., Fenaughty, J.M., Coburn, R.P., and Doonan, I.J. 1990. Growth and productivity of orange roughy (Hoplostethus atlanticus) on the north Chatham Rise. N.Z., J. Mar. Freshwater Res. 24:105-109.

MacDonald, P.D.M. 1987. Analysis of length-frequency distributions. In The age and growth of fish. Edited by R.C. Summerfelt and G.E. Hall. The Iowa State University Press, Ames, Iowa. pp. 371-384.

McFarlane, G.A. and Beamish, R.J. 1995. Validation of the otolith cross-section method of age determination for sablefish (Anoplopoma fimbria) using oxytetracycline. In Recent developments in fish otolith research. Edited by D.H. Secor, J.M. Dean, and S.E. Campana. The Belle W. Baruch Library in Marine Science, No. 19. University of South Carolina Press, Columbia, South Carolina. pp. 319-330.

Marshall, N.B. 1979. Deep-Sea Biology Developments \& Perspectives. Garland STPM Press. New York and London.

Matsui, T., Kato, S., and Smith, S.E. 1990. Biology and potential use of Pacific grenadier, Coryphaenoides acrolepis, off Calofornia. Mar. Fish. Rev. 52(3):1-17. 
Milton, D.A., Short, S.A., ONeill, M.F., and Blaber, S.J.M. 1995. Ageing of three species of tropical snapper (Lutjanidae) from the Gulf of Carpentaria, Australia, using radiometry and otolith ring counts. Fish. Bull. 93:103-115.

Mulcahey, S.A., Killingley, J.S., Phleger, C.F., and Berger, W.H. 1979. Isotopic composition of otoliths from a benthopelagic fish Coryphaenoides acrolepis, Macrouridae:Gadiformes. Oceanologica Acta. 2:423-427.

Smith, D.C., Fenton, G.E., Robertson, S.G., and Short, S.A. 1995. Age determination and growth of orange roughy (Hoplostethus atlanticus): a comparison of annulus counts with radiometric ageing. Can. J. Fish. Aquat. Sci. 52:391-401.

Smith, J.N., Nelson, R., and Campana, S.E.. 1991. The use of Pb-210/Ra-226 and Th228/Ra-228 dis-equilibria in the ageing of otoliths of marine fish. In Radionuclides in the study of marine processes. Edited by P.J. Kershaw and D. Woodhead. Elsevier Science, New York, NY. pp.350-359.

Stein, D.L., and Pearcy, W.G. 1982. Aspects of reproduction, early life history, and biology of macrourid fishes of Oregon, USA. Deep-Sea Res. 29(11A):1373-1379.

Stewart, B.D., Fenton, G.E., Smith, D.C., and Short, S.A. 1995. Validation of otolithincrement age estimates for a deepwater fish species, the warty oreo Allocyttus verrucosus, by radiometric analysis. Mar. Biol. 123:29-38.

Watters, D.L. 1995. Age determination and confirmation from otoliths of the bank rockfish, Sebastes rufus (Scorpaenidae). M.S. thesis, California State University, San Jose, Moss Landing Marine Laboratories. 
Wilson, R.R., Jr. 1982. A comparison of ages estimated by the polarized light method with ages estimated by vertebrae in females of Coryphaenoides acrolepis (Pisces:

Macrouridae). Deep-Sea Res. 29(11A):1373-1379.

Volpe, A.M., Olivares, J.A., and Murrell, M.T.. 1991. Determination of radium isotope ratios and abundances in geologic samples by thermal ionization mass spectrometry. Anal. Chem. 63:913-916. 


\section{CHAPTER 2}

Application of a new ion-exchange separation technique and isotope-dilution thermal ionization mass spectrometry to ${ }^{226} \mathbf{R a}$ determination in otoliths for radiometric age determination of long-lived fishes.

Submitted for publication: Canadian Journal of Fisheries and Aquatic Sciences 


\begin{abstract}
To improve the accuracy and precision of radiometric age determination using ${ }^{210} \mathrm{~Pb}:{ }^{226} \mathrm{Ra}$ disequilibria in otoliths of fishes, a technique was developed using isotopedilution thermal ionization mass spectrometry (TIMS) to determine ${ }^{226} \mathrm{Ra}$. Because TIMS measures radium directly by counting ionized atoms, the accuracy and precision of the technique is superior to conventional $\alpha$-spectrometric methods. Due to their chemical similarities, radium must be separated from interfering quantities of calcium and barium in the otolith matrix. This was accomplished using a new ion-exchange separation procedure. This procedure was tested by applying it to otolith samples from three fish species in three separate radiometric ageing studies. The resultant separations and TIMS determinations indicate the procedure efficiently separates radium from calcium and barium. Measured ${ }^{226} \mathrm{Ra}$ activities for each species were comparable to previous radiometric ageing studies, with the exception of one sample. When results are compared to traditional ${ }^{226} \mathrm{Ra}$ determination techniques, radon emanation and $\alpha$-spectrometry, the new separation technique with isotope-dilution TIMS has significant advantages. Samples over three times smaller than attempted in other studies were processed with increased accuracy and decreased processing time.
\end{abstract}




\section{Introduction}

Fisheries management strategies rely heavily on accurate age determinations. Age is typically determined in fishes by performing several techniques, but the most common is the quantification of growth increments in calcified structures (i.e. otoliths; Chilton and Beamish 1982, Beamish and McFarlane 1987). The annual periodicity of growth increments in these structures is often assumed. Until recently, however, this assumption was rarely validated (Beamish and McFarlane 1983). As a consequence, underestimated longevity may have had serious consequences to existing fisheries (Beamish 1979, Archibald et al. 1983, Mace et al. 1990, McFarlane and Beamish 1995, Smith et al. 1995). The problem with typical growth-increment age validation techniques is that they have limited applicability to deepwater or long-lived fishes because of slow growth, fine growth increment structure, and barotrauma upon capture (MacDonald 1987, Mace et al. 1990, McFarlane and Beamish 1995). One technique that can be used to validate age estimates for these fishes is a radiometric approach which exploits the disequilibria of ${ }^{210} \mathrm{~Pb}$ and ${ }^{226} \mathrm{Ra}$ in otoliths as a natural chronometer (Smith et al. 1991).

An essential requirement for utilizing ${ }^{210} \mathrm{~Pb}:{ }^{226} \mathrm{Ra}$ disequilibria for age determination is the capability of measuring the activity of these radioisotopes with high precision and accuracy at very low levels, from femtogram $\left(10^{-15} \mathrm{~g}\right)$ to attogram $\left(10^{-18} \mathrm{~g}\right)$ quantities. Because backgrolnd in the ${ }^{210} \mathrm{~Pb}-{ }^{210} \mathrm{Bi}$ beta-counting technique via lead sulfate coprecipitation is relatively high (6 to 12 counts per hour), this technique was not employed (Koide and Bruland 1975). Due to the relatively short half-life and low activity of ${ }^{210} \mathrm{~Pb}$, the detection of ${ }^{210} \mathrm{~Pb}$ is typically accomplished through the autodeposition and 
alpha-spectrometric determination of its daughter proxy, ${ }^{210} \mathrm{Po}$ (Flynn 1968). Differences in half-life for ${ }^{210} \mathrm{~Pb}$ and ${ }^{226} \mathrm{Ra}$ lead to low ${ }^{210} \mathrm{~Pb}:{ }^{226} \mathrm{Ra}$ atom ratios. Therefore direct mass determination methods are not feasible for ${ }^{210} \mathrm{~Pb}$ at this time. Because of these constraints, the long counting times required, and the low backgrounds associated with $\alpha$ spectrometry, autodeposition and $\alpha$-spectrometric analysis of ${ }^{210} \mathrm{Po}$ was chosen to determine ${ }^{210} \mathrm{~Pb}$ activity in this study. Two techniques traditionally used to determine ${ }^{226} \mathrm{Ra}$ are the solid scintillation counting of its daughter proxy ${ }^{222} \mathrm{Rn}$ via radon emanation, and direct $\alpha$-spectrometry of plated ${ }^{226} \mathrm{Ra}$ samples.

The radon emanation technique has been applied to otoliths, as part of the radiometric ageing technique, of six fish species: 1) Sebastes diploproa (Bennett et al. 1982); 2) Sebastes mentella (Campana et al. 1990); 3) Anoplopoma fimbria (Kastelle et al. 1994); 4) Sebastes rufus (Watters 1995); and 5) Sebastolobus altivelis and S. alascamus (Kline 1996). This technique uses the $\alpha$-decay of ${ }^{222} \mathrm{Rn}$ as a proxy for ${ }^{226} \mathrm{Ra}$ determination. The first ichthyological application of this technique used whole otoliths for both ${ }^{210} \mathrm{~Pb}$ and ${ }^{226} \mathrm{Ra}$ determination (Bennett et al. 1982). However, use of whole otoliths can be imprecise and requires assumptions of constant growth which are not always robust (Francis 1995). To circumvent the need for such assumptions, a method was developed to extract the oldest part of the otolith, the core, which typically represen's the first few years of growth (Campana et al. 1990). Because cores are small (approximately 0.01 to $0.05 \mathrm{~g}$ ), they must be pooled to attain measurable activity. A sample size of approximately $1 \mathrm{~g}$, however, is typically too small for the radon emanation technique (Bennett et al. 1982). Therefore, ${ }^{226} \mathrm{Ra}$ determination is usually performed on 
pooled whole otoliths with the necessary assumption that ${ }^{226} \mathrm{Ra}$ uptake is in constant proportion to the otolith mass growth-rate.

To determine ${ }^{226} \mathrm{Ra}$, direct $\alpha$-spectrometry has also been used as part of the radiometric ageing technique for six fish species: 1) Hoplostethus atlanticus (Fenton et al. 1991, Smith et al. 1995); 2) Allocyttus verrucosus (Stewart et al. 1995); 3) three species of the family Lutjanidae (Milton et al. 1995); and 4) Macruromus novaezelandiea (Fenton and Short 1995). In this technique ${ }^{226} \mathrm{Ra}$ is isolated by co-precipitating with barium, using $\mathrm{a}^{133} \mathrm{Ba}$ yield tracer followed by $\alpha$-spectrometric determination of the ${ }^{226} \mathrm{Ra}$ on calibrated detectors (Fenton et al. 1990). Because this technique is more sensitive, a lower sample size $(\sim \mathrm{lg})$ is possible. Therefore, this technique has been applied to otolith core samples, and whole otolith samples where cores were too small to be efficiently extracted.

Determining ${ }^{226} \mathrm{Ra}$ in otoliths using these techniques has worked well for radiometric ageing, but aspects of the technique made improvement desirable. Difficulties in developing relevant and verifiable mass growth-rate models and the uncertainty of the constant ${ }^{226} \mathrm{Ra}$ uptake assumption make the use of otolith cores preferable when possible. The large sample size typically required for radon emanation, however, make the use of cores improbable because hundreds to thousands of comparably aged fish would be necessary (>10 g; Campana et al. 1990, Watters 1995, Kline 1996). Yield determinations using ${ }^{133} \mathrm{Ba}$, a $\beta$-technique, introduce additional errors, and direct $\alpha$-counting of ${ }^{226} \mathrm{Ra}$ often leads to detector contamination and high backgrounds. For the small sample sizes typically associated with the use of otolith cores, direct $\alpha$-spectrometry is currently the most applicable. Both techniques, however, are time consuming (3-5 weeks) and can lead 
to large analytical uncertainties (range of $\sim 4-150 \%$ from all previously cited radiometric ageing studies).

In recent studies, thermal ionization mass spectrometry (TIMS) has been used to measure very small quantities of ${ }^{238} \mathrm{U}$ and ${ }^{232} \mathrm{Th}$ series isotopes, including radium, in volcanic rocks. High precision and accuracy, and low detection limits have been reported for this technique (Cohen and O'Nions 1991, Volpe et al. 1991, Cohen et al. 1992, Chabaux et al. 1994). By using isotope-dilution TIMS, the isotope of interest is measured directly by counting the ionized atoms. Although few thermal ionization mass spectrometers exist and processing is sometimes expensive, this technique has significant advantages over the existing radium determination techniques: 1) detection limits are at least 1000 times lower ( $-1 \mathrm{fg}$ or 3 million atoms); 2 ) analytical precision at low concentrations is better than $1.5 \%$ (95\% conf. level); 3 ) measurement of radium is direct and therefore not dependent on decay; and 4) TIMS processing time requires only 1-2 hours (Volpe et al. 1991). In addition, lower detection limits would allow a smaller sample size and may make it unnecessary to pool otoliths. Given these advantages, a technique was developed to enable the application of TIMS to the measurement of ${ }^{226} \mathrm{Ra}$ in otoliths.

Previous applications of TIMS to the determination of ${ }^{226} \mathrm{Ra}$ in natural samples has involved volcanic rocks. The elemental composition of otoliths are, however, very different from that of volcanic rocks and published methods had to be substantially modified. Of concern in the analysis of otoliths are high concentrations of calcium and barium and an organic component called otolin. Each of these constituents must be 
reduced to very low levels, while conserving radium, to prevent ionization suppression of the radium signal and elevated background levels during TIMS analysis (Cohen and O’Nions, 1991).

This paper describes a new technique using TIMS to determine ${ }^{226} \mathrm{Ra}$ directly in otoliths which was adapted from a recently developed ion-exchange separation technique for geological samples (Chabaux et al. 1994). To test the application of this new technique, we have determined ${ }^{226} \mathrm{Ra}$ in otoliths of three fish species using isotope-dilution TIMS. In some otolith samples, ${ }^{210} \mathrm{~Pb}$ was also measured for the purpose of radiometric age determination, the results of which are only briefly discussed here. The focus of this paper is the determination of ${ }^{226} \mathrm{Ra}$ in otoliths using a new ion-exchange technique and isotope-dilution TIMS, with a comparison to the traditional techniques, where the associated analytical features of merit are discussed. 


\section{Materials and Methods}

The activity of ${ }^{226} \mathrm{Ra}$ was determined in sagittal otoliths from three fish species was performed. The species analyzed were shortspine thornyhead (Sebastolobus alascamus) collected from Monterey Bay, California, Atlantic tarpon (Megalops atlanticus) from inshore waters of Florida, and yelloweye rockfish (Sebastes ruberrimus) from off southeastern Alaska. Whole $S$. alascamus otoliths were selected and pooled to attain samples of approximately $1 \mathrm{~g}$. The purpose of these samples was for comparison with similar whole otolith samples processed using radon emanation (Kline 1996) and direct $\alpha$ spectrometry (John Butler, Southwest Fisheries Science Center, P.O. Box 271, La Jolla, CA 92038-0271, personal communication). Whole young-of-the-year $M$. atlanticus otoliths were pooled based on collection site and date to determine if exogenous ${ }^{210} \mathrm{~Pb}$ would present a problem in ageing adults. Because age is less questionable for young-ofthe-year, determining radiometric age can be used to determine if exogenous ${ }^{210} \mathrm{~Pb}$ is incorporated. Otolith cores (first 4 years growth) were extracted using procedures given elsewhere (Andrews et al. 1997, Chapter 3) and were pooled into age-groups for $S$. ruberrimus to attain approximately $0.5 \mathrm{~g}$ core samples for the purpose of determining radiometric age. In addition, one whole otolith sample was processed for ${ }^{226} \mathrm{Ra}$ determination to compare ${ }^{226} \mathrm{Ra}$ activity with the core samples.

Due to the extremely low levels of ${ }^{226} \mathrm{Ra}$ and ${ }^{210} \mathrm{~Pb}$, trace-metal precautions were exercised during sample processing (Linn 1988, Fabry and Delaney 1989, Watters 1995). All acids used were double distilled (GFS chemicals $\otimes$ ) and dilutions were made using Millipore $\otimes$ filtered Milli-Q (MQ) water $\left(18 \mathrm{M} \Omega \mathrm{cm}^{-1}\right)$. Because ${ }^{210} \mathrm{~Pb}$ determination was 
performed prior to ${ }^{226} \mathrm{Ra}$ analysis in radiometric age determiriation, the procedures used are briefly described here.

Otolith cleaning and dissolution

Otolith samples were cleaned, dried, and weighed prior to dissolution. Rough cleaning began with hydrating the otoliths in de-ionized water for 5 minutes. Samples were agitated and rinsed three times with each of the following: 1) a mixture of de-ionized water and Micro® laboratory cleaner, 2) de-ionized water, and 3) MQQ water. Fine cleaning was performed by sequentially stepping between agitation in four cleaning solutions with a Branson 2200 sonicator and a triple rinse with MQ water. The four cleaning solutions with agitation times were: 1) MQ water (10 min), 2) $0.15 \mathrm{~N} \mathrm{HNO}_{3}(1 \mathrm{~min})$, 3) basic 1:1 mixture of $\left.30 \% \mathrm{H}_{2} \mathrm{O}_{2}: 0.4 \mathrm{~N} \mathrm{NaOH}(10 \mathrm{~min}), 4\right) \mathrm{MQ}$ water (10 min), and 5) $0.001 \mathrm{~N} \mathrm{HNO}_{3}$ (3 times at $1 \mathrm{~min}$ ). After the final rinse, samples were dried for at least $24 \mathrm{hr}$ in an oven at $80^{\circ} \mathrm{C}$, cooled in a desiccator, and weighed to $\pm 0.0001 \mathrm{~g}$. Samples were dried to a constant weight.

Dried and veighed samples were placed in acid cleaned $100 \mathrm{~mL}$ Teflon® PFA griffin beakers. While on a hot plate at $80^{\circ} \mathrm{C}, 8 \mathrm{~N} \mathrm{HNO}_{3}$ was added to the otoliths in $1 \mathrm{~mL}$ aliquots until dissolved. The dissolved sample was dried, re-dissolved with $1 \mathrm{~mL}$ of $8 \mathrm{~N}$ $\mathrm{HNO}_{3}$, and dried again. This was repeated 5 times. Prior to drying the fifth dissolution completely, $1 \mathrm{~mL}$ of $\mathrm{N} \mathrm{HCl}$ was added to form an aqua regia solution. This solution was dried, re-dissolved with $1 \mathrm{~mL} \mathrm{~N} \mathrm{HCl}$, and dried again. Dissolution in $1 \mathrm{~mL}$ of $\mathrm{N} \mathrm{HCl}$ was repeated 5 times which left the final sample in the desired chloride form. Drying 
temperatures were kept low in order to minimize volatilization potential of polonium. The repeated drying and dissolution enhanced the oxidation of otolin, a potential interferant.

Determination of ${ }^{210} \mathrm{~Pb}$ activity

To determine ${ }^{210} \mathrm{~Pb}$ activity in the otolith samples, the $\alpha$-decay of ${ }^{210} \mathrm{Po}\left(\mathrm{t}^{1 / 2}=\right.$ $138.4 \mathrm{~d}$ ) was used as a daughter proxy for ${ }^{210} \mathrm{~Pb}$. To ensure that ${ }^{210} \mathrm{Po}:{ }^{210} \mathrm{~Pb}$ was in secular equilibrium and that all of the ${ }^{210} \mathrm{Po}$ was due to ingrowth from ${ }^{210} \mathrm{~Pb}$, all samples were greater than 2 years old. Samples prepared for ${ }^{210}$ Po analysis were spiked with a yield tracer, ${ }^{208}$ Po, calibrated against NBS and geological standards (Williams 1988). The amount added was estimated to be 5 times the activity of ${ }^{210} \mathrm{Po}$ in the otolith sample to reduce error in the ${ }^{210} \mathrm{~Pb}$ activity determination. This amount was added to the sample once the otoliths were first put into solution and before the repeated dissolutions previously discussed.

To isolate the polonium isotopes for the purpose of $\alpha$-spectrometry, the isotopes were autodeposited onto a silver planchet. Spiked samples were redissolved in approximately $50 \mathrm{~mL}$ of $0.5 \mathrm{~N} \mathrm{HCl}$ on a hot plate covered with a watch-glass. In previous studies, ascorbic acid was added to inhibit autodeposition of divalent iron (Kline 1996). Because ascorbic acid is an organic that can act as an interferant in the TIMS analysis and because iron content in otoliths is low (Dannevig 1956), it was not used in this study. Samples were completely dissolved and the temperature was elevated to $90-100^{\circ} \mathrm{C}$ before plating. The ${ }^{210} \mathrm{Po}$ and ${ }^{208} \mathrm{Po}$-tracer were autodeposited at this temperature (higher than suggested because of inaccurate temperature monitoring, $80^{\circ} \mathrm{C}$ ) onto a purified silver 
planchet $(99.999 \%)$ held in a rotating teflon holder over a 4 hour period (Flynn 1968). Planchets were counted using both silicon surface barrier detectors and ion implant detectors in Tennelec TC256 $\alpha$-spectrometers interfaced with a multi-channel analyzer and an eight channel digital multi-plexer with Nucleus® software on an IBM-PC. The activity of ${ }^{210}$ Po was quantified by its integrated peak area relative to that of the ${ }^{208} \mathrm{Po}$ yield-tracer, which when decay corrected, was quantitatively equivalent to ${ }^{210} \mathrm{~Pb}$ activity. Radium blanks included these steps to account for any potential radium contamination. The sample remaining after polonium autodeposition was taken to dryness and saved for ${ }^{226} \mathrm{Ra}$ analysis.

The separation of radium from calcium and barium is essent:al for obtaining good ionization efficiency during TIMS. This was achieved by applying a three column, ionexchange separation procedure. Elution characteristics for each column separation were analyzed using calcium and barium standards and flame atomic absorption spectrophotometry (AA) to optimize the sample collection intervals. In the first two ionexchange columns, most of the calcium was separated from barium and radium. Because barium co-elutes with radium, and not calcium, barium was used as a proxy for radium in determining radium elution characteristics. The eluate from the resultant collection interval for the barium and radium fraction was used in the third ion-exchange column. Distribution coefficients provided by the manufacturer were used to estimate the acid strength necessary to achieve the greatest separation between radium, barium, and any remaining calcium in the third cation exchange column. Based on these findings, an optimized ion-exchange separation procedure was developed (Table 1). 
Radium separation

The radium separation procedure consisted of two cation-exchange columns. The first column type was a $10 \mathrm{~mL}$ chromatography column with a $20 \mathrm{~mL}$ reservoir (Bio-Rad Laboratories, Econo-Pac 10 Column). The conditioned column contained $10 \mathrm{~mL}$ of Bio$\mathrm{Rad} A G \otimes 50 \mathrm{~W}-\mathrm{X8}$ cation exchange resin and had an aspect ratio of 3.9. The second column type was a custom $150 \mu \mathrm{L}$ microcolumn made of TFE heat-shrink tubing (6.35 mm ID, Penntube Plastics) shrunk over a hand machined stainless steel die. Die dimensions were $6.35 \mathrm{~mm}(0.25 ")$ in diameter by $57 \mathrm{~mm}$ (2.25") in length for the reservoir which tapers down to $2.38 \mathrm{~mm}(0.094 ")$ in diameter by $35 \mathrm{~mm}\left(1.38^{\prime \prime}\right)$ in length for the column volume. Enough tubing was used to create an $800 \mu \mathrm{L}$ reservoir and a constricted tip with minimal dead volume. A frit made of porous polyethylene $(2 \mathrm{~mm}$ thickness with $10 \mu \mathrm{m}$ pore size) was cut and squeezed tightly down the column and into the tip. The conditioned microcolumn contained $150 \mu \mathrm{L}$ of $\mathrm{Sr} \circledast$ resin and had and aspect ratio of 13.1.

To determine ${ }^{226} \mathrm{Ra}$ using isotope-dilution TIMS, the dissolved otolith sample (prior to repeated dissolutions and plating) should be spiked gravimetrically with a ${ }^{228} \mathrm{Ra}$ yield-tracer. The ${ }^{228} \mathrm{Ra}$ solution was prepared by separating ${ }^{228} \mathrm{Ra}$ from its parent, ${ }^{232} \mathrm{Th}$. The atomic ratio of ${ }^{232} \mathrm{Th}$ to ${ }^{230} \mathrm{Th}$ in the solution is greater than 1.6 million, producing a ${ }^{228} \mathrm{Ra}$ to ${ }^{226} \mathrm{Ra}$ ratio in the yield tracer of 0.2855 as of June 1,1995 . The ${ }^{228} \mathrm{Ra}$ spike solution was calibrated extensively against NBS and geological standards. The amount of ${ }^{228} \mathrm{Ra}$ added to each sample was estimated to attain a ${ }^{226} \mathrm{Ra}:{ }^{228} \mathrm{Ra}$ atom ratio close to one. The spiked sample was dried and examined to determine the next step in the separation procedure. If the residue was not white, the sample was redissolved with $1 \mathrm{~mL}$ of $8 \mathrm{~N}$ 
$\mathrm{HNO}_{3}$ and dried. This was repeated until a white residue was obtained. Before the final drying was complete, an aqua regia transition to $\mathrm{N} \mathrm{HCl}$ was created by adding $1 \mathrm{~mL}$ of $6 \mathrm{~N} \mathrm{HCl}$. This solution was taken to dryness. Dissolution with $\mathrm{N} \mathrm{HCl}$ and drying was repeated three times. All of these steps were repeated until the residue was as white as possible.

\section{Calcium removal: two column separation}

A rinsed slurry of Bio-Rad AG® 50W-X8 cation exchange resin and MQ water was added into an acid cleaned $10 \mathrm{~mL}$ chromatography column with a $20 \mathrm{~mL}$ reservoir (Bio-Rad Laboratories, Econo-Pac 10 column) to achieve $13 \mathrm{~mL}$ of settled resin. The settled resin was cleaned and conditioned by passing $100 \mathrm{~mL}$ of MQ water followed by 5 $\mathrm{mL} 2.5 \mathrm{~N} \mathrm{HCl}, 5 \mathrm{~mL} 4.0 \mathrm{~N} \mathrm{HCl}$, and $40 \mathrm{~mL} 6.0 \mathrm{~N} \mathrm{HCl}$ through the column.

The sample was re-dissolved in $5 \mathrm{~mL}$ of $\mathrm{N} \mathrm{HCl}$ over mild heat $\left(50-60^{\circ} \mathrm{C}\right)$ covered with a watch glass. The $5 \mathrm{~mL}$ sample was cooled, loaded onto the column, allowed to settle into the resin and the beaker was rinsed with an additional $5 \mathrm{~mL}$ of $\mathrm{N} \mathrm{HCl}$. Using the sample pipette tip, the acid rinse was introduced by allowing $1 \mathrm{~mL}$ to settle into the resin before adding the remaining $4 \mathrm{~mL}$. Once the acid rinse settled into the resin, two 1 $\mathrm{mL}$ aliquots of $\mathrm{N} \mathrm{HCl}$ were added to begin washing the column. Each of these aliquots were allowed to settle into the resin prior to adding $28 \mathrm{~mL}$ of $\mathrm{N} \mathrm{HCl}$ column wash. The column wash was allowed to settle into the resin and the collected eluant containing the bulk of the calcium was discarded $(40 \mathrm{~mL})$. An acid cleaned $100 \mathrm{~mL}$ Teflon $\otimes$ PFA griffin beaker was placed under the column to collect the radium fraction. The radium fraction 
was collected in the next $80 \mathrm{~mL}$ of $\mathrm{N} \mathrm{HCl}$ added to the column in portions that kept the reservoir full to maximize the flow rate $\left(-1.5 \mathrm{~mL} \mathrm{~min}^{-1}\right)$. Once the $80 \mathrm{~mL}$ sample fraction was collected, the beaker was placed on a hot plate at $90-100^{\circ} \mathrm{C}$ and taken to dryness. The sample was never boiled and the heat was reduced when a crystalline residue began to form. While samples were drying, the same columns were cleaned and conditioned, as in the first preparation, for a second pass and the separation was repeated.

\section{Barium removal: third column separation}

The acid cleaned microcolumn was prepared for sample processing by adding a slurry of MQ water and 50-100 $\mu \mathrm{m} \mathrm{Sr囚} \mathrm{resin} \mathrm{(EiChroM} \mathrm{Industries).} \mathrm{For} \mathrm{best} \mathrm{results,} \mathrm{the}$ column was filled with MQ water first, then the resin was added to the water and allowed to settle into the column to just below the taper of the reservoir. Cleaning and conditioning were performed by passing $1000 \mu \mathrm{L}$ of MQ water followed by $800 \mu \mathrm{L}$ of $1.1 \mathrm{~N} \mathrm{HNO}_{3}$ through the column.

To prepare a sample for introduction to the third column, the sample was dissolved with $100 \mu \mathrm{L}$ of $8 \mathrm{~N} \mathrm{HNO}_{3}$. Droplets were swirled in the beaker bottom, gathered together, and dried at $90-100^{\circ} \mathrm{C}$. If the dried sample spot was not white, the sample was treated with an aqua regia solution of $10-30 \mu \mathrm{L}$ of $8 \mathrm{~N} \mathrm{HNO}_{3}$ and $10-30 \mu \mathrm{L}$ of $6 \mathrm{~N} \mathrm{HCl}$, dried at $90-100^{\circ} \mathrm{C}$, and re-dissolved in $10-30 \mu \mathrm{L}$ of $8 \mathrm{~N} \mathrm{HNO}_{3}$. The last two steps were repeated until the sample was as white as possible.

The sample spot was re-dissolved with $50 \mu \mathrm{L}$ of $1.1 \mathrm{~N} \mathrm{HNO}_{3}$ over mild heat (60$70^{\circ} \mathrm{C}$ ), cooled, and added to the microcolumn with a $100 \mu \mathrm{L}$ pipette. The sample was 
allowed to settle into the resin and then a beaker rinse of $50 \mu \mathrm{L} 1.1 \mathrm{~N} \mathrm{HNO}_{3}$ was added to the column. A column wash of $150 \mu \mathrm{L}$ of $1.1 \mathrm{~N} \mathrm{HNO}_{3}$ was added and allowed to settle into the resin. The eluant $(250 \mu \mathrm{L})$ was discarded. The final sample fraction was collected in an acid cleaned $3 \mathrm{~mL}$ Teflon® PFA sample vial. Radium elution was performed by adding $450 \mu \mathrm{L}$ of $1.1 \mathrm{~N} \mathrm{HNO}_{3}$ to the column, while the barium remained on the column. The collected sample was then placed on a hot plate at $90-100^{\circ} \mathrm{C}$ and dried. If the spot was not clear and very small $(0.5 \mathrm{~mm})$, an aqua regia solution of 1 drop of $8 \mathrm{~N}$ $\mathrm{HNO}_{3}$ and 1 drop of $\mathrm{N} \mathrm{HCl}$ was added and dried at $90-100^{\circ} \mathrm{C}$. These steps were repeated until the sample would not lighten or shrink any further. The sample spot was then re-dissolved two times in 1 drop of $₫ \mathrm{~N} \mathrm{HCl}$ and dried into the chloride form. Microcolumns were cleaned by passing $2000 \mu \mathrm{L}$ of MQ water and were stored upright in a vial of MQ water.

Thermal ionization mass spectrometry

To utilize TIMS, the final sample from the separation procedure must be loaded onto a metallic filament. The design was a single filament assembly made of 4 pass zonerefined $99.999 \%$ rhenium ( 0.020 " wide and 0.001 " thick; H. Cross Co.). Prior to loading the sample, the filament was out-gassed in a diffusion pump vacuum chamber at 3.5 amps for $30 \mathrm{~min}\left(-1700^{\circ} \mathrm{C}\right)$ once the vacuum was less than $10^{-6}$ torr. Filaments were allowed to cool in the pumped down chamber before removal. To minimize organic interference during analysis, sample loading began immediately after out-gassing. Two $\mu \mathrm{L}$ of tantalum activator ( $1 \%$ Ta solution, Birck 1986) solution were evaporated on to the filament to 
enhance ionization (Cohen and O'Nions 1991). Samples in the teflcn vials were transferred to the filament in two successive $1 \mu \mathrm{L}$ additions of $1 \mathrm{~N} \mathrm{HCl}$. The tantalum activator and the sample were dried as they were loaded by passing 0.8 amps through the filament. Once loaded, an additional $20 \mathrm{~s}$ period of increased amperage (1.5 amps) was applied to further secure the sample to the filament and drive of any remaining acid.

Radium analysis was performed on a Vacuum Generators 54-30 Thermal Ionization Mass Spectrometer, equipped with an energy filter and an ion-counting dalydetector. The dark current on the detector was $20 \mathrm{cpm}$ and dead time was $22 \mathrm{~ns}$. The accuracy and linearity of this detector at signals up to 1 million cps has been verified by repeated measurements of NBS standard U-010. This TIMS radium analysis procedure is similar to the procedure outlined in Cohen and ONions (1991).

Prepared filament samples were placed in the TIMS sample turret, pumped down overnight, and analyzed the following day. First a programmed warm-up sequence raised the filament to 2.4 amps $\left(1150^{\circ} \mathrm{C}\right)$ over $15 \mathrm{~min}$. After raising the filament manually to approximate operating temperatures $\left(1197\right.$ to $\left.1220^{\circ} \mathrm{C}\right)$, the residual ${ }^{138} \mathrm{Ba}$ signal was used to focus the beam for counting the much weaker ${ }^{226} \mathrm{Ra}$ and ${ }^{228} \mathrm{Ra}$ signals. The ${ }^{138} \mathrm{Ba}$ signal typically varied between 20,000 and 3 million counts per second (cps) at this point. Once focused, unspiked samples (samples containing no added ${ }^{228} \mathrm{Ra}$ ) were monitored to determine if measurable natural ${ }^{228} \mathrm{Ra}$ existed in the otoliths. No measurable natural ${ }^{228} \mathrm{Ra}$ was recovered and, therefore, no adjustment was necessary.

Spiked samples were analyzed with a programmed sequence of readings at atomic mass unit (amu) 226 and 228 with background readings at amu 225.5. First the scanning 
of the amu range 224.5 to 228.5 was performed to ensure that organic interference had been minimized. When the background from amu 224.5 to 228.5 appeared uniform, and the ${ }^{226} \mathrm{Ra}$ signal was as high as could be attained by focusing procedures ( 30 to $>100 \mathrm{cps}$ ), analysis was begun. On spiked samples, where ${ }^{226} \mathrm{Ra}:{ }^{228} \mathrm{Ra}$ was near unity, analysis was performed by peak-hopping between amu 226 and amu 228 after taking a 20 s baseline measurement at amu 225.5. A measurement cycle consisted of a $5 \mathrm{~s}$ integration on amu 228 , a 10 second integration on amu 226, and a 5 s integration on amu 228 . Twenty ratios were taken per block and an analysis generally consisted of 5 blocks (or until the desired precision was attained). Data were obtained in the filament temperature range of $1180-1300^{\circ} \mathrm{C}$. At higher temperatures, calcium ionization interfered with the radium ionization. The ${ }^{226} \mathrm{Ra}:{ }^{228} \mathrm{Ra}$ atom ratio was calculated as the mean $( \pm \mathrm{SE})$ of all the readings taken in the analysis with outlying values statistically eliminated by the analysis routine.

Mass fractionation during analysis can not be accounted for, but is believed to be much less $(\sim 1 \%$ per amu) than our normally obtained precision $(\sim 1 \% \pm 2$ SE). This assumption is strongly supported by the absence of a systematic decrease in measured atomic ${ }^{226} \mathrm{Ra}:{ }^{228} \mathrm{Ra}$ ratios on extended runs.

Because the TIMS detected atomic ${ }^{226} \mathrm{Ra} \cdot{ }^{228} \mathrm{Ra}$ ratio was equal to the unknown atomic ratio of the sample, the known number of atoms in the ${ }^{228} \mathrm{Ra}$ spike can be used to determine the unknown number of ${ }^{226} \mathrm{Ra}$ atoms. Hence, ${ }^{226} \mathrm{Ra}$ activity is determined by multiplying the number of ${ }^{226} \mathrm{Ra}$ atoms by the ${ }^{226} \mathrm{Ra}$ decay constant. 


\section{Results}

\section{Radium separation}

Based on AA determinations, the separation of calcium and barium (used as a proxy for radium) for the first pass on the AG® 50W-X8 ion-exchange column was good, but the elements co-eluted to a small extent (Figure 1). To conserve any sample in the coelution, the selected sample collection interval began in the tail of the calcium elution at 40 $\mathrm{mL}$ and ended at $120 \mathrm{~mL}$. Less than $10 \%$ of the total calcium was found in the selected collection interval.

The second pass on the AG® 50W-X8 ion-exchange column better separated the calcium and barium (radium) fractions which did not co-elute to a measurable extent (Figure 2). The selected sample collection interval was the same as in the first column pass. A calculated one percent of the total calcium may have remained in the sample fraction. Recovery of barium, and presumably radium, through the first two ion-exchange columns was greater than $90 \%$.

An acid strength of $1.1 \mathrm{~N} \mathrm{HNO}_{3}$ achieved the greatest separation between calcium, barium, and radium on the $\mathrm{Sr} \otimes$ resin microcolumn. Based on the distribution coefficients of the $\mathrm{Sr} \otimes$ resin, a radium sample collection interval of 250 to $700 \mu \mathrm{L}$ was selected between the calcium and barium elution intervals (Figure 3). A small sample spot $(<0.5$ $\mathrm{mm}$ ) remained after drying and was used for radium determination on the TMS.

To optimize the elemental separations and radium recovery, the collection intervals for each column separation were shifted slightly from the first trial run (Table 1 ). The initial collection interval for the first two columns was from 35 to $120 \mathrm{~mL}$. Occasional 
high calcium in the TIMS analysis was attributed to this collection interval. Therefore, a shift of the collection interval away from the calcium peak to 40 to $120 \mathrm{~mL}$ was adopted for each column pass (Figures $1 \&$ 2). The amount of crystalline residue visible at the end of each column pass was reduced as a result of this shift. The trial collection interval for the third column was from 250 to $700 \mu \mathrm{L}$. This collection on this interval resulted in the high ${ }^{226} \mathrm{Ra}$ counts using TIMS (100-130 counts per second for $20 \mathrm{~min}$ ). Samples analyzed after this shift improved because they have significantly lower calcilim, a stronger radium signal, and lower analytical uncertainty $(<1 \%)$.

Thermal ionization mass spectrometry

Seventeen samples consisting of 15 otolith samples from three fish species and two spiked ${ }^{228} \mathrm{Ra}$ yield-tracer blanks were processed for radium determination using isotopedilution TIMS. Three of the 15 otolith samples, one from each species, were not spiked with ${ }^{228} \mathrm{Ra}$ to verify that natural quantities of ${ }^{228} \mathrm{Ra}$ were insignificant relative to potential spike quantities. Results indicate that naturally occurring ${ }^{228} \mathrm{Ra}$ for each species is at or below TIMS background. Spiked blanks indicated the ion-exchange separation procedures do not contribute measurable ${ }^{226} \mathrm{Ra}$ to samples. The twelve spiked samples produced ${ }^{226} \mathrm{Ra}$ activities ranging from $0.0251 \pm 0.0001 \mathrm{dpm} \mathrm{g}^{-1}$ to $1.63 \pm 0.02 \mathrm{dpm} \mathrm{g}^{-1}$ (Table 2).

During sample analysis, the signal strength of calcium, barium, and radium were observed qualitatively. The ${ }^{226} \mathrm{Ra}$ signal was usually strong (as high as $500 \mathrm{cps}$ ) and had low or no background interference from organics (usually $<1 \mathrm{cps}$ ). The residual calcium 
and barium signals were much stronger than the radium signals (approximately 20,000 and 3 million cps, respectively). Samples with the highest analytical uncertainties typically had the highest residual calcium and barium signals.

\section{Technique comparison}

Determination of ${ }^{226} \mathrm{Ra}$ using the ion-exchange separation procedure and isotopedilution TIMS in otoliths from three fish species revealed a wide range of activity levels (Table 2). This was expected due to habitat and geographical variation among the species. Whole and cored otolith samples from $S$. alascamus and $S$. ruberrimus contained the lowest ${ }^{226} \mathrm{Ra}$ activities and have comparable levels. The whole young-of-the-year otoliths from $M$. atlanticus contained ${ }^{226} \mathrm{Ra}$ activities that ranged from approximately 10 to 100 times the activity of the two deep-water species. The ${ }^{226} \mathrm{Ra}$ activities calculated from the TIMS results for each fish species were part of separate radiometric ageing studies which are discussed elsewhere.

To allow direct comparison of these results with existing studies, some reported ${ }^{226} \mathrm{Ra}$ uncertainties were recalculated as a percent of the reported ${ }^{226} \mathrm{Ra}$ activity. These comparisons are reported here with other features that are an improvement relative to existing techniques. The ${ }^{226} \mathrm{Ra}$ activities for $S$. alascamus are unique because they were compared with ${ }^{226} \mathrm{Ra}$ results from radon emanation and direct $\alpha$-spectrometry for the same species. The TIMS ${ }^{226} \mathrm{Ra}$ activities for this species are the lowest, with radon emanation and direct $\alpha$-spectrometry ranging higher (Table 3). Each determination was performed on similar, but independent samples. Because the $S$. ruberrimus samples are otolith-core 
samples, the sample size and ${ }^{226} \mathrm{Ra}$ measurements were compared to results from two recent radiometric ageing studies where otolith cores were used (Table 4). Sample size, analytical uncertainty, and processing time were significantly reduced relative to these studies. 


\section{Discussion}

The primary objective of this study was to separate radium from calcium and barium in otoliths, and to determine ${ }^{226} \mathrm{Ra}$ using isotope-dilution TMMS. The initial approach was to use a technique developed for volcanic rocks where barium is the primary suppressant to the detection of radium using TIMS (Volpe et al. 1991). Attempts to use this technique resulted in samples too high in calcium and barium to measure radium. Because otoliths are high in calcium (38\% by weight; Dannevig 1956, Macpherson and Manriquez 1977), in addition to barium (-5-10 ppm; Edmonds et al. 1991), we applied a recently developed ion-exchange separation technique (Chabaux et al. 1994). With minor modifications, calcium and barium were successfully reduced and measurable radium was recovered.

In the developmental stages of the ion-exchange separation procedure there were problems with organic contamination. Samples analyzed using TIMS had an elevated and noisy background (high counts at atomic mass 225.5) which we attributed to organic interference from otolin (0.2-10\% in otoliths by weight; Degens et al. 1969, Radtke 1984). This observation led to the rigorous sample dissolution and oxidation procedures reported here. As a result of this procedure, the product of the ion-exchange separation procedures had very little visible organic residue. However, occasionally there appeared to be a small amount of organic residue in the final sample, which we attributed to resin from the first two ion-exchange columns. When this residue is present, it should not be loaded onto the TIMS filament because it raises the organic background. Instead it should be brought up in acid and passed through the Sr@ resin column a second time. As a result of the 
dissolution and oxidation procedures, the observed organic interference on the thermal ionization mass spectrometer was reduced to very low levels ( $<\mathrm{l} \mathrm{cps})$.

The difference between the ${ }^{226} \mathrm{Ra}$ levels determined for $S$. alascanus otoliths using radon emanation and direct $\alpha$-spectrometry prompted a follow up ${ }^{226} \mathrm{Ra}$ determination using the new TIMS technique (Table 3 ). The ${ }^{226} \mathrm{Ra}$ activities determined using TIMS are lower than the results for each determination, but more similar to Kline (1996). Because some samples were taken from a location further north off the Farallon Islands, California, variation may be from differing environmental concentrations of radium. Variation of radium in the natural environment is especially evident in the following study of juvenile M. atlanticus.

Determination of ${ }^{226} \mathrm{Ra}$ and ${ }^{210} \mathrm{~Pb}$ for young-of-the-year $M$. atlanticus samples was part of a feasibility study to determine if radiometric age determination would be applicable to adult otolith cores. The order of magnitude range of ${ }^{226} \mathrm{Ra}$ activity among the samples $\left(0.199 \pm 0.001\right.$ to $\left.1.63 \pm 0.02 \mathrm{dpm} \mathrm{g}^{-1}\right)$ may be attributed to the variable water chemistry of the inshore waters where the juveniles were collected (Fanning et al. 1982, Crabtree et al. 1995, Moore 1996). However, this variability was not a detrimental factor for this technique because ${ }^{226} \mathrm{Ra}$ and ${ }^{210} \mathrm{~Pb}$ were determined from the same sample.

To determine if exogenous ${ }^{210} \mathrm{~Pb}$ would be a factor in radiometric age determination of adult $M$. atlanticus, age was calculated for the young-of-the-year samples using the measured ${ }^{210} \mathrm{~Pb}$ and ${ }^{226} \mathrm{Ra}$ activities from each sample. If exogenous ${ }^{210} \mathrm{~Pb}$ is accumulated in significant quantities, then the calculated radiometric age would be greater than the known age of these young-of-the-year juveniles $(<1 \mathrm{yr})$. Measurements 
of ${ }^{210} \mathrm{~Pb}$ in these samples were very low $\left(0.0559 \mathrm{dpm} \mathrm{g}^{-1}\right)$ and resulted in radiometric ages that were close to $1 \mathrm{yr}$. Therefore we concluded that exogenous ${ }^{210} \mathrm{~Pb}$ is not a factor in juvenile otoliths of $M$. atlanticus. A follow up study to validate the estimated longevity of M. atlanticus using the new ion-exchange separation technique and isotope-dilution TIMS was successful (Andrews et al. 1997a).

The cored $S$. ruberrimus samples demonstrate several important aspects of this new technique (Table 4). First, the cored samples were analyzed fo- both ${ }^{210} \mathrm{~Pb}$ and ${ }^{226} \mathrm{Ra}$. This means it is not necessary to assume that radium activity among the cores in the sample is equal and constant. Second, the sample sizes required can be very small and have low ${ }^{226} \mathrm{Ra}$ activity. This demonstrates the capability of the new technique to detect ${ }^{226} \mathrm{Ra}$ in smaller samples than attempted in other studies with high accuracy and precision at low levels.

Because ${ }^{226} \mathrm{Ra}$ activities observed for $S$. alascamus and $M$. atlanticus were inconsistent among the samples, variation of ${ }^{226} \mathrm{Ra}$ uptake among the individuals in the sample must be factored in for future radiometric ageing studies. To increase the accuracy of radiometric age determination using otolith cores, measurement of ${ }^{226} \mathrm{Ra}$ must be performed on each pooled core sample and the assumption of constant ${ }^{226} \mathrm{Ra}$ uptake must be avoided. This assumption has been avoided in several studies by measuring ${ }^{210} \mathrm{~Pb}$ and ${ }^{226} \mathrm{Ra}$ activities in each sample (Kastelle et al. 1994, Fenton and Short 1995). Variation of ${ }^{226} \mathrm{Ra}$ activity within the pooled sample has no effect on age determination because average ${ }^{210} \mathrm{~Pb}:{ }^{.26} \mathrm{Ra}$ disequilibria yields average age. Because of the analytical advantages 
inherent in the new technique, this assumption becomes unnecessary and radiometric age determination becomes more accurate.

In a companion study, this technique was sucessfully applied to the radiometric age determination of the Pacific grenadier, Coryphaenoides acrolepis. This study serves as important demonstration of the effectiveness and utility of the new technique in radiometric age determination (Andrews et al. 1997b; Chapter 3, Figure 7).

Some of the advances and advantages of the new technique are demonstrated by comparing the results of this study with two recent radiometric ageing studies (Table 4). By comparing the isotope-dilution TIMS results with the radon emanation results for Anoplopoma fimbria (Kastelle et al. 1994), the new technique measured ${ }^{226} \mathrm{Ra}$ activity that is about ten times lower in samples more than three times smaller with lower analytical uncertainty. A comparison with the $\alpha$-spectrometry results for Macruronus novaezelandiae (Fenton and Short 1995) indicate ${ }^{226} \mathrm{Ra}$ activities are comparable, but sample size is about three times smaller with greatly reduced analytical uncertainty. Processing time for this technique was significantly reduced from 3.5-6 weeks, for the other techniques, to 7-10 days.

Because this technique has improved the accuracy and processing time of ${ }^{226} \mathrm{Ra}$ determination, the most significant source of error and analytical time in radiometric age determination is now associated with ${ }^{210} \mathrm{~Pb}$ determination via $\alpha$-spectrometry. In general, higher sample age and higher ${ }^{226} \mathrm{Ra}$ activity result in higher ${ }^{210} \mathrm{~Pb}$ activity and consequently, lower analytical uncertainty. For samples with $10{ }^{210} \mathrm{~Pb}$ activity, improvements in detection limits and reagent and background levels are the next steps to reduce error in 
${ }^{210} \mathrm{~Pb}$ determination. The time required, however, to acquire adequate counts in $\alpha$ spectrometry for ${ }^{210} \mathrm{~Pb}$ determination on young fish is still about 3 weeks for the low levels typically encountered. But for fish that are old (decades), count times can be lower and accuracy can increase because the activity of ${ }^{210} \mathrm{~Pb}$ increases.

In the context of other radiometric ageing studies, the new ion-exchange separation technique with isotope-dilution TIMS provides a valuable contribution to the developing school of radiometric age determination. The ${ }^{226} \mathrm{Ra}$ activities determined for the otoliths of the three species studied are generally in the range of values reported by all of the previously cited fish ageing studies $\left(0.004 \pm 0.006\right.$ to $\left.0.517 \pm 0.021 \mathrm{dpm} \mathrm{g}^{-1}\right)$, with the exception of one $M$. atlanticus sample $\left(1.63 \pm 0.02 \mathrm{dpm} \mathrm{g}^{-1}\right)$. This is the highest ${ }^{226} \mathrm{Ra}$ activity yet reported in the otoliths of fish by more than a factor of three. Preliminary radiometric age determinations made for $S$. ruberrimus, and the successful application of the new technique to the Pacific grenadier (Andrews et al. 1997b, Chapter 3) and Atlantic tarpon (Andrews et al. 1997a), indicate the new ion-exchange separation procedure coupled with isotope-dilution TIMS is an effective technique for determining ${ }^{226} \mathrm{Ra}$ in otoliths for the purpose of radiometric age determination. 


\section{References}

Andrews, A.H., Burton, E.J., Coale, K.H., and Cailliet, G.M. 1997. Final report: Application of radiometric age determination to the Atlantic tarpon, Megalops atlanticus. Florida Department of Environmental Protection Contract No. MR113. Andrews, A.H., Cailliet, G.M., Coale, K.H. 1997. Age and growth of the Pacific grenadier (Family Macrouridae, Coryphaenoides acrolepis) with age estimate validation using an improved radiometric ageing technique. This issue.

Archibald, C.P., Fournier, D., and Leaman, B.M. 1983. Reconstruction of stock history and development of rehabilitation strategies for Pacific Ocean perch in Queen Charlotte Sound, Canada. North American Journal of Fisheries Management. 3:283-294.

Beamish, R.J. 1979. New information on the longevity of Pacific ocean perch (Sebastes alutus). J. Fish. Res. Board Can. 36:1395-1400.

Beamish, R.J. and McFarlane, G.A. 1983. The forgotten requirement for age validation in fisheries biology. Trans. Amer. Fish. Soc. 112:735-743.

Beamish, R.J. and McFarlane, G.A. 1987. Current trends in age determination methodology. In The age and growth of fish. Edited by R.C. Summerfelt and G.E. Hall. The Iowa State University Press, Ames, Iowa. pp. 15-42.

Bennett, J.T., Boehlert, G.W., and Turekian, K.K.. 1982. Confirmation of longevity in Sebastes diploproa (Pisces: Scorpaenidae) from ${ }^{210} \mathrm{~Pb} /{ }^{226} \mathrm{Ra}$ measurements in otoliths. Mar. Biol. 71:209-215. 
Birck, J.L. 1986. Precision K-Rb-Sr isotopic analysis: application to $\mathrm{Rb}-\mathrm{Sr}$ chronolgy. Chem. Geol. 56:73-83.

Campana, S.E., Zwanenburg, K.C.T., and Smith, J.N.. $1990 .{ }^{210} \mathrm{~Pb} /{ }^{226} \mathrm{Ra}$ determination of longevity in redfish. Can. J. Fish. Aquat. Sci. 47:163-165.

Chabaux, F., Othman, D.B., and Birck, J.L. 1994. A new Ra-Ba chromatographic separation and its application to Ra mass-spectrometric measurement in volcanic rocks. Chem. Geol. 119:191-197.

Chilton, D.E. and Beamish, R.J. 1982. Age determination methods for fishes studied by the groundfish program at the Pacific biological station. Can. Spec. Publ. Fish. Aquat. Sci. No. 60.

Cohen, A.S. and ONions, R.K. 1991. Precise determination of femtogram quantities of radium by thermal ionization mass spectrometry. Anal. Chem. 63:2705-2708.

Cohen. A.S., Belshaw, N.S., and O'Nions, R.K. 1992. High precision uranium, thorium and radium isotope ratio measurements by high dynamic range thermal ionisation mass spectrometry. Int. J. Mass Spec. Ion Proc. 116:71-81.

Crabtree, R.E., Cyr, E.C., and Dean, J.M. 1995. Age and growth of tarpon, Megalops atlanticus, from South Florida waters. Fish. Bull. 93:619-628.

Dannevig, E.H. 1956. Chemical composition of the zones in cod otoliths. J. Cons. Int. Explor. Mer. 21(2):156-159.

Degens, E.T., Deuser, W.G., and Haedrich, R.L. 1969. Molecular structure and composition of otoliths. Mar. Biol. 2:105-113. 
Edmonds, J.S., Caputi, N., and Morita, M. 1991. Stock discrimination by trace-element analysis of otoliths of orange roughy (Hoplostethus atlanticus), a deep-water marine teleost. Aust. J. Mar. Freshwater Res. 42:383-389.

Fabry, V.J. and Delaney, M.L. 1989. Lead-210 and polonium-210 in pteropod and heteropod mollusc shells from the north Pacific: evaluation of sample treatments and variation with shell size. J. Mar. Res. 47:933-949.

Fanning, K.A., Breland, J.A., and Byrne, R.H. 1982. Radium-226 and radon-222 in the coastal waters of west Florida: high concentrations and atmospheric degassing. Science. 215:667-670.

Fenton, G.E., Ritz, D.A., and Short, S.A. $1990 .{ }^{210} \mathrm{~Pb} /{ }^{226} \mathrm{Ra}$ disequilibria in otoliths of blue grenadier, Macruromus novaezelandiae; problems associated with radiometric ageing. Aust. J. Freshwater Res. 41:467-473.

Fenton, G.E., Short, S.A., and Ritz, D.A. 1991. Age determination of orange roughy, Hoplostethus atlanticus (Pisces: Trachichthyidae) using ${ }^{210} \mathrm{~Pb}:{ }^{226} \mathrm{Ra}$ disequilibria. Mar. Biol. 109:197-202.

Fenton, G.E. and Short, S.A. 1995. Radiometric analysis of blue grenadier, Macruronus novaezelandiae, otolith cores. Fish. Bull. 93:391-396.

Flynn, W.W. 1968. The determination of low levels of polonium-210 in environmental materials. Anal. Chim. Acta 43:221-227.

Francis, R.I.C.C. 1995. The problem of specifying otolith-mass growth parameters in the radiometric estimation of fish age using whole otoliths. Mar. Biol. 124:169-176. 
Kastelle, C.R., Kimura, D.K., Nevissi, A.E., and Gunderson, D.R. 1994. Using Pb210/Ra-226 disequilibria for sablefish, Anoplopoma fimbria, age validation. Fish. Bull. 92:292-301.

Koide, M., and Bruland, K.W. 1975. The electrodeposition and determination of radium by isotopic dilution in sea water and in sediments simultaneously with other natural radionuclides. Anal. Chim. Acta. 75:1-19.

Kline, D.E. 1996. Radiometric age verification for two deep-sea rockfish (Sebastolobus altivelis and Sebastolobus alascamus). M.S. thesis, California State University, San Jose, Moss Landing Marine Laboratories.

Linn, L.J. 1988. Trace metals in Galapagos corals: quarter-annual and annual cycles of copper, manganese, cadmium, and lead. M.S. thesis, University of California, Santa Cruz.

Mace, P.M., Fenaughty, J.M., Coburn, R.P., and Doonan, I.J. 1990. Growth and productivity of orange roughy (Hoplostethus atlanticus) on the north Chatham Rise. N.Z., J. Mar. Freshwater Res. 24:105-109.

MacDonald, P.D.M. 1987. Analysis of length-frequency distributions. In The age and growth of fish. Edited by R.C. Summerfelt and G.E. Hall. The Iowa State University Press, Ames, Iowa. pp. 371-384. 
McFarlane, G.A. and Beamish, R.J. 1995. Validation of the otolith cross-section method of age determination for sablefish (Anoplopoma fimbria) using oxytetracycline. In Recent developments in fish otolith research. Edited by D.H. Secor, J.M. Dean, and S.E. Campana. The Belle W. Baruch Library in Marine Science, No. 19. University of South Carolina Press, Columbia, South Carolina. pp. 319-329.

MacPherson, E. and Manriquez M. 1977. Variations in constituent elements of the otolith and their relationship to growth in Merluccius capensis. Invest. Pesq. 41:205-217. (Translated from Spanish by Can. Transl. Fish. Aquat. Sci. No.4604, 1979.).

Milton, D.A., Short, S.A., ONeill, M.F., and Blaber, S.J.M. 1995. Ageing of three species of tropical snapper (Lutjanidae) from the Gulf of Carpentaria, Australia, using radiometry and otolith ring counts. Fish. Bull. 93:103-115.

Moore, W.S. 1996. Large groundwater inputs to coastal waters revealed by ${ }^{226} \mathrm{Ra}$ enrichments. Nature. 380:612-614.

Radtke, R.L. 1984. Cod fish otoliths: information storage structures. In The propagation of cod Gadus morhua. Edited by E. Dahl, D.S. Danielssen, E. Moksness, and P. Solendal. Flodevigen Rapporster. 1:273-298. Arendal, Norway.

Smith, D.C., Fenton, G.E., Robertson, S.G., and Short, S.A. 1995. Age determination and growth of orange roughy (Hoplostethus atlanticus): a comparison of annulus counts with radiometric ageing. Can. J. Fish. Aquat. Sci. 52:391-401. 
Smith, J.N., Nelson, R., and Campana, S.E.. 1991. The use of Pb-210/Ra-226 and Th228/Ra-228 dis-equilibria in the ageing of otoliths of marine fish. In Radionuclides in the study of marine processes. Edited by P.J. Kershaw and D. Woodhead. Elsevier Science, New York, NY. pp.350-359.

Stewart, B.D., Fenton, G.E., Smith, D.C., and Short, S.A. 1995. Validation of otolithincrement age estimates for a deepwater fish species, the warty oreo Allocyttus verrucosus, by radiometric analysis. Mar. Biol. 123:29-38.

Watters, D.L. 1995. Age determination and confirmation from otoliths of the bank rockfish, Sebastes rufus (Scorpaenidae). M.S. thesis, California State University, San Jose, Moss Landing Marine Laboratories.

Williams, R.W. 1988. Uranium and thorium decay series disequilibria in young volcanic rocks. Ph.D. thesis. University of California, Santa Cruz.

Volpe, A.M., Olivares, J.A., and Murrell, M.T.. 1991. Determination of radium isotope ratios and abundances in geologic samples by thermal ionization mass spectrometry. Anal. Chem. 63:913-916. 


\section{Table captions}

Table 1. Overview of column separation procedures. Radium and barium were first separated from calcium by passing the sample through the AG\&50W-X8 column twice. The radium and barium fraction from each pass was taken to dryness before the next column pass. Sample introduction on the second column pass was reduced from $5 \mathrm{~mL}$ to $1 \mathrm{~mL}$ because the dried sample is reduced and to narrow the elution peak for better separation. Radium was separated from barium and residual calcium by passing the redissolved sample through the $\mathrm{Sr} \otimes$ resin column. The final radium fraction was taken to dryness and processed using TLMS.

Table 2. Summary of sample types for each species. Number of otoliths used corresponds to the number of fish in each sample because one otolith of each pair was sectioned for traditional ageing. Total sample weight and measured ${ }^{226} \mathrm{Ra}$ activity with $\%$ error (1 SE) are given for each sample.

Table 3. Comparison of results for $S$. alascanus otoliths using each technique. Otolith samples were similar, but from different fish samples. The lowest analytical uncertainty, for a sample size much lower than radon emanation and comparable to $\alpha$-spectrometry, was the result of isotope-dilution TIMS. 
Table 4. A comparison of the isotope-dilution TIMS results for $S$. ruberrimus cores with two studies utilizing otolith cores and one of the other techniques. Because of the advantages of TIMS, sample size is lower for samples with low activity, and analytical uncertainty and processing time is reduced. 


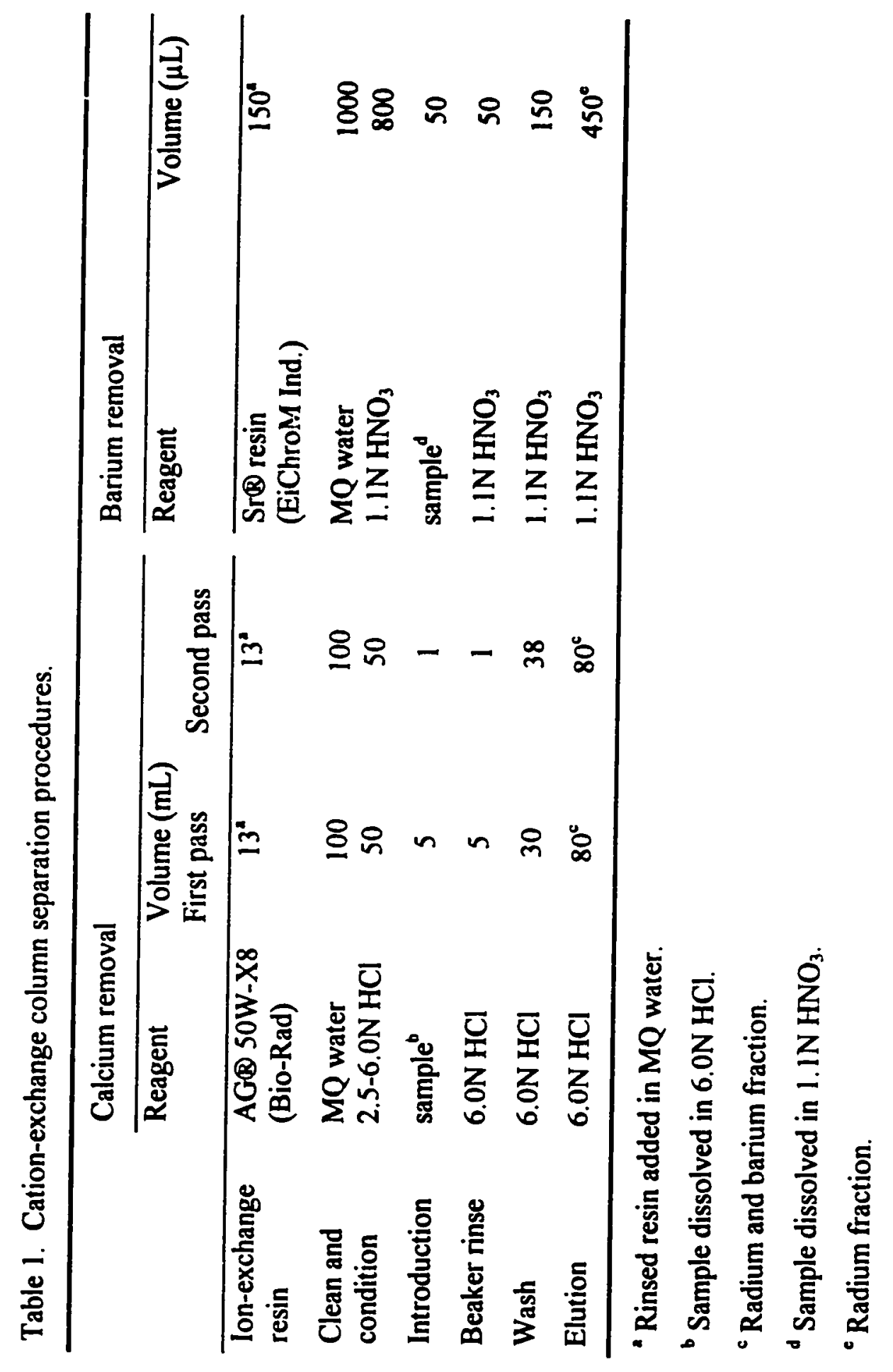




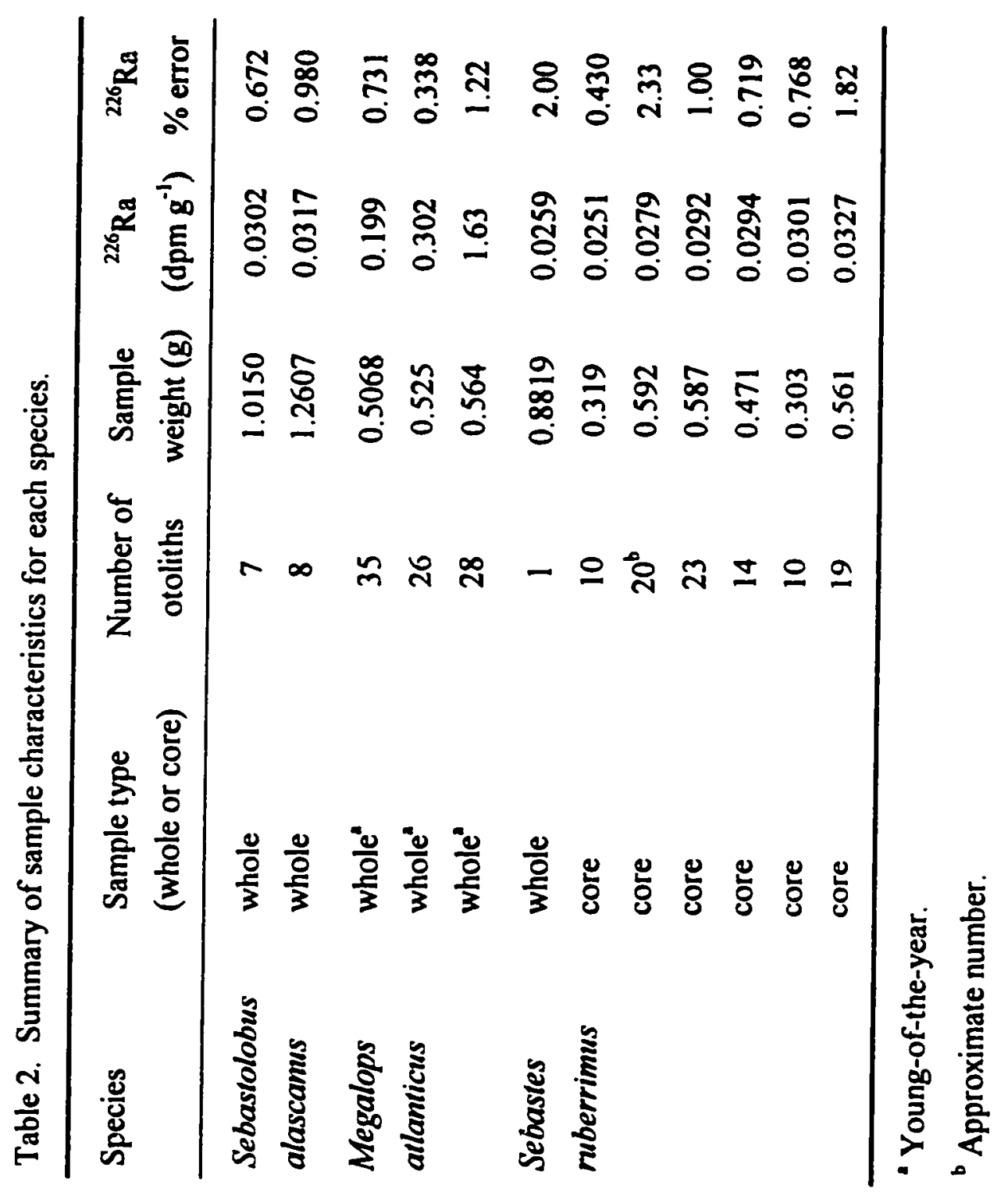




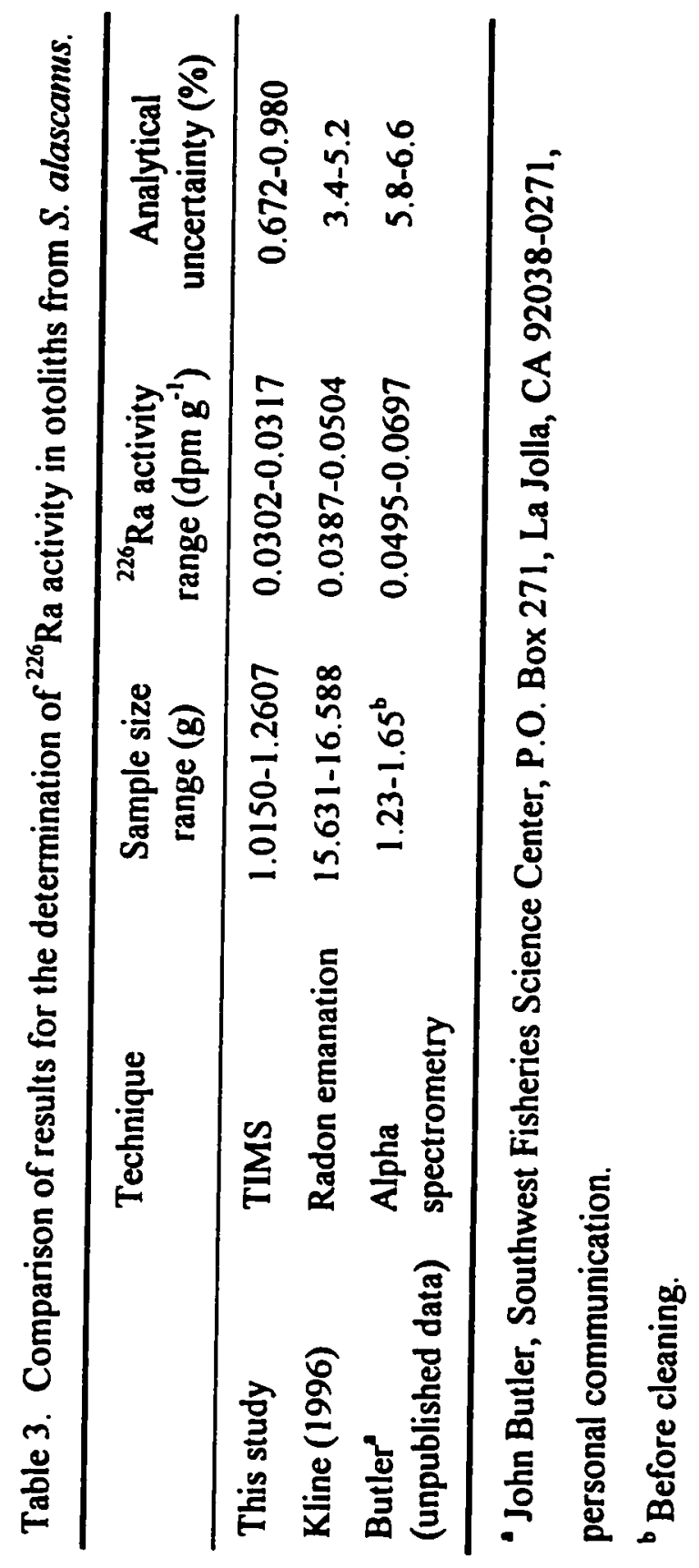




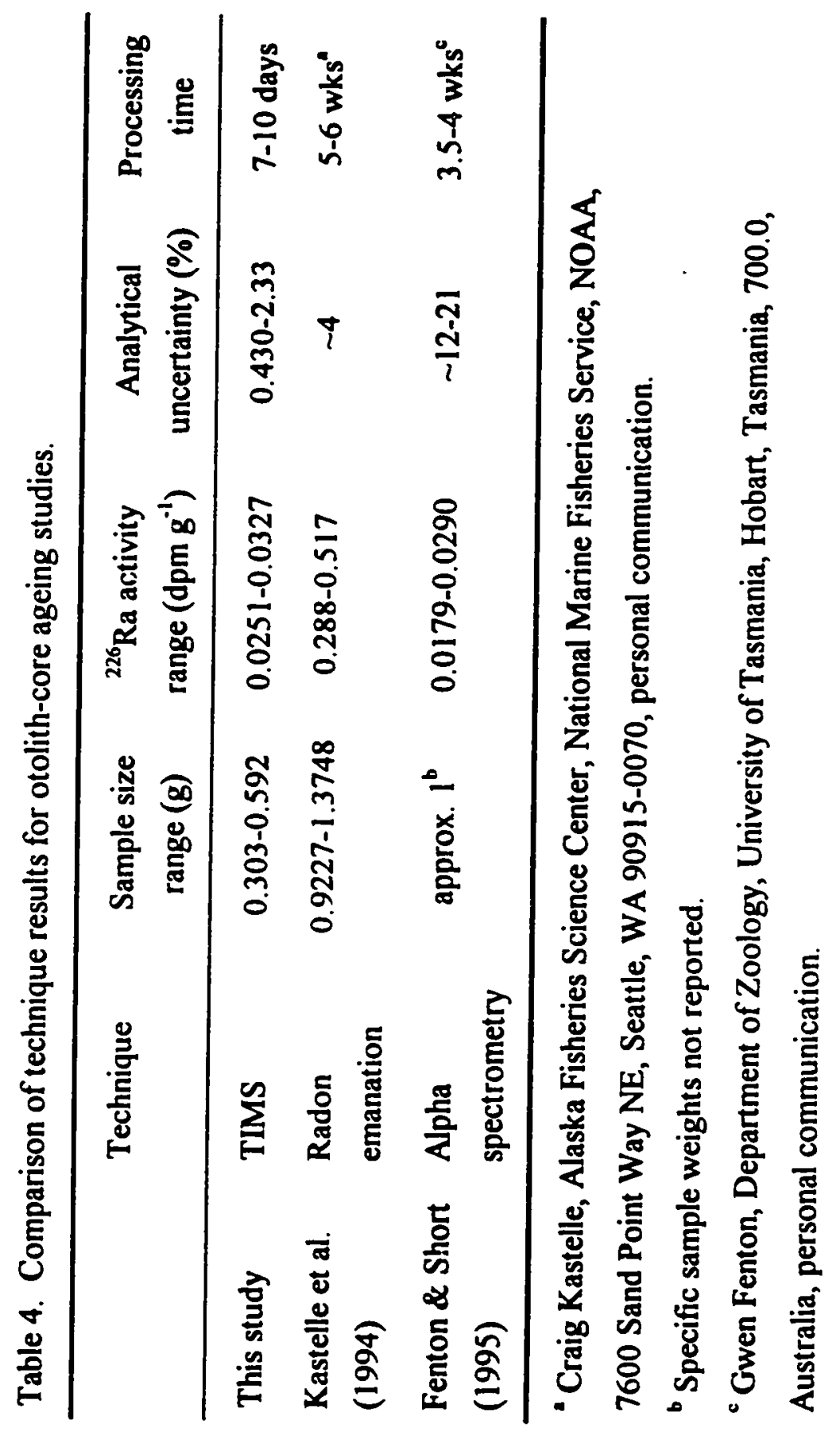




\section{Figure captions}

Figure 1. Elution characteristics of the first pass using $6.0 \mathrm{~N} \mathrm{HCl}$ on the $A G \otimes 50-X 8$ cation exchange column for calcium ( $(\mathbf{O})$ and barium ( $\square)$. In these experiments barium was used as a stable proxy for radium. Calcium eluted strongly in the first $40 \mathrm{~mL}$ and then tailed to approach zero at $60 \mathrm{~mL}$. The beginning of the barium elution is within the calcium tail and, therefore, the collection interval for the radium and barium fraction is from 40 to $120 \mathrm{~mL}$.

Figure 2. Elution characteristics of the second pass using $6.0 \mathrm{~N} \mathrm{HCl}$ on the $A G \otimes 50-X 8$ cation exchange column for calcium (O) and barium ( $\boldsymbol{(})$. To more clearly evaluate the separation, calcium and barium elutions were performed separately, but plotted together. The collection interval for the radium and barium fraction was from 40 to $120 \mathrm{~mL}$

Figure 3. Elution characteristics of the third column pass using $1.1 \mathrm{~N} \mathrm{HNO}_{3}$ on the $\mathrm{Sr} B$ resin microcolumn for calcium (O) and barium ( $\square$ ). Based on the distribution coefficients provided by EiChroM Ind., radium eluted between calcium and barium. The optimal collection interval which minimizes calcium and barium was determined to be $250-700 \mu \mathrm{L}$. The small peaks in between the calcium and barium elution intervals were attributed to low level contamination. Radium in this interval was determined using TIMS. 


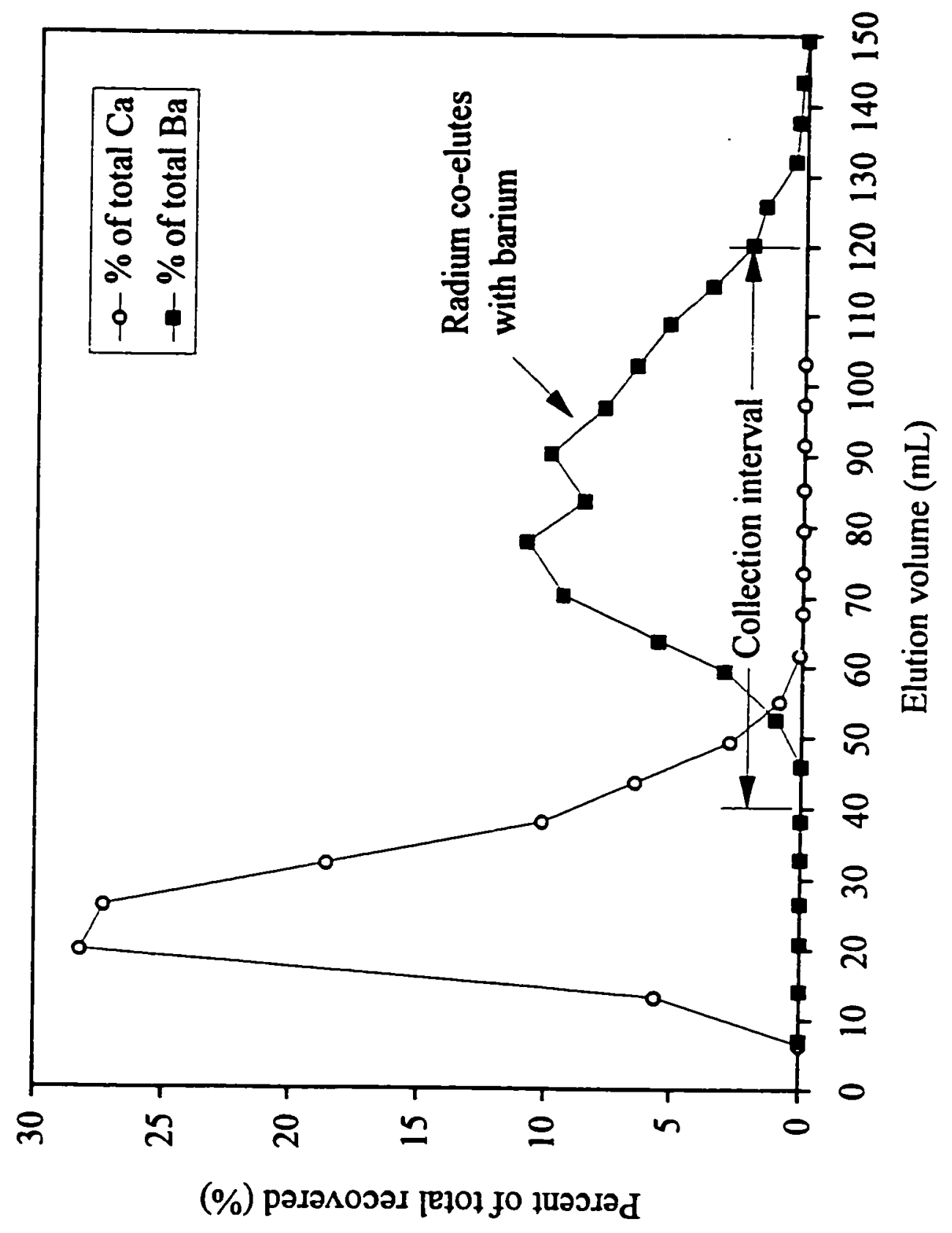




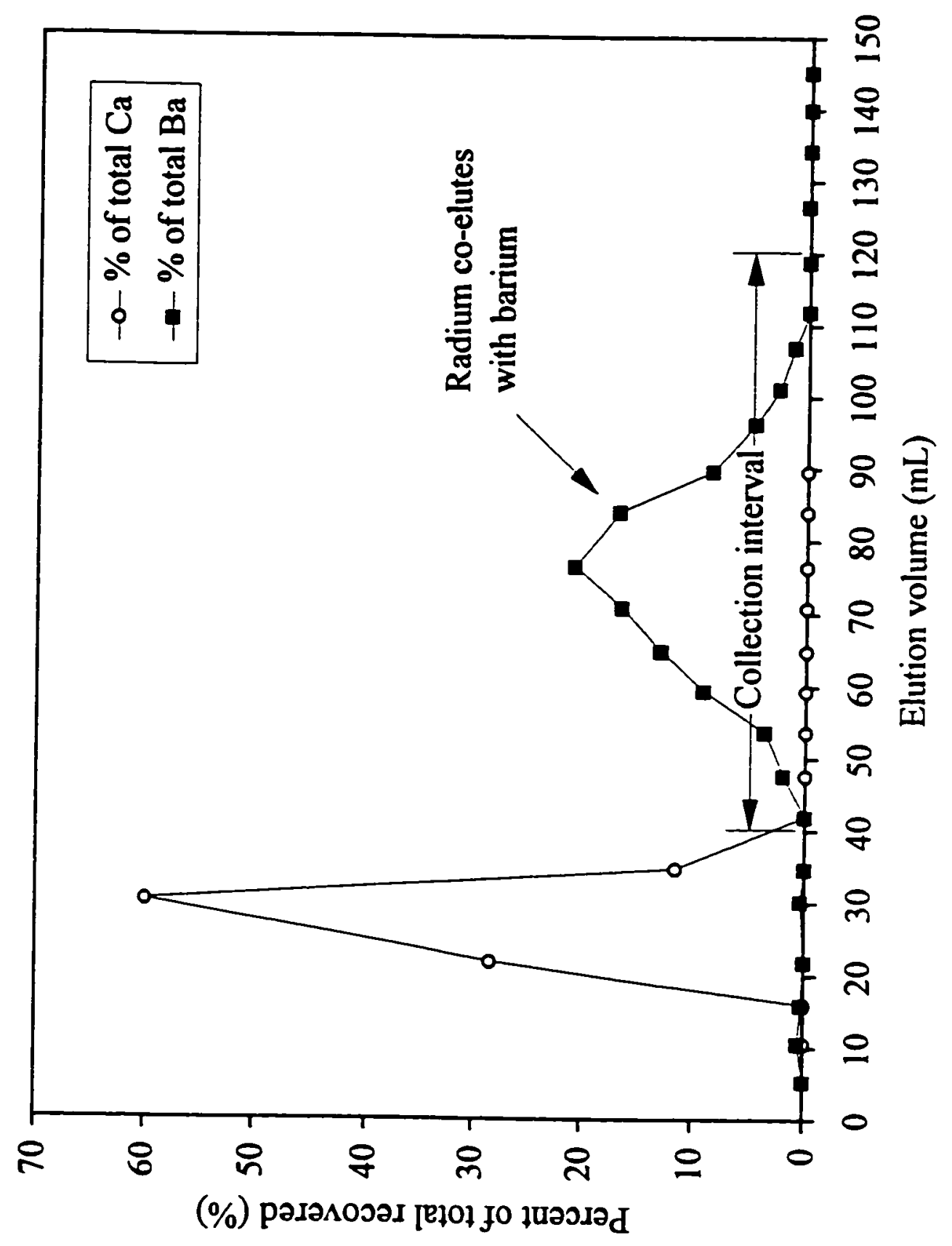




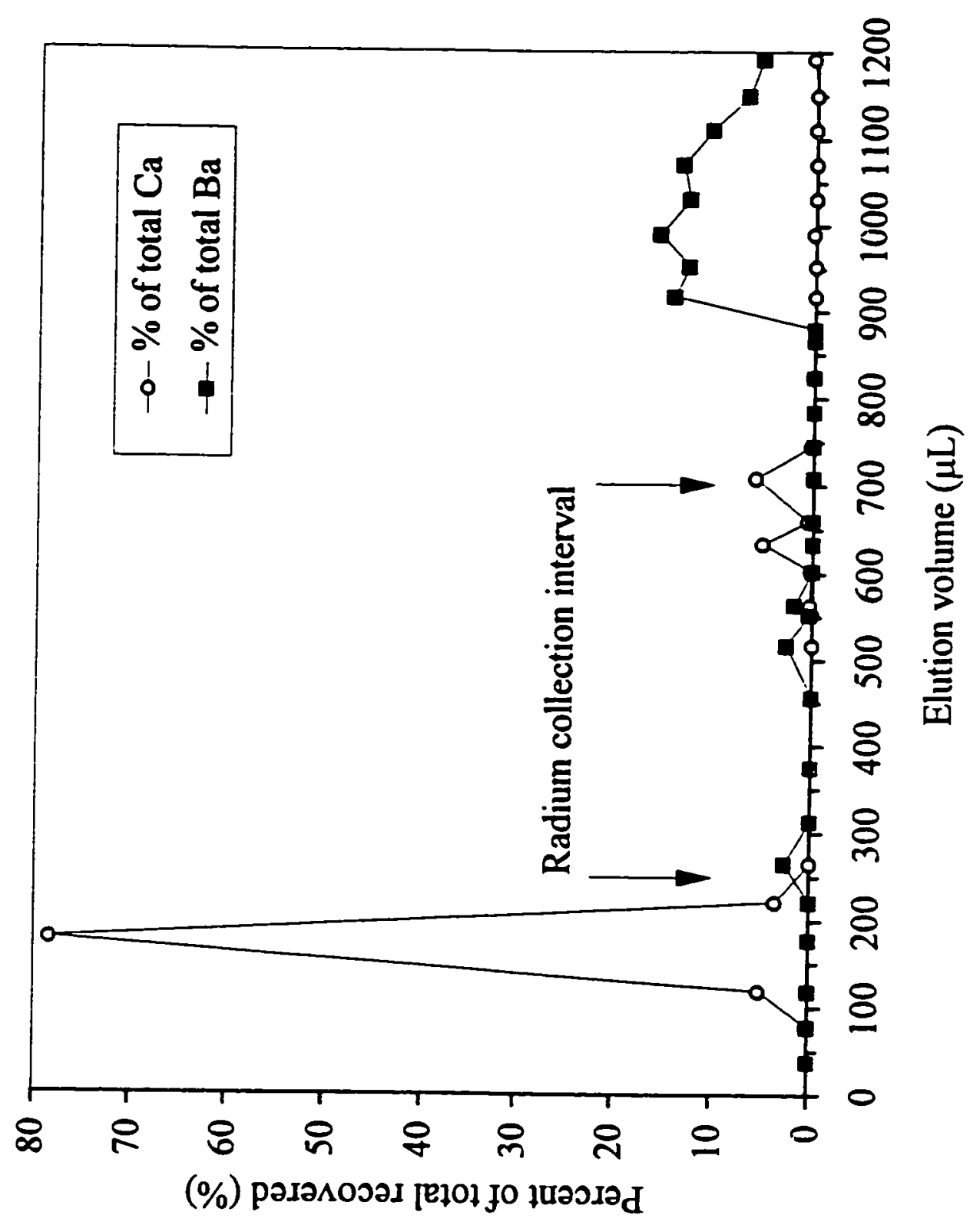




\section{CHAPTER 3}

Age and growth of the Pacific grenadier (Family Macrouridae, Coryphaenoides acrolepis) with age estimate validation using an improved radiometric ageing technique

Submitted for publication: Canadian Journal of Fisheries and Aquatic Sciences 


\begin{abstract}
Current and historic longevity estimates for the Pacific grenadier range from 6 to greater than 60 years. Age estimates in this study using the quantification of growth increments in thin otolith (ear-bone) sections indicate the Pacific grenadier is a long-lived fish that may approach 75 years. To validate this trend, age was determined using the radioactive disequilibria of ${ }^{210} \mathrm{~Pb}$ and ${ }^{226} \mathrm{Ra}$ in otolith cores from adult Pacific grenadier. Radiometric ages closely agree with age estimates from the quantification of growth increments. This confirms the annual periodicity of these increments. Radiometric results indicate the Pacific grenadier can live at least 56 years and growth increments indicate longevity may be greater than 73 years. Because the Pacific grenadier is long-lived and matures late in life, it may be vulnerable to heavy fishing pressure. Therefore, conservation measures need to be taken immediately to sustain this rapidly developing fishery.
\end{abstract}




\section{Introduction}

The Pacific grenadier, Coryphaenoides acrolepis (family Macrouridae), is a benthopelagic, deep-water fish species which inhabits the continental slopes of the northern Pacific Ocean. Its range is circum-north Pacific from Baja California, Mexico to northern Japan and into the Bering Sea (Iwamoto and Stein 1974, Cohen et al. 1990). Its typical depth range is from 600 to $2500 \mathrm{~m}$ (Okamura 1970, Iwamoto and Stein 1974) with a population density maximum near $1500 \mathrm{~m}$ (Stein and Pearcy 1982, Matsui et al. 1990).

Until recently, fishermen regarded the Pacific grenadier as a trash fish because the fillets were small ( $-25 \%$ of the total fish weight) and had low market value ( $\$ 0.08$ to 0.16 per pound ex-vessel). In recent years, the Pacific grenadier has been discovered to have desirable culinary attributes (Kremsdorf et al. 1979, Matsui et al. 1990) and has become a large commercial fishery in California and Oregon (Figure 1). Landings for Monterey Bay, California have increased substantially from practically zero for 1992 to nearly $900 \mathrm{t}$ ( -2 million pounds) for 1996 (Figure 2). Prior to 1995, greater than $95 \%$ of the landings were from trawlers. For 1995 and 1996 greater than $90 \%$ of the landings were from set lines targeting the Pacific grenadier (Leos 1997). Because of these landings, the Pacific grenadier is no longer in the "other" category and has become the fifth largest fishery in Monterey Bay, California and thirteenth in the state of California at $1,130 \mathrm{t}(-2.5$ million pounds) for 1996 (Leos 1996 and 1997).

To properly manage this rapidly developing fishery, the age structure and growth characteristics of the Pacific grenadier must be known along with other life history parameters. Some life history aspects are known (Stein and Pearcy 1982, Matsui et al. 
1990), but longevity estimates remain controversial. Recent and historic age and longevity estimates range from 6 to greater than 60 years (Kulikova 1957, Brothers et al. 1976, Mulcahey et al. 1979, Wilson 1982, Matsui et al. 1990).

Fisheries management strategies rely heavily on accurate age determinations. Age is typically determined in fishes by performing one of several techniques, but most commonly the quantification of growth increments in calcified structures (Chilton and Beamish 1982, Beamish and McFarlane 1987). The annual periodicity of growth increments in these structures is often assumed. Until recently this assumption was rarely validated (Beamish and McFarlane 1983). As a consequence, underestimation of longevity may have had serious consequences to existing fisheries; for example the decline of the Pacific ocean perch (Sebastes alutus) of the northeastern Pacific Ocean and the orange roughy (Hoplostethus atlanticus) off New Zealand (Beamisi. 1979, Archibald et al. 1983, Mace et al. 1990, McFarlane and Beamish 1995, Smith et al. 1995) may be attributed to age underestimation and over fishing. The problem with typical growthincrement age validation techniques is that they have limited applicability to deepwater or long-lived fishes (Macdonald 1987, Mace et al. 1990, McFarlane and Beamish 1995). One technique that can be used to validate age estimates for these fishes is the radiometric ageing technique which uses the disequilibria of ${ }^{210} \mathrm{~Pb}$ and ${ }^{226} \mathrm{Ra}$ in otoliths as a natural chronometer (Smith et al. 1991). This technique has been successfully applied to 12 fish species (Bennett et al. 1982, Campana et al. 1990, Fenton et al. 1991, Kastelle et al. 1994, Fenton and Short 1995, Milton et al. 1995, Smith et al. 1995, Stewart et al. 1995, Watters 1995, Kline 1996). 
In this study, the age and growth of the Pacific grenadier is estimated using a traditional ageing technique and validated using a novel radiometric ageing technique. Improvements made to the radiometric ageing technique in a concurrent study have been utilized here (Andrews et al . 1997, Chapter 2). 


\section{Materials and Methods}

Lengths were recorded for, and sagittal otoliths were extracted from, fish collected at various locations. Specimens ranged in size as much as was available from sampling. Fish collected east of Santa Cruz, California in November 1992 were processed fresh; others were collected during slope surveys conducted by Alaska Department of Fish and Game in October of 1992 and December 1993, shipped frozen, and then processed. Some otoliths were previously extracted and made available by the Oregon Department of Fish and Wildlife. As otoliths were extracted, total length (TL), pre-anal fin length (PAF), snout to dorsal fin (SD), and head length (HL) were recorded to the nearest millimeter. PAF was defined as snout to the posterior insertion of the anal fin. SD was defined as snout to the posterior insertion of the dorsal fin. HL was defined as snout to the anterior most tip of the operculum. The condition of the tail was carefully examined and specimens with intact tails were noted for a partial length analysis. Physical data for most otoliths was collected for comparison with fish lengths and age. Otolith weight was measured to the nearest milligram and length, width, and height were measured to the nearest $0.1 \mathrm{~mm}$. Weight of right and left otoliths were compared using a $t$ test to determine if significant differences occurred between sides.

To ensure a selection of clean otoliths for radiometric analysis, each otolith was carefully cleaned and stored. Extracted otoliths were initially stored in de-ionized water and ethanol (50\%) buffered with marble chips. Further cleaning of adhering tissues was made later with the same solution in the lab. Cleaned otoliths were stored dry in acid cleaned glass vials. 
Before otoliths were selected for traditional ageing, limitations of sample size in the radiometric age determination process were considered. Based on the findings of Campana et al. (1990), radiometric analysis of age-groups, consisting of pooled otolith cores, was selected. Because otolith cores are typically the first few years of life and can be very small, dimensions and weight of otoliths from juvenile fish (estimated age $5 \mathrm{yr}$ ) were examined. The pooled sample size of an age-group was typically limited to approximately 0.5 to $1.0 \mathrm{~g}$ by the ${ }^{210} \mathrm{~Pb}$ determination procedures. Depending upon the weight of the otolith cores, the number of otoliths needed to perform the analysis was determined and a subsample of otoliths were held aside for radiometric analysis.

\section{Traditional otolith ageing}

Before the ageing criteria were adopted, an objective study of growth increments was performed. Sections were interpreted as many ways as possible under a range of magnifications ( $10 x$ to $80 x$ ), where increments were split or lumped depending on what was visible for the magnification. A subjective decision was made based on several very clear sections that showed growth increments gradually becoming finer toward the margin (Figure 3). Criteria based on these sections provided the most consistent results and varied the least with respect to fish length. However, transverse sections were inherently difficult because section angle was very critical and dark patches, possibly proteinaceous inclusions, often obscured growth increments.

Otoliths selected for traditional ageing were transversely sectioned for growth increment analysis. Each otolith was centered and mounted on cards with casting resin. 
Transverse sections containing the nucleus were removed using a Buehler-Isomet lowspeed bone saw with two Norton® low density diamond blades separated by acetate spacers ( $0.6 \mathrm{~mm}$ total). Sections were placed on a slide, mounted with Cytoseal, and allowed to dry overnight. Sections were thinned to optimal viewing thickness using a Buehler Ecomet III lapping wheel with 600 grit silicon-carbide paper. Growth increments were viewed with transmitted light at a magnification of 32 to 80 times under an Olympus dissecting scope. Each section was analyzed by counting concentric growth increments radiating from the nucleus out to the margin. The sulcal region was usually used, but the distal margin was also used for some samples. Otolith sections that did not have quantifiable increments were removed from the analysis. Readable otoliths were aged independently by two readers three times. Average percent error (APE) and index of precision (D) were used to test the reproducibility of ageing between readers (Beamish and Fournier 1981, Chang 1982). Consultation between readers over ageing criteria was used to resolve differences and final age estimates were assigned by the first reader. A von Bertalanffy growth function was fitted, using FISHPARM software (Elsevier Scientific Publishing Co.), to the final age estimates to describe growth parameters.

Age-group determination and core extraction

Because otoliths were difficult to age and the amount of otolith material must be maximized for radiometric analysis, age-groups were determined using otolith and fish parameters, instead of sectioning. For otoliths to be used in age-groups, sexes were separated and age was estimated based on a linear regression of otolith weight and 
estimated age from the aged otoliths. To discriminate dissimilar fish and maximize similarities among the members of the potential age-groups, age was also estimated based on a multiple linear regression incorporating fish length (PAF), otolith weight, and an interaction term (Otolith length multiplied by PAF). A comparison of each regression age was made to determine if the otoliths for each fish would be included in the age-group. Fish with regression ages that differed by greater than $10 \%$ were not included in the agegroup. The age range for each age-group was kept as narrow as was permitted by the amount of otolith mass needed. The average age of the age-group was a weighted average based on the estimated age of each core in the sample. An age-group weight of 1 gram was targeted, but lower amounts were used where insufficient sample was available.

The otoliths selected for each age-group were cored to the size of a 5 year old otolith. Dimensions determined from 3 juvenile otoliths were $5.0 \mathrm{~mm}$ long, $3.0 \mathrm{~mm}$ high, and $1.0 \mathrm{~mm}$ thick. Each core was extracted by cutting a centered transverse section and hand grinding to the core dimensions. This was performed by mounting the otolith on cards with casting resin and cutting with a Buehler-Isomet low-speed bone saw. The Norton® low density diamond blades were separated by an aluminum spacer $(6 \mathrm{~mm})$. Sections were ground down to core size by hand on a Buehler Ecomet III lapping wheel with 320 grit silicon-carbide paper. A weight of approximately $0.02 \mathrm{~g}$ per otolith core was targeted. 
Radiometric analysis

To address some of the assumptions of this technique, juvenile otoliths and whole adult otoliths were analyzed. To determine if exogenous ${ }^{210} \mathrm{~Pb}$ is a factor by being incorporated during otolith formation, a sample of juvenile fish was added to the agegroups. For comparative purposes, a whole-otolith pair was analyzed for ${ }^{226} \mathrm{Ra}$ to assess if an ontogenetic difference occurs in ${ }^{226} \mathrm{Ra}$ uptake.

Each pooled otolith core sample was analyzed for ${ }^{210} \mathrm{~Pb}$ and ${ }^{226} \mathrm{Ra}$. To determine ${ }^{210} \mathrm{~Pb}$, alpha-spectrometry of ${ }^{210} \mathrm{Po}$, its daughter product, was performed. Determination of ${ }^{226} \mathrm{Ra}$ was performed using a new technique that utilizes isotope-dilution thermal ionization mass spectrometry (TIMS; Andrews et al. 1997). The details of ${ }^{210} \mathrm{~Pb}$ determination are described here, but only the details of ${ }^{226} \mathrm{Ra}$ determination that vary from the established procedure are stated here.

Because of the extremely low levels of ${ }^{210} \mathrm{~Pb}$ and ${ }^{226} \mathrm{Ra}$, trace-metal precautions were exercised during sample cleaning and processing (Linn 1988, Fabry and Delaney 1989, Watters 1995). All acids used were double distilled (GFS chemicals $\bigotimes$ ) and dilutions were made using Millipore $\bigotimes$ filtered Milli-Q water $\left(18 \mathrm{M} \Omega \mathrm{cm}^{-1}\right)$. Thorough cleaning and repeated dissolution of the core samples was performed prior to radiometric analysis (Andrews et al. 1997). 
${ }^{210} \mathrm{~Pb}$ activity determination

To determine ${ }^{210} \mathrm{~Pb}$ activity in the otolith core samples, the activity of ${ }^{210} \mathrm{Po}$ was used as a proxy for ${ }^{210} \mathrm{~Pb}$. Because background in the ${ }^{210} \mathrm{~Pb}-{ }^{210} \mathrm{Bi}$ beta-counting technique via lead sulfate coprecipitation is relatively high ( 6 to 12 counts per hour), this technique was not employed (Koide and Bruland 1975). Due to the relatively short half-life and low activity of ${ }^{210} \mathrm{~Pb}$, the detection of ${ }^{210} \mathrm{~Pb}$ is typically accomplished through the autodeposition and $\alpha$-spectrometric determination of its daughter proxy, ${ }^{210} \mathrm{Po}$ (Flynn 1968). Differences in half-life for ${ }^{210} \mathrm{~Pb}$ and ${ }^{226} \mathrm{Ra}$ lead to low ${ }^{210} \mathrm{~Pb}$. ${ }^{226} \mathrm{Ra}$ atom ratios. Therefore direct mass determination methods are not feasible for ${ }^{210} \mathrm{~Pb}$ at this time. Because of these constraints, the long counting times required, and the low backgrounds associated with $\alpha$-spectrometry, autodeposition and $\alpha$-spectrometric analysis of ${ }^{210}$ Po was chosen to determine ${ }^{210} \mathrm{~Pb}$ activity in this study.

To ensure that all of the ${ }^{210} \mathrm{Po}$ is due to ingrowth from ${ }^{210} \mathrm{~Pb}$, and that ${ }^{210} \mathrm{Po}:{ }^{210} \mathrm{~Pb}$ was in secular equilibrium, all samples were at least $2 \mathrm{yr}$ old. Samples prepared for ${ }^{210} \mathrm{Po}$ analysis were spiked with a yield tracer, ${ }^{208} \mathrm{Po}$, calibrated against NBS and geological standards (Williams 1988). The amount added was estimated to be 5 times the activity of ${ }^{210} \mathrm{Po}$ in the otolith sample to reduce counting error in the determination of ${ }^{210} \mathrm{~Pb}$ activity.

To isolate the polonium isotopes for the purpose of $\alpha$-spectrometry, the isotopes were autodeposited onto a silver planchet. Spiked samples were redissolved in approximately $50 \mathrm{~mL}$ of $0.5 \mathrm{~N} \mathrm{HCl}$ on a hot plate covered with a watch-glass. Samples were completely dissolved and the temperature was elevated to $90-\mathrm{i} 00^{\circ} \mathrm{C}$ before plating. 
The ${ }^{210} \mathrm{Po}$ and ${ }^{208} \mathrm{Po}$-tracer were autodeposited at this temperature (higher than suggested because of inaccurate temperature monitoring, $80^{\circ} \mathrm{C}$ ) onto a purified silver planchet (99.999\%, A.F. Murphy Die and Machine Co.) held in a rotating teflon holder over a 4 hour period (Flynn 1968). Planchets were counted using both silicon surface barrier detectors and ion implant detectors in eight Tennelec TC256 alpha-spectrometers interfaced with a multi-channel analyzer and an eight channel digital multi-plexer. Counts were collected with Nucleus@ software on an IBM-PC. Radium blanks included these steps to account for any potential radium contamination. The sample remaining after polonium autodeposition was dried down and saved for ${ }^{226} \mathrm{Ra}$ analysis.

Activity of ${ }^{210}$ Po was calculated in the following manner. Counts collected using $\alpha$-spectrometry for ${ }^{210} \mathrm{Po}$ and ${ }^{208} \mathrm{Po}$ were corrected for background and reagent counts by subtracting the amount of counts calculated to occur for counting time using the rates measured for reagent blanks. Adjusted sample counts for ${ }^{208}$ Po and ${ }^{210}$ Po were corrected for decay during the counting period in two steps. First, the time in the count interval, where counts before and after were equal, was calculated,

$$
t_{\text {mid }}=\frac{\ln \left(\left(1+e^{\left(-\lambda^{2 x x_{P O}} t_{\text {fin }}\right)}\right)\right)}{2} *\left(-\lambda^{\left.2 \times x_{P O}\right)}\right.
$$

where $t_{\text {mid }}$ was the point in the counting interval, for each isotope, at which the counts collected before and after are equal; $\lambda^{2 \mathrm{xx}}$ Po was the decay constant for ${ }^{208} \mathrm{Po}(\ln (2) / 2.898$ 
$y r)$ or ${ }^{210} \mathrm{Po}(\ln (2) / 0.3789 \mathrm{yr})$; and $t_{\min }$ was the time from autodeposition to the end of the counting interval. Secondly, $t_{\text {mid }}$ was used to calculate the ${ }^{210}$ Po and ${ }^{208}$ Po counts, corrected for decay since autodeposition,

$$
\mathrm{Cts}^{2 \mathrm{Xx}} \mathrm{Po}_{\mathrm{u}_{s}}=\frac{\mathrm{Cts}^{2 \mathrm{Xx}} \mathrm{Po}_{\mathrm{m}}}{\left(e^{\left(\left(-\lambda^{\left.20 \mathrm{P}_{0}\right) \cdot u_{-}}\right)\right.}\right)},
$$

where $\mathrm{Cts}^{2 \mathrm{xX}} \mathrm{Po}_{\mathrm{u}}$ was the decay corrected ${ }^{210} \mathrm{Po}$ or ${ }^{208} \mathrm{Po}$ counts to the time of autodeposition, $\mathrm{Cts}^{2 \mathrm{XX}} \mathrm{Po}_{\mathrm{m}}$ was the measured ${ }^{210} \mathrm{Po}$ or ${ }^{208} \mathrm{Po}$ counts, and $\lambda^{2 \mathrm{XX}} \mathrm{Po}$ was the decay constant for ${ }^{210} \mathrm{Po}$ or ${ }^{208} \mathrm{Po}$.

Because the ${ }^{210} \mathrm{Po} /{ }^{208} \mathrm{Po}$ activity ratio was equal to the measured ${ }^{210} \mathrm{Po} /{ }^{208} \mathrm{Po}$ count ratio and the ${ }^{208}$ Po yield-tracer activity was known, then ${ }^{210}$ Po activity was determined using,

$$
\mathrm{A}^{210} \mathrm{Po}_{\text {unk }}=\mathrm{A}^{208} \mathrm{Po}_{\text {known }} *\left(\frac{\mathrm{Cts}^{210} \mathrm{Po}}{\mathrm{Cts}^{208} \mathrm{Po}}\right),
$$

where $\mathrm{A}^{210} \mathrm{Po}_{\text {unk }}$ was the unknown ${ }^{210} \mathrm{Po}$ activity of the sample, $\mathrm{A}^{208} \mathrm{Po}$ known was the activity of the ${ }^{208} \mathrm{Po}$ yield tracer, and $\mathrm{Cts}{ }^{210} \mathrm{Po} / \mathrm{Cts}^{208} \mathrm{Po}$ was the ratio of the corrected counts for ${ }^{210}$ Po and ${ }^{208}$ Po. 
Because the activity of ${ }^{210} \mathrm{Po}$ was in secular equilibrium with ${ }^{210} \mathrm{~Pb}$, then the activity of ${ }^{210} \mathrm{Po}$ was equal to the ${ }^{210} \mathrm{~Pb}$ activity. This activity was then corrected for ${ }^{210} \mathrm{~Pb}$ ingrowth from the time of capture to autodeposition by applying,

$$
A^{210} \mathrm{~Pb}_{L c}=A^{210} \mathrm{~Pb}_{u}-\mathrm{A}^{226} \mathrm{Ra}_{\mathrm{TMS}} *\left(1-\mathrm{e}^{(-\lambda d t)}\right)
$$

where $\mathrm{A}^{210} \mathrm{~Pb}$ was the ${ }^{210} \mathrm{~Pb}$ activity at the time of capture, $\mathrm{A}^{210} \mathrm{~Pb}$ was the ${ }^{210} \mathrm{~Pb}$ activity corrected to the time of autodeposition, $\mathrm{A}^{226} \mathrm{Ra}$ TMs was the ${ }^{226} \mathrm{Ra}$ activity measured using TIMS (determined later), $\lambda$ was the decay constant for ${ }^{210} \mathrm{~Pb}(\ln (2) / 22.26 \mathrm{yr})$, and $d t$ was the time between capture and autodeposition.

${ }^{226}$ Ra activity determination

Determination of ${ }^{226} \mathrm{Ra}$ was performed using the new elemental separation procedure and isotope-dilution TIMS described elsewhere (Andrews et al. 1997, Chapter 2). The only exception to the procedure used for these samples was the collection intervals used for each column separation. In the first two column passes, where calcium removal occurs, the collection interval was from 35 to $120 \mathrm{~mL}$, instead of 40 to $120 \mathrm{~mL}$. For the third column pass, where radium is isolated, the collection interval was from 300 to $700 \mu \mathrm{L}$, instead of 250 to $700 \mu \mathrm{L}$. These intervals were changed as a result of this study to improve radium separation and recovery and to further reduce calcium. 
Radiometric age determination

Age determination was performed using the measured ${ }^{210} \mathrm{~Pb}$ and ${ }^{226} \mathrm{Ra}$ activities in the following equations. Because the activities were measured using the same sample, the calculation was independent of sample mass. For adult samples, where estimated age was greater than the 5 yr core, radiometric age was calculated as follows to compensate for the ingrowth gradient of ${ }^{210} \mathrm{~Pb}:{ }^{226} \mathrm{Ra}$ in the otolith core,

$$
\mathrm{t}_{1 \mathrm{gc}}=\frac{\ln \left(\frac{1-\frac{\mathrm{A}^{210} \mathrm{~Pb}_{\mathrm{k}}}{\mathrm{A}^{226} \mathrm{Ra}_{\mathrm{TMS}}}}{\frac{1-\mathrm{e}^{-\lambda \mathrm{T}}}{\lambda \mathrm{T}}}\right)}{-\lambda}+\mathrm{T},
$$

where $t_{\text {sge }}$ was the radiometric age for the time of capture, $A^{210} \mathrm{~Pb}_{c c}$ was the ${ }^{210} \mathrm{~Pb}$ activity corrected to time of capture, $A^{226} \mathrm{Ra}$ TMs was the ${ }^{226} \mathrm{Ra}$ activity measured using TIMS, $\lambda$ was the decay constant for ${ }^{210} \mathrm{~Pb}$, and $\mathrm{T}$ was the core age $(5 \mathrm{yr})$. The radiometric age calculation for the juvenile age-group was much simpler because estimated age was lower than 5 years. Age was calculated using,

$$
t_{\triangle B C}=\frac{\ln \left(1-\left(\frac{A^{210} \mathrm{~Pb}_{k c}}{A^{226} \operatorname{Ra}_{\mathrm{TMS}}}\right)\right)}{-\lambda}
$$


where $t_{a g e}$ was the radiometric age, $A^{210} \mathrm{~Pb}_{v e}$ was the ${ }^{210} \mathrm{~Pb}$ activity corrected to time of capture, $A^{226}{ }^{R a}$ TMS was the ${ }^{226} \mathrm{Ra}$ activity, and $\lambda$ was the decay constant for ${ }^{210} \mathrm{~Pb}$.

\section{Analytical uncertainty calculation}

Determination of error for each isotope was as follows. The uncertainties for the corrected ${ }^{210} \mathrm{~Pb}$ activity were based on the total counts after correction for background and reagents:

$$
\sigma A^{210} \mathrm{~Pb}=A^{210} \mathrm{~Pb} * \sqrt{\left(\frac{\sqrt{\mathrm{N}^{208} \mathrm{Po}}}{\mathrm{N}^{208} \mathrm{Po}}\right)^{2}+\left(\frac{\sqrt{\mathrm{N}^{210} \mathrm{Po}}}{\mathrm{N}^{210} \mathrm{Po}}\right)^{2}}
$$

where $\sigma \mathrm{A}^{210} \mathrm{~Pb}$ is the standard deviation of the ${ }^{210} \mathrm{~Pb}$ activity, $\mathrm{A}^{210} \mathrm{~Pb}$ is the corrected ${ }^{210} \mathrm{~Pb}$ activity, $\mathrm{N}$ is the number of counts corrected for background and reagents for ${ }^{208} \mathrm{Po}$ or ${ }^{210} \mathrm{Po}$ (Wang et al. 1975). Uncertainty for ${ }^{226} \mathrm{Ra}$ activity is calculated during sample analysis using TIMS (Andrews et al. 1997). These uncertainties were used to calculate high and low radiometric ages.

Age estimate accuracy

A comparison of estimated age versus radiometric age was performed in two plots and one statistical analysis. First, the estimated age of the age-groups and measured ${ }^{210} \mathrm{~Pb}:{ }^{226} \mathrm{Ra}$ activity ratios were plotted with expected ${ }^{210} \mathrm{~Pb}:{ }^{226} \mathrm{Ra}$ ingrowth curves. 
Concordance of these data with the expected ingrowth curves were used as an indicator of age estimate accuracy. A direct comparison of estimated age was also performed by plotting the radiometric age opposite estimated age. A linear regression of these data were compared to a line of agreement or one-to-one. A paired two-sample $t$-test was used to determine if a significant difference existed between the line of agreement and the regression line. 


\section{Results}

A total of 747 Pacific grenadier was collected from waters off California, Oregon, and Washington. Of these fish, 128 with complete tails were used in the partial length analysis. All three partial lengths (PAF, SD, and HL) had linear relationships which could be used to determine total length (Figure 4). Fish used in this analysis ranged in size from $124 \mathrm{~mm}$ to $688 \mathrm{~mm}$ TL. Because PAF had the largest proportion of total length, it was chosen as the length used in growth analyses and is used to determine total length.

\section{Traditional ageing}

Fish chosen for traditional age determination numbered 178 and ranged in size from $22 \mathrm{~mm}$ to $272 \mathrm{~mm}$ PAF. Transverse sections were very difficult to age. APE was comparable between readers at about $6 \%$, but $\mathrm{D}$ indicates precision was better for the first reader ( 6 and $10 \%$ respectively). Forty-three percent of the readings between readers were within 1 year, $55 \%$ within 2 years, $80 \%$ within 5 years, and $95 \%$ within 10 years (Table 1). Most of the differences between readers resulted from lower age estimates made by the second reader on old otolith sections (69\%). Precision estimates were $6.3 \%$ (APE) between readers. Consultation between readers usually resolved differences greater than $10 \%$. Age estimates were ultimately finalized by the first reader. For 32 of the specimens, the second otolith of the pair was sectioned for another attempt at ageing. Twenty were still unageable after both sections. Ninety-two of the otoliths selected were ageable (52\%). Left and right otoliths were not differentiated because there was no systematic difference between sides ( $t$ test, $\mathrm{p}>95 \%$ ). 
Three von Bertalanffy growth functions fitted to the PAF lengths and estimated ages to describe growth characteristics for females, males, and combined sexes, where juveniles were factored into each determination (Figure 5). The growth curves for males and combined sexes have comparable growth curves, but females appear to have slower growth and a higher maximum length.

Age-group determination and core extraction

The regression of otolith weight and estimated age indicate there is a linear relationship for females and males, with some scatter (Figure 6). These regressions were used to determine age for the otoliths considered for radiometric age determination. By comparing the multiple linear regression ages, dissimilar fish were identified by having regression ages that differed by greater than $10 \%$. This process eliminated 9 to $33 \%$ of the potential age-group members.

A total of 6 adult age-groups ( 3 female, 3 male) and one juvenile age-group was selected for radiometric analysis (Table 2). Age-groups range from as low as $1 \mathrm{yr}$ for the juvenile sample to a maximum of $56 \mathrm{yr}$ for the oldest age-group. The number of fish in the adult age-groups ranged from 10 to 21 , but the juvenile age-group numbered higher at 46 because the otoliths were small. Some otolith cores were lost in the coring process due to breakage. Average core weight for the female samples, processed first, were slightly higher $(0.03 \mathrm{~g})$ than the targeted core weight $(0.02 \mathrm{~g})$. Male samples were cored a little smaller and more closely approached the target core weight. Total sample weight for each 
age-group ranged from $0.4717 \mathrm{~g}$ to $1.2279 \mathrm{~g}$. Mean length was also calculated for each age-group $( \pm \sigma)$.

Radiometric analysis

The results of the radiometric determinations are given in the form of activity (dpm $\mathrm{g}^{-1}$ ) and a ratio of activities (Table 3). The activity of ${ }^{210} \mathrm{~Pb}$ increased, as expected, 25 times from $0.0023 \mathrm{dpm} \mathrm{g}^{-1}$ in the juvenile samples to $0.0568 \mathrm{dpm} \mathrm{g}^{-1}$ in to oldest adult sample. Error for this determination ranged from 4.4 to $7.8 \%$. The activity of ${ }^{226} \mathrm{Ra}$

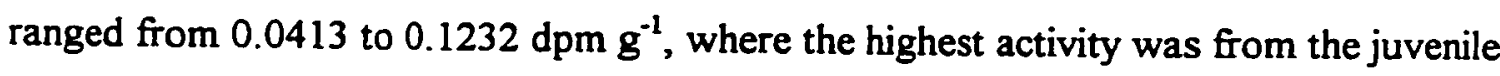
sample. This was 2.2 times higher than the mean adult sample activity $(0.0560 \pm 0.01)$ and nearly 3 times the lowest activity measured. The activity of the adult whole-otolith pair is comparable to the lowest adult sample. Error for ${ }^{226} \mathrm{Ra}$ was very low and ranged from 0.278 to $3.073 \%(1 \sigma)$. The activity ratio of ${ }^{210} \mathrm{~Pb}:{ }^{226} \mathrm{Ra}$ increased as predicted by estimated age from a low of 0.0186 for the juvenile age-group to 0.810 for the oldest adult age-group.

Radiometric age determination

Radiometric age determined using the activity ratio was comparable to the average estimated age of the age-groups (Table 4). Each age-group range overlaps the radiometric age range, with the exception of the juvenile age-group. The low radiometric age for the 1-3 yr age-group indicates ${ }^{210} \mathrm{~Pb}$ uptake by juveniles was insignificant. 
Therefore, radiometric age was determined based on the measured activity ratios and no adjustment was necessary.

Age estimate accuracy

A graphical comparison of the age-groups versus the measured ${ }^{210}{ }^{\mathrm{Pb}}:{ }^{226} \mathrm{Ra}$ activity ratio plotted with the expected ingrowth curves indicated age estimate accuracy (Figure 7). The 1-3 yr age-group was closely associated with the ingrowth curve for an $R_{0}$ of 0.0 , which indicates it was the most accurate model for what to expect in adult otolith cores. The strong concordance of the data points with the expected ingrowth curve indicates high age estimate accuracy.

A direct comparison of estimated age with radiometric age indicated ages are statistically in agreement (Figure 8). Data points were all in close proximity to the line of agreement. A regression of these data shows a high correlation and a slope very close to one with an intercept near the origin (adjusted $R^{2}=0.957$ ). A paired two-sample $t$-test comparison indicates there was no significant difference between estimated age and radiometric age $(t=0.427, P=0.684)$. 


\section{Discussion}

\section{Partial length defined}

Partial lengths are used to indicate total length of grenadier for the north Atlantic (Atkinson $1981 \&$ 1991). The Pacific grenadier often has a tail that is apparently intact, but a few centimeters can be missing with little evidence. Most broken tails occurred during capture by trawling. In some cases, tails were lost during life and regenerated, where regenerated means growth of fin rays from the severed edge. For a few fish, approximately 10 to $20 \%$ of the total length was lost during life. In this study, approximately $80 \%$ of the fish collected had damaged, broken or regenerated tails. For fish greater than $500 \mathrm{~mm}$ TL, tail loss was as high as $18 \%$ of the total length.

Partial length for grenadier is poorly defined. "Anal-fin length" (defined as tip of snout to base of first anal fin ray) was adopted as the partial length for the roundnose grenadier by NAFO in 1980, where no acronym was assigned (Atkinson 1981). This length was adopted because the anus is often distorted by air-bladder expansion and extrusion of intestines caused by barotrauma. Pre-anal length (length anterior to the anus), however, was used instead of anal fin length in an age and growth study of the roundnose grenadier (Bergstad 1990). In two age and growth studies of the Pacific grenadier, "anal length" was used, where SVL (snout to vent length) was assigned (Wilson 1982, Matsui et al. 1990). In a partial length study of the roughhead grenadier (Macrourus berglox), "pre-anal fin length (AFL)" was used as the equivalent to anal fin length (Atkinson 1991). More recently, in another age and growth study of the roundnose 
grenadier, pre-anus (PA) was used, but pre-anal fin length (PAF) was also noted and nicely illustrated (Kelly et al 1997).

Based on the advantages of using the anterior most fin ray of the anal fin over the anus and the unambiguous acronym (PAF), we chose PAF as the pertial length for the Pacific grenadier. It is further proposed that partial length be standardized for grenadier in these terms, and that use of $\mathrm{HL}$ or SD be used where the anal fin is missing or badly damaged (Figure 4).

\section{Traditional age estimation}

A graphical comparison of growth curves from this study and other studies reveal both differences and similarities (Figure 9). Kulikova (1957) did not calculate growth parameters, but for comparative purposes, growth parameters were calculated using the average length given for each estimated age. In this case, the growth constant is very high and longevity is very low relative to validated estimates in this study (Table 5). This growth constant is unrealistically greater than many fast growing fishes (i.e. tuna and billfishes; Prince and Pulos 1983). The growth curve fitted to age estimates determined by Matsui et al. (1990) is very similar to the male and combined sexes growth curves in this study (Figure 9). It must be noted that Matsui et al. (1990) used snout to anus length (less than PAF by approximately $1 \%$ ). The upper end of the female growth curve in this study is largely unsupported by data, but it is important to mention that some otoliths from females greater than $300 \mathrm{~mm}$ PAF were aged at up to greater than $90 \mathrm{yr}$. These otoliths were not used in this study because growth increments were very fine and confusing 
toward the margin and were also aged as low as $65 \mathrm{yr}$. The difficulty of ageing otolith sections for this species was comparable to recent findings for the roundnose grenadier (Coryphaenoides rupestris, Kelly et al. 1997). The asymptotic length of the female growth curve more closely approximates the maximum size reported ( $-900 \mathrm{~mm} T \mathrm{~L}$, Cohen et al. 1990). Therefore, it is possible that females get larger than males with increasing age.

A comparison of historic and recent age estimates indicate the age and growth of the Pacific grenadier is controversial and age is usually underestimated (Table 6). The first Pacific grenadier age estimates are for specimens collected in the Bering and Okhotsk Seas and the Kuril-Kamchatka trench, where scales were used to estimate a longevity of 6 years (Kulikova 1957). This result underestimates the longevity determined in this study by an order of magnitude. Scales can, however, be unreliable as a conserved record of age (Mugiya 1974, Simkiss 1974, Ichii and Mugiya 1983, Beamish and McFarlane 1987, Yoklavich and Boehlert 1987). In a study of the microstructure of otoliths, extrapolation of daily increments were used to estimate the age of one fish (Brothers et al. 1976). This estimate is low by a factor of three for a fish of this length in this study. The first attempt at quantification of annual growth increments in transverse otolith sections utilized 15 fish collected off San Diego, California (Mulcahey et al. 1979). They found otoliths difficult to age and cautiously estimated age at 15 to $25 \mathrm{yr}$ for the size range of fish used. In this study, comparably sized fish would be 2 to 3 times older. A detailed examination of scales, vertebrae, and otoliths from 130 fish collected off southern California resulted in an estimated longevity of approximately $20 \mathrm{yr}$ (Wilson 1982). Otoliths sections were 
determined, however, to be too ambiguous for age estimation. Because of the difficulty in ageing the otoliths in this study, we largely agree, but this longevity estimate is low by a factor of 3 to 4. Most recently, otolith break-and-burn was used on 60 fish collected off northern Baja California, Mexico to central California (Matsui et al. 1990). Longevity was estimated at greater than 60 years, which is comparable to the results of this study.

\section{Radiometric analysis}

Use of otolith cores for radiometric age determination is typically limited to a minimum of approximately 1 gram of material because of instrument detection limits (Kastelle et al. 1994, Fenton and Short 1995). Because of cleaner procedures and the application of isotope-dilution TIMS, sample size can be lower than $0.5 \mathrm{~g}$ (Table 2). Reduced error associated with ${ }^{226} \mathrm{Ra}$ determination make the analytical uncertainty of ${ }^{210} \mathrm{~Pb}$ determination the limiting factor in radiometric ageing. In this study, uncertainty in ${ }^{210} \mathrm{~Pb}$ activity contributes $7.8 \%$ of the error where counts are very low (juvenile samples) and decreases to approximately $5 \%$ as age and counts increase (Table 3). Typically the error for ${ }^{226} \mathrm{Ra}$ determination is lower than $1 \%$. In this study, reported error greater than $1 \%$ is attributed to high calcium in the sample. An alteration of the technique remedied the problem (Andrews et al. 1997).

In some radiometric ageing studies ${ }^{226} \mathrm{Ra}$ activity is inferred, rather than measured directly, because of the detection limits of ${ }^{222} \mathrm{Rn}$ emanation (Bennett et al. 1982, Campana 1990, Watters 1995, Kline 1996). It is clear from the results of this study that ${ }^{226} \mathrm{Ra}$ activity can vary significantly among samples and, presumably, among individuals for some 
fishes (Table 2). The ${ }^{226} \mathrm{Ra}$ activity for the juvenile sample was the highest activity measured in this study. Some juvenile specimens were collected from upper slope areas near the Columbia River mouth. Because freshwater is a source of ${ }^{226} \mathrm{Ra}$ it is possible that environmental levels of ${ }^{226} \mathrm{Ra}$, are elevated in this area (Osterberg et al. 1963, Fanning et al. 1982, Moore 1996). This may explain the elevated ${ }^{226} \mathrm{Ra}$ activity in the juvenile otoliths. Use of an average ${ }^{226} \mathrm{Ra}$ activity in this study causes significant changes to radiometric age. This emphasizes the necessity of measuring ${ }^{210} \mathrm{~Pb}$ and ${ }^{226} \mathrm{Ra}$ for each sample in future studies.

\section{Assumption clarification}

The radiometric ageing technique requires several assumptions depending on the analytical circumstances. The typical assumptions are as follows: 1) the otolith is a closed system with no loss or migration of post-formational radionuclides in the ${ }^{226} \mathrm{Ra}$ decay series through to ${ }^{210} \mathrm{Po}$; this is necessary because loss of nuclides would result in lower ${ }^{210} \mathrm{~Pb}$ activity and subsequently underestimated age, 2) uptake of exogenous nuclides in the ${ }^{226} \mathrm{Ra}$ decay series is negligible relative to ingrowth from ${ }^{226} \mathrm{Ra}$; this is necessary in order to attribute ${ }^{210} \mathrm{~Pb}$ activity in the otolith to the decay of $\left.{ }^{226} \mathrm{Ra}, 3\right)$ uptake of ${ }^{226} \mathrm{Ra}$ is in constant proportion to the otolith mass growth-rate; this assumption is only necessary when whole otoliths are used and is largely circumvented when otolith cores are used (Kimura and Kastelle 1995). These assumptions can be more closely scrutinized with the increased accuracy of the radiometric ageing technique using isotope-dilution TIMS (Andrews et al. 1997). 
The two most important assumptions are that the otolith is a closed system and that incorporation of exogenous ${ }^{210} \mathrm{~Pb}$ is negligible. Loss of ${ }^{222} \mathrm{Rn}$ and sources of exogenous ${ }^{210} \mathrm{~Pb}$ or ${ }^{210} \mathrm{Po}$ are potential violations of these assumptions (West and Gauldie 1994). If ${ }^{222} \mathrm{Rn}$ loss was a problem, radiometric disequilibria of ${ }^{210} \mathrm{~Pb}:{ }^{226} \mathrm{Ra}$ would consistently underestimate fish age. In this study it is very unlikely that the traditional age estimates of each age-group would be underestimated by the precise amount necessary to compensate for ${ }^{222} \mathrm{Rn}$ loss. Because the use of TIMS has increased the accuracy of the radiometric ageing technique, tolerance for such an error is very low. Based on the results of this study and other concurrent studies, ${ }^{222} \mathrm{Rn}$ loss is very improbable or insignificant. In the case of exogenous ${ }^{210} \mathrm{~Pb}$ or ${ }^{210} \mathrm{Po},{ }^{210} \mathrm{~Pb}$ was eliminated as a possible factor by ageing the juvenile age-group (1-3 yr). It is highly unlikely that uptake of ${ }^{210} \mathrm{~Pb}$ in adults would be different from juveniles. If any exogenous ${ }^{210} \mathrm{Po}$ was incorporated into the core, it would decay away well before radiometric analysis (half-life $=138.4$ days). Therefore, this study clearly supports these assumptions and concerns regarding these assumptions are less substantiated.

Age estimate accuracy

The strong concordance of measured ${ }^{210} \mathrm{~Pb}:{ }^{.26} \mathrm{Ra}$ with the expected ingrowth curves validates age estimation using growth increments in the Pacific grenadier (Figure 7). Because the 1-3 yr age-group shows extremely low ${ }^{210} \mathrm{~Pb}$ activity, we believe the most applicable ingrowth model is for an $R_{0}$ of 0.0 . Variation of the data points around the ingrowth curve can be explained by the analytical uncertainty associated with the 
technique and the age-group age range. An additional consideration is variation in the otolith weight models (Figure 6). Because otoliths were difficult to age, there is a fair amount of scatter associated with otolith weight as a predictor of age. It is clear, however, that these effects are minimal relative to the average age of each sample because anomalous otoliths were removed using the regression comparisons.

Statistical agreement between estimated age and radiometric age further supports validation of age estimates (Figure 8). Radiometric age determinations confirm a longevity of at least 56 years and validates the annual periodicity of the growth increments used to estimate age. Based on these growth increments, longevity of the Pacific grenadier is at least 73 years.

Life histories

Longevity estimates for two similar grenadier species of the North Atlantic differ considerably. The roundnose grenadier (Coryphaenoides rupestris) has longevity estimates that range from 50 to $72 \mathrm{yr}$, which are comparable to the Pacific grenadier (Bergstad 1990, Kelly et al. 1997). Age validation of these estimates is limited to young fish using marginal increment analysis (Gordon and Swan 1996). This species can attain a greater length (1.5 to $2 \mathrm{~m} \mathrm{TL}$ ) and appears to have a faster growth rate than the Pacific grenadier. In contrast, the roughhead grenadier (Macrourus berglcix) has a relatively low estimated longevity of $13 \mathrm{yr}$ for males and $22 \mathrm{yr}$ for females (Savvatimsky 1994). Females exceed the length of males and approach $1 \mathrm{~m} \mathrm{TL}$, which is comparable to the Pacific grenadier. Age estimates, however, are based largely on scales and validation has yet to 
be performed. Grenadier from other parts of the world are thought to have similarly low longevity, but validation is necessary (Rannou 1976, Middleton and Musick 1986, Morales-Nin 1990). It is possible that the grenadier family has a series of species complexes that differ in growth characteristics, as is thought to be the case for the eastern Pacific Ocean rockfishes (Sebastes spp.; Boehlert and Kappenman 1980, O'Connell and Funk 1986, Leaman and Nagtegaal 1987, Pearson et al. 1991).

Maturity at length from several studies can be used to estimate age at maturity for the Pacific grenadier. Length at maturity is estimated at $500 \mathrm{~mm}$ TL (ca. $170 \mathrm{~mm}$ PAF) for males and between 460 to $650 \mathrm{~mm} \mathrm{TL}$ (ca. 153 to $230 \mathrm{~mm} \mathrm{PAF}$ ) for females (Stein and Pearcy 1982, Matsui et al. 1990). Based on the growth functions calculated for each sex, maturity may occur between 20 to $40 \mathrm{yr}$ for females and at $20 \mathrm{yr}$ for males. This is much later than the typically larger and faster growing roundnose grenadier, where 50\% maturity occurs at 8 to 11 yr (Kelly et al. 1997).

It is important to consider the potential age of the fish being landed because landings for the Pacific grenadier have increased substantially (Figures 1 and 2). Landings for Oregon have been about $91 \%$ male, where most range in size from 450 to $650 \mathrm{~mm}$ TL (Mike Hosie, Oregon Department of Fish and Wildlife, PO Box 5430, Charleston, OR 97420 , personal communication). The small percentage of females landed are typically larger at about 550 to $650 \mathrm{~mm} \mathrm{TL}$. Based on the calculated growth functions, fish being landed may range in age from 20 to $50 \mathrm{yr}$ for males and 30 to $40 \mathrm{yr}$ for females. Landings for Monterey Bay, California consist of fish ranging in size from 550 to $650 \mathrm{~mm}$ TL $(-95 \%)$ with some small individuals at about $300 \mathrm{~mm} \mathrm{TL} \mathrm{(} \mathrm{-5 \% ).} \mathrm{Sex} \mathrm{composition} \mathrm{is} \mathrm{not}$ 
known. Based on both growth functions, age of the large fish may be between 30 to $50 \mathrm{yr}$ and the small fish may be about $10 \mathrm{yr}$. Because maturity occurs late in life, many of the fish being landed may be sexually immature.

The depth distribution of the Pacific grenadier may provide a viable management strategy. Because size and abundance appear to increase to a depth of approximately $1500 \mathrm{~m}$ (Stein and Pearcy 1982), it may be possible to implement a size refuge for the Pacific grenadier by limiting fishing to a depth range (i.e. 1200 to $1800 \mathrm{~m}$ ). By fishing in this depth range, juvenile and old adults could be protected in a strategy comparable to that of white sturgeon (Acipenser transmontamus) in California, where small and large fish are released. With this strategy, recruitment and growth of immature fish on the upper slope could be more protected, and larger, older fish at depth could provide an undisturbed source of productivity for the population. In addition to this limitation, a seasonal restriction should be implemented to reduce to impact on individuals during spawning season. A moratorium on fishing for the early fall (August) to late winter (February) would encompass the period where reproduction appears to hit a peak (Matsui et al. 1990).

Much remains unknown about the Pacific grenadier that is necessary to develop a sustainable fishery. Population size and distribution, and the movement of individuals in the population, are probably the most important aspects of this fishery that need research. Population size and individual movement may be assessed using recently developed acoustical techniques (Priede et al. 1990). Catch per unit effort infermation needs to be compiled and analyzed for abundance estimates in areas already being fished. Other 
studies including tag and recapture coupled with deep trawling and submersible transects could be used to estimate population characteristics at depths greater than current commercial fishing depths. 


\section{References}

Andrews, A.H., Coale, K.H., Nowicki, J. , Lundstrom, C., Palacz, Z., and Cailliet, G.M.. 1997. Application of a new ion-exchange separation technique and isotope-dilution thermal ionization mass spectrometry to ${ }^{226} \mathrm{Ra}$ determination in otoliths for radiometric age determination of long-lived. This issue.

Archibald, C.P., Foumier, D., and Leaman, B.M. 1983. Reconstruction of stock history and development of rehabilitation strategies for Pacific Ocean perch in Queen Charlotte Sound, Canada. North American Joumal of Fisheries Management. 3:283-294.

Atkinson, D.B. 1981. Partial length as a replacement for total length in measuring grenadiers. J. Nw. Atl. Fish. Sci. 2:53-56.

Atkinson. D.B. 1991. Rela'ionships betweer pre-anal fin length and total length of roughhead grenadier in the north-west Atlantic. J. Nw. Atl. Fish. Sci. 11:7-9.

Beamish, R.J. 1979. New information on the longevity of Pacific ocean perch (Sebastes alutus). J. Fish. Res. Board Can. 36:1395-1400.

Beamish, R.J., and Fournier, D.A., 1981. A method of comparing the precision of a set of age determinations. Can. J. Fish. Aquat. Sci. 38:982-983.

Beamish, R.J. and McFarlane, G.A. 1983. The forgotten requirement for age validation in fisheries biology. Trans. Amer. Fish. Soc. 112:735-743.

Beamish, R.J. and McFarlane, G.A. 1987. Current trends in age determination methodology. In The age and growth of fish. Edited by R.C. Summerfelt and G.E. Hall. The Iowa State University Press, Ames, Iowa. pp. 15-42. 
Bennett, J.T., Boehlert, G.W., and Turekian, K.K.. 1982. Confirmation of longevity in Sebastes diploproa (Pisces: Scorpaenidae) from 210-Pb/226-Ra measurements in otoliths. Mar. Biol. 71:209-215.

Bergstad, O.A. 1990. Distribution, population structure, growth and reproduction of the roundnose grenadier Coryphaenoides rupestris (Pisces: Macrouridae) in the deep waters of the Skagerrak. Mar Biol. 107:25-39.

Boehlert, G.W. and Kappenman, R.F. 1980. Variation of growth with latitude in two species of rockfish (Sebastes pinniger and S. diploproa) from the Northeast Pacific Ocean. Mar. Ecol. 3:1-10.

Brothers, E.B., Mathews, C.P., Lasker, R. 1976. Daily growth increments in otoliths from larval and adult fishes. Fish. Bull. 74(1):1-8.

Campana, S.E., Zwanenburg, K.C., and Smith, J. N. 1990. 210-Pb/226-Ra determination of longevity in redfish. Can. J. Fish. Aquat. Sci. 47:163-165.

Chang, W.Y.B. 1982. A statistical method for evaluating the reproducibility of age determination. Can. J. Fish. Aquat. Sci. 39:1208-1210.

Chilton, D.E. and Beamish, R.J. 1982. Age determination methods for fishes studied by the groundfish program at the Pacific biological station. Can. Spec. Publ. Fish. Aquat. Sci. No. 60.

Cohen, D.M., Inada, T., Iwamoto, T., Scialabba, N. 1990. FAO species catalogue. Vol. 10. Gadiform fishes of the world (Order Gadiformes). An annotated and illustrated catalogue of cods, hakes, grenadiers and other gadiform fishes known to date. FAO Fisheries Synopsis. No. 125, Vol. 10. Rome, FAO. 
Fabry, V.J. and Delaney, M.L. 1989. Lead-210 and polonium-210 in pteropod and heteropod molluse shells from the North Pacific evaluation of sample treatments and variation with shell size. J. Mar. Res. 47:933-949.

Fanning, K.A., Breland, J.A., and R.H. Byrne. 1982. Radium-226 and Radon-222 in the coastal waters of west Florida: high concentrations and atmospheric degassing. Science 215:667-670.

Fenton, G.E. and, Short S.A. 1995. Radiometric analysis of blue grenadier, Macruronus novaezelandiae, otolith cores. Fish. Bull. 93:391-396.

Fenton, G.E., Short, S.A., and Ritz, D.A. 1991. Age determination of orange roughy, Hoplostethus atlanticus (Pisces: Trachichthyidae) using 210-Pb:226-Ra disequilibria. Mar. Biol. 109:197-202.

Flynn, W.W. 1968. The determination of low levels of polonium-210 in environmental materials. Anal. Chim. Acta. 43:221-227.

Gordon, J.D.M., and Swan, S.C. 1996. Validation of age readings from otoliths of juvenile roundnose grenadier, Coryphaenoides rupestris, a deep-water macrourid fish. J. Fish Biol. 49(A):289-297.

Ichii, T. and Mugiya, Y. 1983. Comparative aspects of calcium dynamics in calcified tissues in the goldfish Carassius auratus. Bull. Japan. Soc. Sci. Fish. Manag. 49:1039-1044.

Iwamoto, T., and Stein, D.L. 1974. A systematic review of the rattail fishes (Macrouridae: Gadiformes) from Oregon and adjacent waters. Calif. Acad. Sci., Occas. Pap.

111:1-79. 
Kastelle, C.R., Kimura, D.K., Nevissi, A.E., and Gunderson, D.R. 1994. Using Pb210/Ra-226 disequilibria for sablefish, Anoplopoma fimbria, age validation. Fish. Bull. 92:292-301.

Kelly, C.J., Connolly, P.L., and Braken, J.J. 1997. Age estimation, growth, maturity and distribution of the round nose grenadier from the Rockall trough. J. Fish Biol. 50:1-17.

Kimura, D.K. and Kastelle, C.R. 1995. Perspectives on the relationship between otolith growth and the conversion of isotope activity ratios to fish ages. Can. J. Fish. Aquat. Sci. 52:2296-2303.

Kline, D.E. 1996. Radiometric age verification for two deep-sea rockfish (Sebastolobus altivelis and Sebastolobus alascanus). M.S. thesis, California State University, San Jose, Moss Landing Marine Laboratories.

Kremsdorf, D.L., Josephson, R.V., Spindler, A.A., Phleger, C.F. 1979. Gross composition, sensory evaluation, and cold storage stability of underutilized deep sea Pacific rattail fish, Coryphaenoides acrolepis. J. Food Sci. 44:1044-1048.

Koide, M., and Bruland, K.W. 1975. The electrodeposition and determination of radium by isotopic dilution in sea water and in sedinents simultaneously with other natural radionuclides. Anal. Chim. Acta. 75:1-19.

Kulikova, E.B. 1957. Growth and age of deep-water fishes. Trudy Inst. Okean. Akad. Nauk. 20:347-355. (Translated from Russian by Am. Inst. Biol. Soc. p. 284-290 1959). 
Leaman, B.M. and Nagtegaal, D.A. 1987. Age validation and revised natural mortality rate for yellowtail rockfish. Trans. Amer. Fish. Soc. 116:171-175.

Leos, B. (ed.). 1996. Monterey Bay commercial fisheries report: an annual newsletter to the commercial fishing industry. California Department of Fish and Game. No. 7.

Leos, B. (ed.). 1997. Monterey Bay commercial fisheries report: an annual newsletter to the commercial fishing industry. California Department of Fish and Game. No. 8.

Linn, L.J. 1988. Trace metals in Galapagos corals: quarter-annual and annual cycles of copper, manganese, cadmium, and lead. M.S. Thesis, University of California Santa Cruz, 89p.

Mace, P.M., Fenaughty, J.M., Coburn, R.P., and Doonan, I.J. 1990. Growth and productivity of orange roughy (Hoplostethus atlanticus) on the north Chatham Rise. N.Z., J. Mar. Freshwater Res. 24:105-109.

MacDonald, P.D.M. 1987. Analysis of length-frequency distributiors. In The age and growth of fish. Edited by R.C. Summerfelt and G.E. Hall. The Iowa State University Press, Ames, Iowa. pp. 371-384.

McFarlane, G.A. and Beamish, R.J. 1995. Validation of the otolith cross-section method of age determination for sablefish (Anoplopoma fimbria) using oxytetracycline. In Recent developments in fish otolith research. Edited by D.H. Secor, J.M. Dean, and S.E. Campana. The Belle W. Baruch Library in Marine Science, No. 19. University of South Carolina Press, Columbia, South Carolina. pp. 319-329.

Matsui, T., Kato, S., and Smith, S.E. 1990. Biology and potential use of Pacific grenadier, Coryphaenoides acrolepis, off California. Mar. Fish. Rev. 52(3):1-17. 
Middleton, R.W. and Musick, J.A. 1986. Abundance and distribution of the family Macrouridae (Pisces: Gadiformes) in the Norfolk Canyon area. Fish. Bull. $84(1): 35-62$.

Milton, D.A., Short, S.A., ONeill, M.F., Blaber, S.J.M. 1995. Ageing of three species of tropical snapper (Lutjanidae) from the Gulf of Carpentaria, Australia, using radiometry and otolith ring counts. Fish. Bull 93:103-115.

Moore, W.S. 1996. Large groundwater inputs to coastal waters revealed by ${ }^{226} \mathrm{Ra}$ enrichments. Nature 380:612-614.

Morales-Nin, B. 1990. A first attempt determining growth patterns of some Mediterranean deep-sea fishes. Sci. Mar. 54(3):241-248.

Mugiya, Y. 1974. Calcium-45 behavior at the level of the otolithic organs of rainbow trout. Bull. Jpn. Soc. Sci. Fish. 40:457-463.

Mulcahey, S.A., Killingley, J.S., Phleger, C.F., and Berger, W.H. 1979. Isotopic composition of otoliths from a benthopelagic fish Coryphaenoides acrolepis, Macrouridae:Gadiformes. Oceanologica Acta. 2:423-427.

O'Connell, V.M., and Funk, F.C. 1986. Age and growth of yelloweye rockfish (Sebastes ruberrimus) landed in southeastern Alaska. In: Proceedings of the International Rockfish Symposium. Alaska Sea Grant Report No. 87-2. pp. 171-185.

Okamura, O. 1970. Studies on the macrouroid fishes of Japan-morphology, ecology and phylogeny. Rep. Usa Mar. Biol. Sta. 17(1-2):1-179.

Osterberg, C., Carey, A.G., and Curl, H. 1963. Acceleration of sinking rates of radionuclides in the ocean. Nature. 200:1276-1277. 
Pearson, D.E., Hightower, J.E., and Chan, J.T.H. 1991. Age, growih, and potential yield for shortbelly rockfish Sebastes jordani. Fish. Bull. 89:403-409.

Priede, I.G., Smith, K.L. Jr., and Armstrong, J.D. Foraging behavior of abyssal grenadier fish: inferences from acoustic tagging and tracking in the North Pacific Ocean. Deep-Sea Res. 37(1):81-101.

Prince, E.D., and Pulos, L.M. (eds.). 1983. Proceedings of the international workshop on age determination of oceanic pelagic fishes: tunas, billfishes, and sharks. NOAA Technical Report NMFS 8.

Rannou, M. 1976. Age and growth of a bathyal fish: Nezumia sclerorhynchus (Macrouridae, Gadiform) in Alboran Sea. Cahiers de Biologie Marine. Tome XVII:413-421. (Translated by Dr. Beatrice Mounaix)

Savvatimsky, P.I. 1994. Age structure of roughhead grenadier (Macrourus berglax) in the Northwest Atlantic, 1985. NAFO Sci. Coun. Studies. 20:53-64.

Simkiss, K. 1974. Calcium metabolism of fish in relation to ageing. In The proceedings of an international symposium on ageing of fish. Edited by T.B. Bagenal. Unwin Brothers Limited, The Gresham Press, Old Woking, Surrey, England.

Smith, D.C., Fenton, G.E., Robertson, S.G., and Short, S.A. 1995. Age determination and growth of orange roughy (Hoplostethus atlanticus): a comparison of annulus counts with radiometric ageing. Can. J. Fish. Aquat. Sci. 52:391-401. 
Smith, J.N., Nelson, R., and Campana, S.E. 1991. The use of Pb-210/Ra-226 and Th228/Ra-228 disequilibria in the ageing of otoliths of marine fish. In: P.J. Kershaw and D.S. Woodhead, (eds.), Radionuclides in the study of marine processes, p.350-359, Elsevier Applied Science, New York, USA.

Stein, D.L., and Pearcy, W.G. 1982. Aspects of reproduction, early life history, and biology of macrourid fishes of Oregon, USA. Deep-Sea Res. 29(11A):1373-1379.

Stewart, B.D., Fenton, G.E., Smith, D.C., and Short, S.A. 1995. Validation of otolithincrement age estimates for a deepwater fish species, the warty oreo Allocyttus verrucosus, by radiometric analysis. Mar. Biol. 123:29-38.

Wang, C.H., Willis, D.L., and Loveland, W.D. 1975. Radiotracer Methodology in the Biological, Environmental, and Physical Sciences. Prentice Hall, Englewood Cliffs, New Jersey, USA, 480p.

Watters, D.L. 1995. Age determination and confirmation from otoliths of the bank rockfish, Sebastes rufus (Scorpaenidae). M.S. thesis, California State University, San Jose, Moss Landing Marine Laboratories.

West, I.F., and Gauldie, R.W. 1994. Perspective: Determination of fish age using ${ }^{210} \mathrm{~Pb}:{ }^{226} \mathrm{Ra}$ disequilibrium methods. Can. J. Fish. Aquat. Sci. 51:2333-2340.

Williams, R.W. 1988. Uranium and thorium decay series disequilibria in young volcanic rocks. Ph.D. thesis. University of California, Santa Cruz.

Wilson, R.R., Jr. 1982. A comparison of ages estimated by the polarized light method with ages estimated by vertebrae in females of Coryphaenoides acrolepis (Pisces:

Macrouridae). Deep-Sea Res. 29(11A):1373-1379. 
Yoklavich, M.M. and Boehlert, G.W. 1987. Daily growth increments in otoliths of juvenile black rockfish, Sebastes melanops : an evaluation of autoradiography as a new method of validation. Fish. Bull. 85(4):826-832. 


\section{Table captions}

Table 1. A comparison of the agreement between readers revealed the difficulty of reading otolith sections from Pacific grenadier. Less than half were within one year of each other. Readings with the widest disagreement $(> \pm 5 \mathrm{yr})$ were from otolith sections of large fish and higher estimated age.

Table 2. Composition of age-groups used for radiometric age determination. Both otoliths were used from each fish, except where otoliths were lost in the coring process. Target samples size was $1 \mathrm{~g}$. Some samples were closer to $0.5 \mathrm{~g}$ because of insufficient sample. Mean length (PAF mm) was given for comparison.

Table 3. Results of radiometric analysis for ${ }^{210} \mathrm{~Pb}$ and ${ }^{226} \mathrm{Ra}$ activity determinations for each age-group. A single otolith pair from one fish was also listed for comparison with core results.

Table 4. Comparison of estimated ages and radiometric ages for each age-group. High and low radiometric ages were determined using analytical uncertainty extremes.

Table 5. Comparison of von Bertalanffy growth function parameters for other studies with the results of this study. 
Table 6. Comparison of historic and recent age and longevity estimates for the Pacific grenadier. Technique and number of fish used in each study were listed with fish lengths and age estimates. 
Table 1. Comparison of reader agreement.

\begin{tabular}{|c|c|c|c|c|c|}
\hline \multirow{2}{*}{$\begin{array}{l}\text { Age } \\
\text { difference }\end{array}$} & \multirow{2}{*}{$\begin{array}{c}\text { Percent of } \\
\text { observations }\end{array}$} & \multicolumn{2}{|c|}{ Agreement } & \multirow[b]{2}{*}{ $\pm 5 y r$} & \multirow[b]{2}{*}{ $\pm 10 \mathrm{yr}$} \\
\hline & & $\pm 1 \mathrm{yr}$ & $\pm 2 \mathrm{yr}$ & & \\
\hline$->10 y r$ & 5 & & & & \\
\hline-6 to $10 \mathrm{yr}$ & 14 & & & & 4 \\
\hline-3 to $5 \mathrm{yr}$ & 19 & & & 4 & \\
\hline$-2 y r$ & 9 & & 4 & & \\
\hline$-1 y \mathbf{y r}$ & 12 & 4 & & & \\
\hline 0 & 16 & $43 \%$ & $55 \%$ & $80 \%$ & $95 \%$ \\
\hline$+1 \mathrm{yr}$ & 15 & $t$ & & & \\
\hline$+2 \mathrm{yr}$ & 3 & & 1 & & \\
\hline+3 to $5 \mathrm{yr}$ & 6 & & & 1 & \\
\hline+6 to $10 \mathrm{yr}$ & 1 & & & & 1 \\
\hline$+>10 \mathrm{yr}$ & 0 & & & & \\
\hline
\end{tabular}




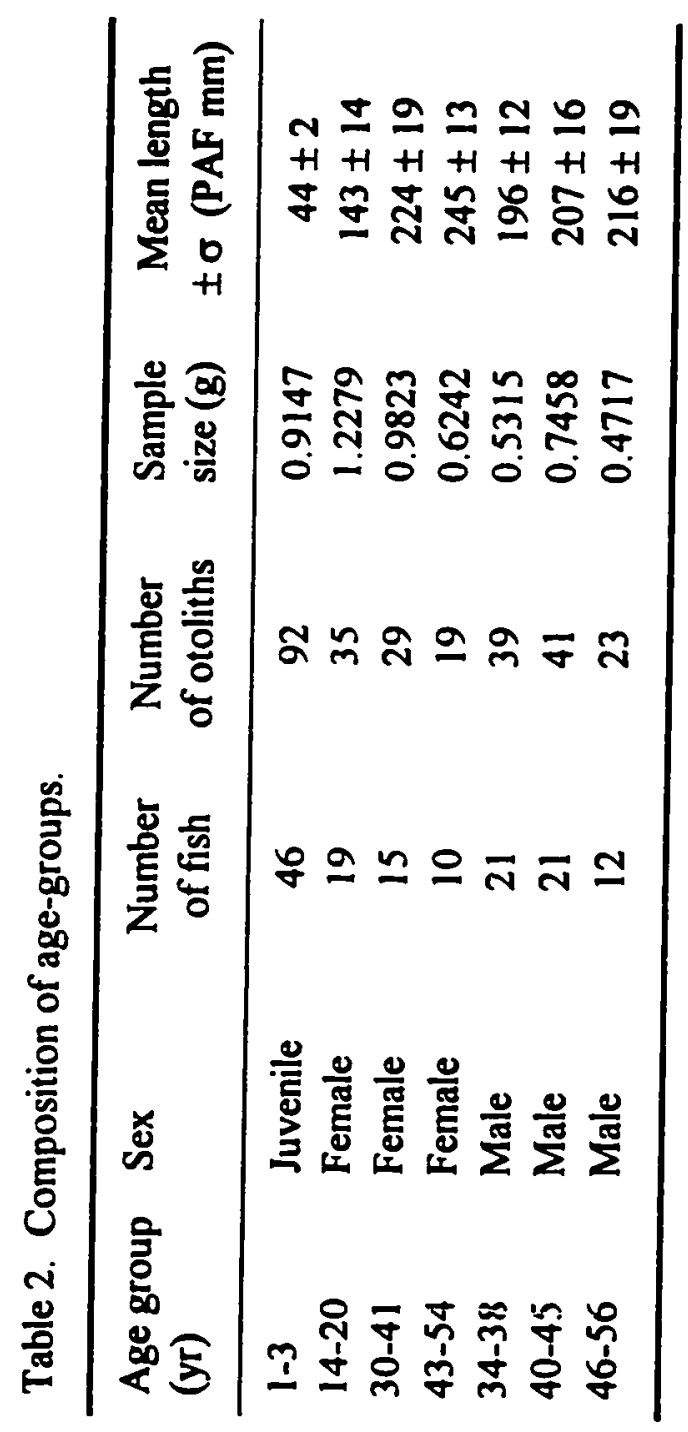




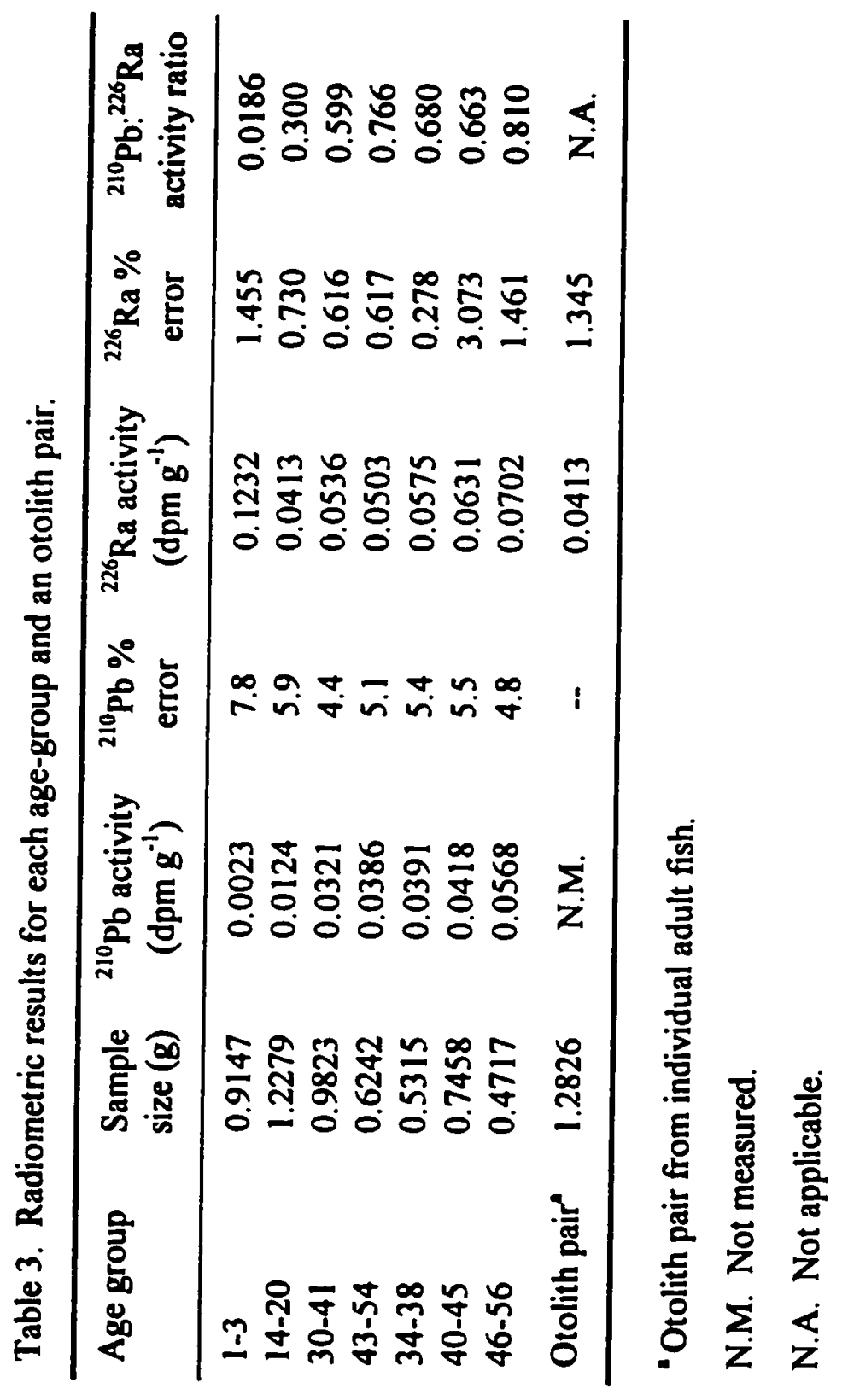




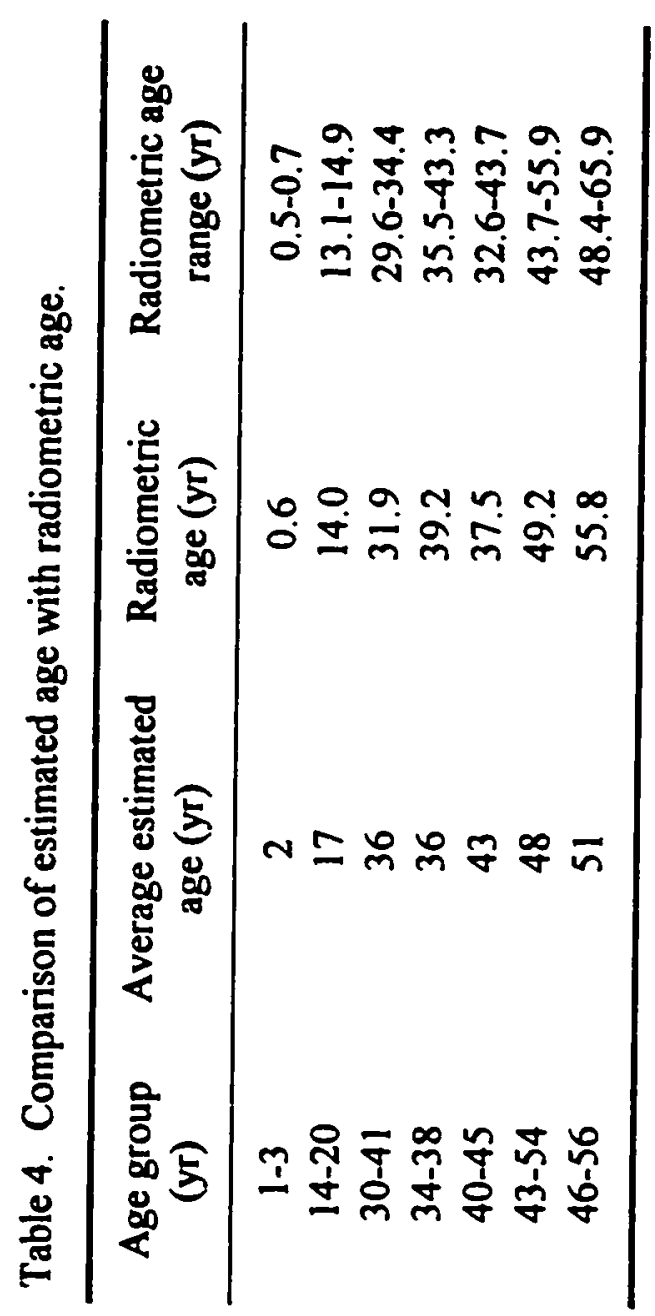




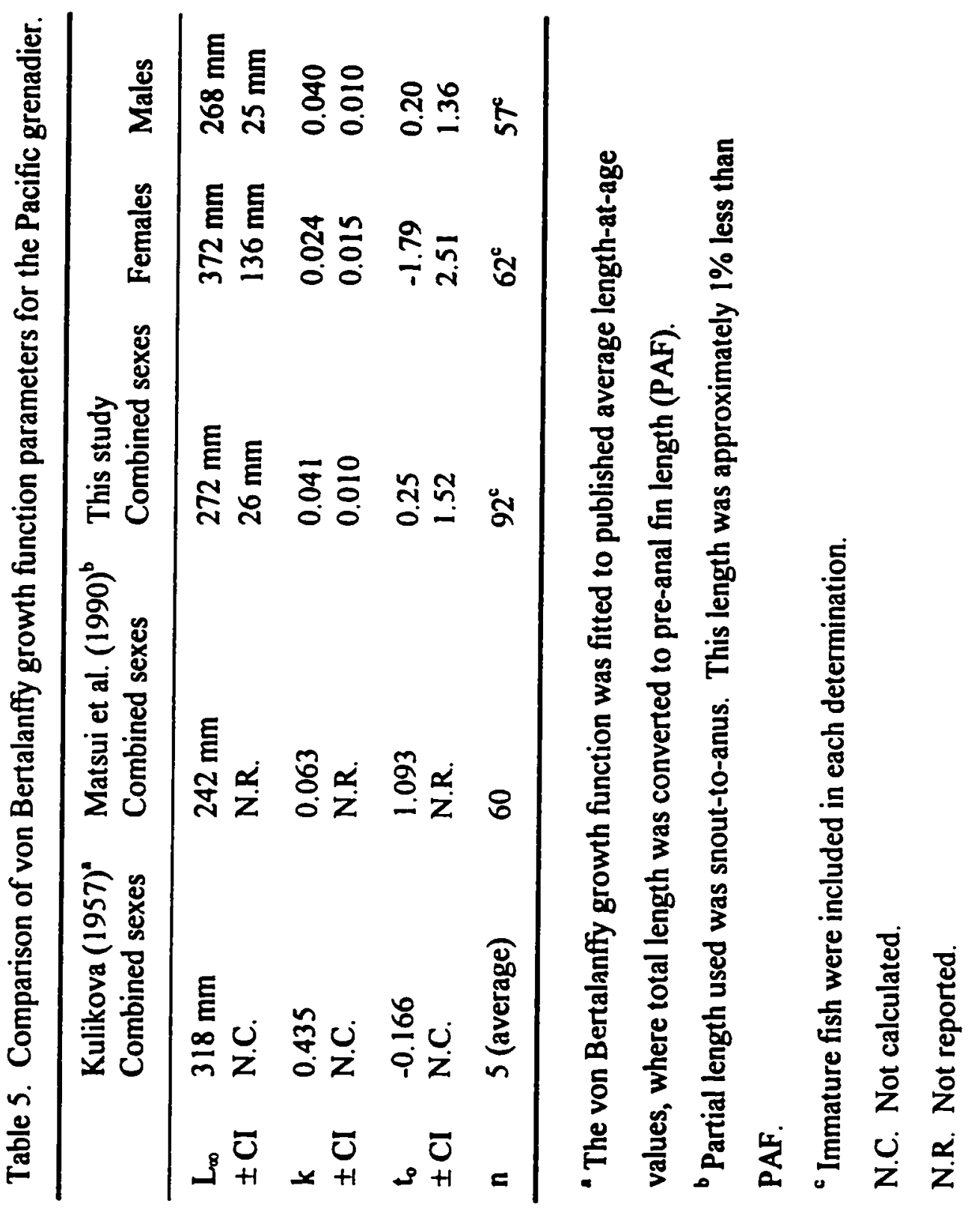




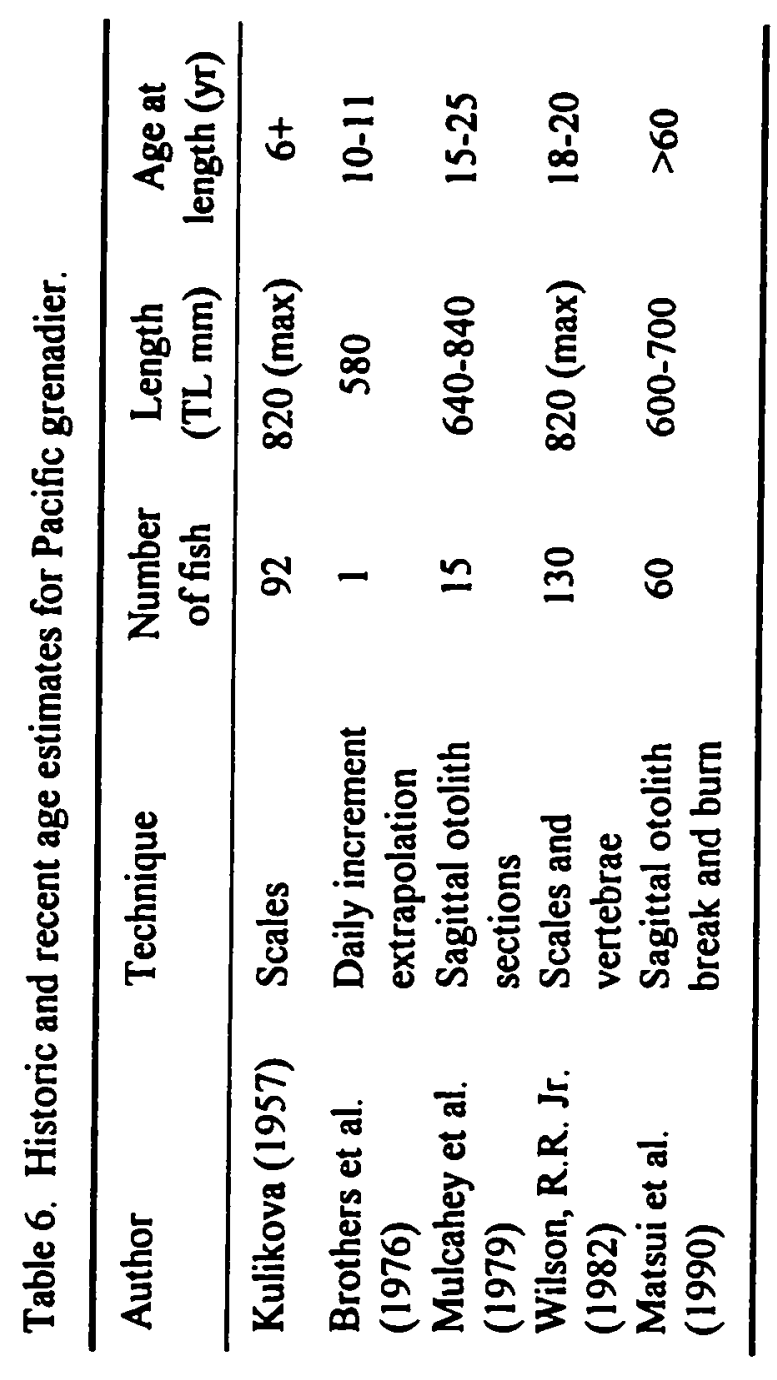




\section{Figure captions}

Figure 1. Landings of Pacific grenadier for California and Oregon from 1972 to 1996 given in metric tons (t). Landings for California up to 1992 are primarily from Eureka, California. After 1992, landings substantially increased from Monterey Bay, California. Total landings for California and Oregon for 1996 exceeded $1500 \mathrm{t}$ (3.3 million pounds).

Figure 2. Pacific Grenadier landings in metric tons ( $t$ ) reported for each of the 3 ports in Monterey Bay, California from 1980 to 1996. Through the 1980's the landings have been negligible, with the exception of 1984 where $6.2 \mathrm{t}$ was brought in to Moss Landing. Since 1992 landings have substantially increased to nearly $900 \mathrm{t}$ ( -2 million pounds) in 1996.

Figure 3. Three views of a transverse otolith section at different magnifications. The full section view is at a magnification of $10 \mathrm{X}$. The two successive views are at $32 \mathrm{X}$ and $50 \mathrm{X}$. Markers indicate quantified growth increments which rapidly become compressed toward the margin. This increment pattern was used as a search image in ageing other otolith sections. This section was aged at 41 yr. 
Figure 4. Linear relationships of three partial lengths were calculated as an indicator of total length ( $T L ; n=128)$. Head length $(H L)$, snout to dorsal fin length $(S D)$, and preanal fin length (PAF) can be used to indicate TL. PAF was the primary partial length used in this study because it is the largest proportion of TL.

Figure 5. Von Bertalanffy growth functions were fitted to estimated ages and pre-anal fin lengths (PAF) for females $(\boldsymbol{x})$, males $(0)$, and immature $(\bullet)$. Immature fish were used in each growth function. Total length (TL) was calculated based on PAF (Figure 3).

Figure 6. Linear relationships for females and males were calculated using estimated age and otolith weight. These equations were used to determine potential age-group members for unaged otoliths used in the radiometric age determinations.

Figure 7. Observed ${ }^{210} \mathrm{~Pb}:{ }^{226} \mathrm{Ra}$ activity ratios for age-groups plotted with expected activity ratio ingrowth curves. Strong concordance of the observed activity ratios (data points) with the expected activity ratio ingrowth curves was an indication of age estimate accuracy. Horizontal error bars represent age range of otolith core samples. Vertical error bars indicate analytical uncertainty in the determination of ${ }^{210} \mathrm{~Pb}$ and ${ }^{226} \mathrm{Ra}$ activities. Expected activity ratio ingrowth curves represent possible initial uptake ratios $\left(R_{0}\right)$ of ${ }^{210} \mathrm{~Pb}:{ }^{226} \mathrm{Ra}$. 
Figure 8. Comparison of estimated age versus radiometric age using a paired two-sample $t$ test indicate the ages were not significantly different $(t=0.427, P=0.684)$. The solid line represents agreement between age estimates and had a slope of 1 . The dashed line was a regression of the compared ages. Bars for estimated ages represent the age range of each age-group. Bars for the radiometric ages represent the range between high and low age based on analytical uncertainties.

Figure 9. Comparison of von Bertalanffy growth functions for two other studies with the results of this study. The growth function for Kulikova (1957) was calculated using the published average length-at-age where total lengths were converted to PAF. 


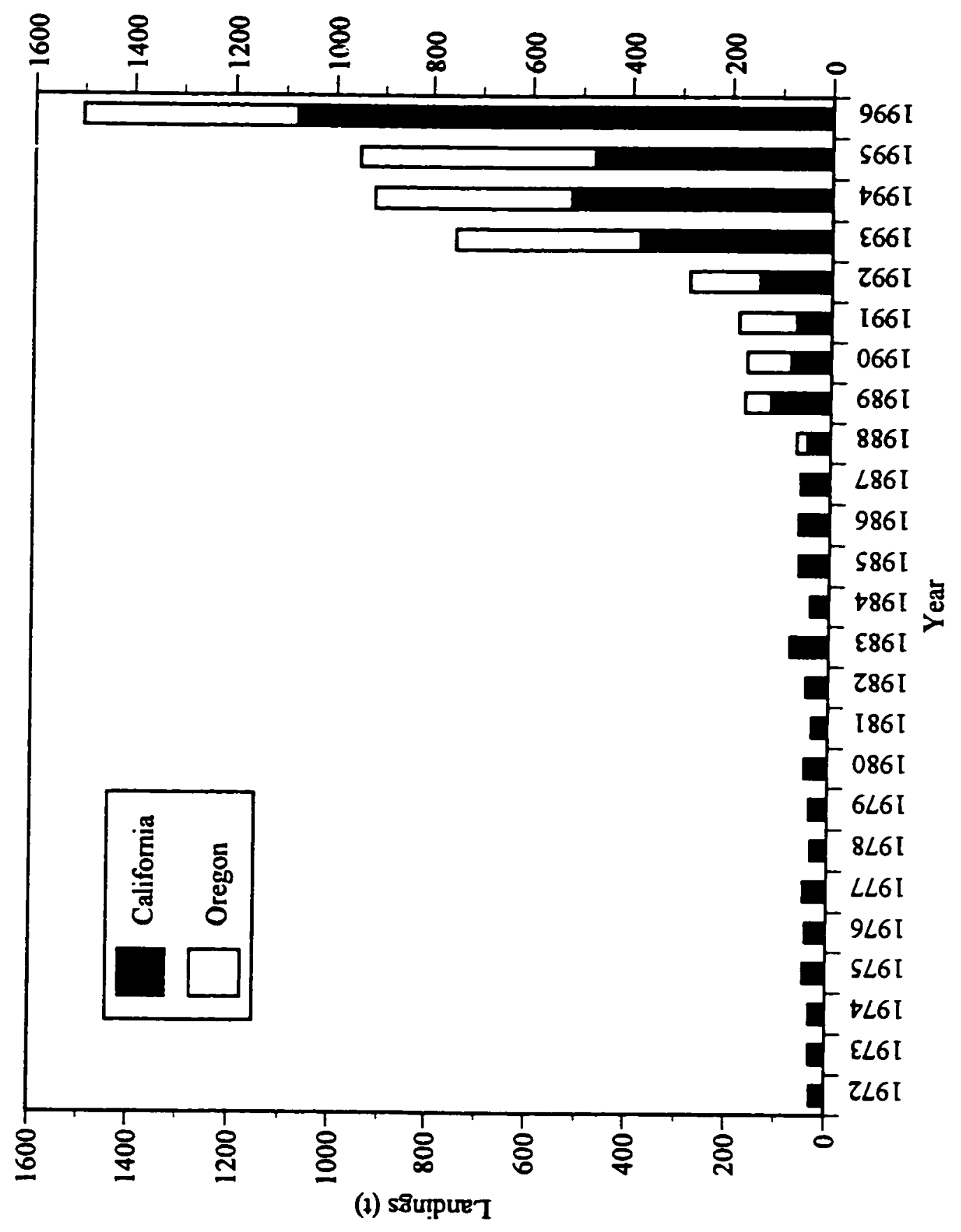




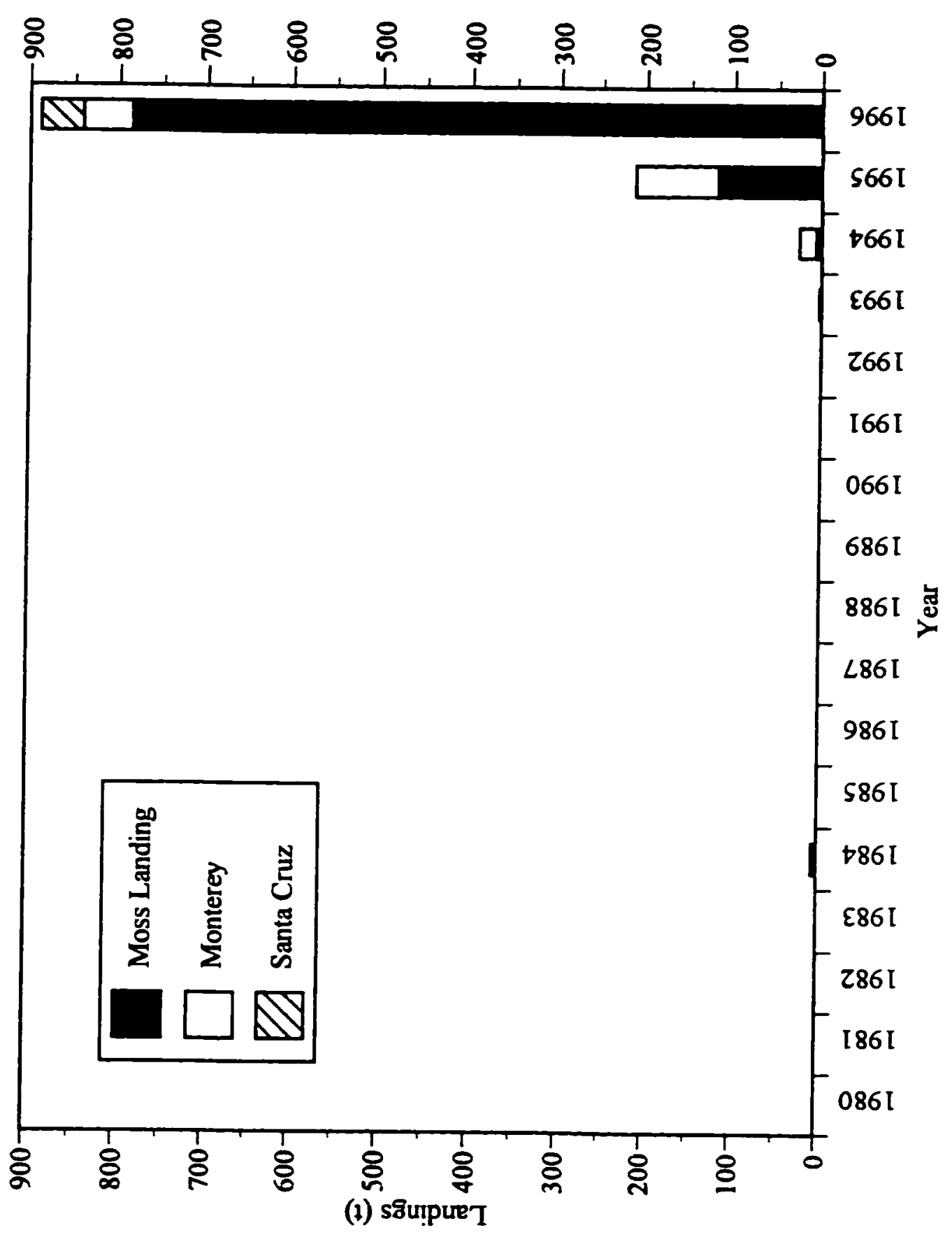



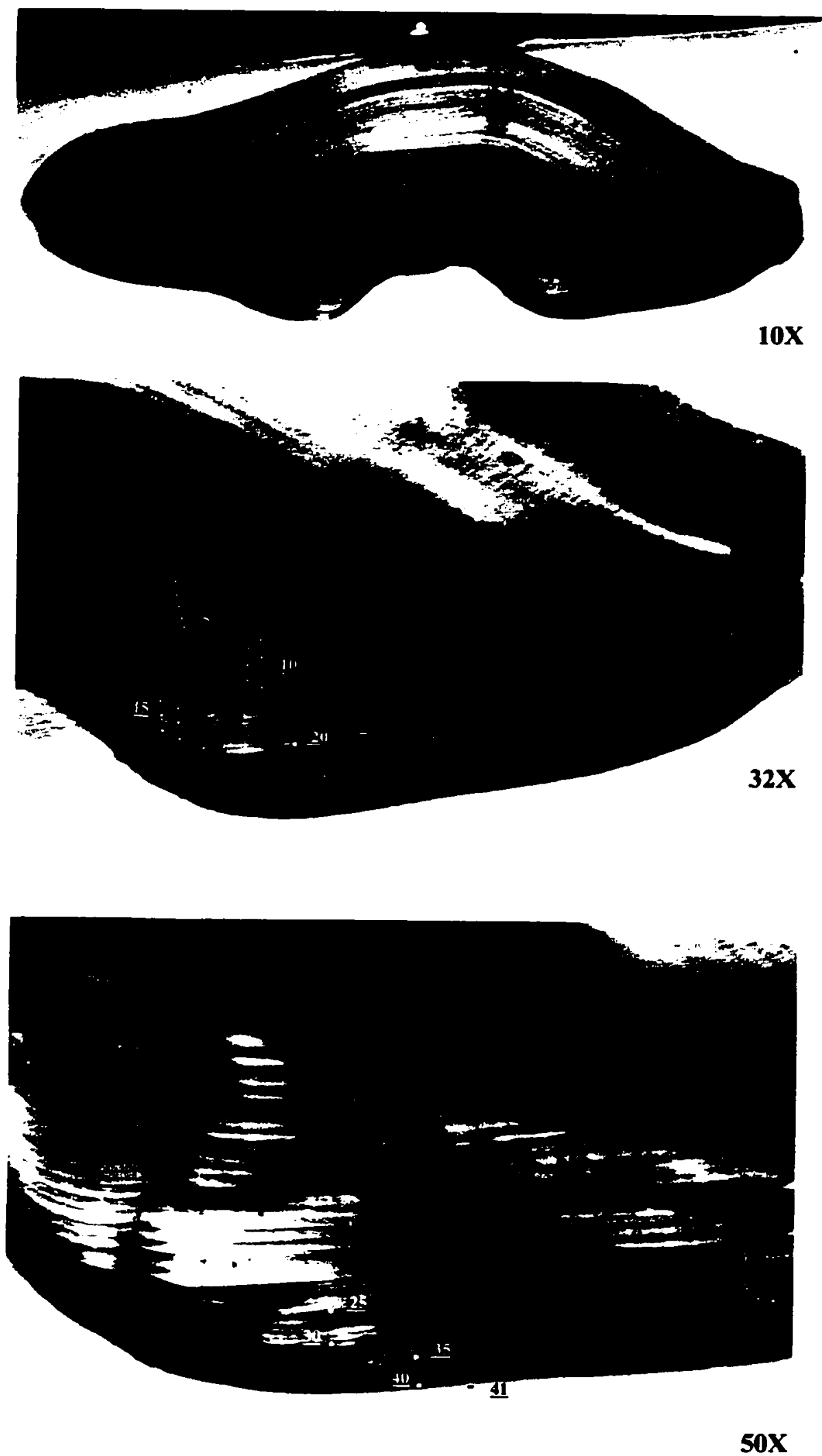

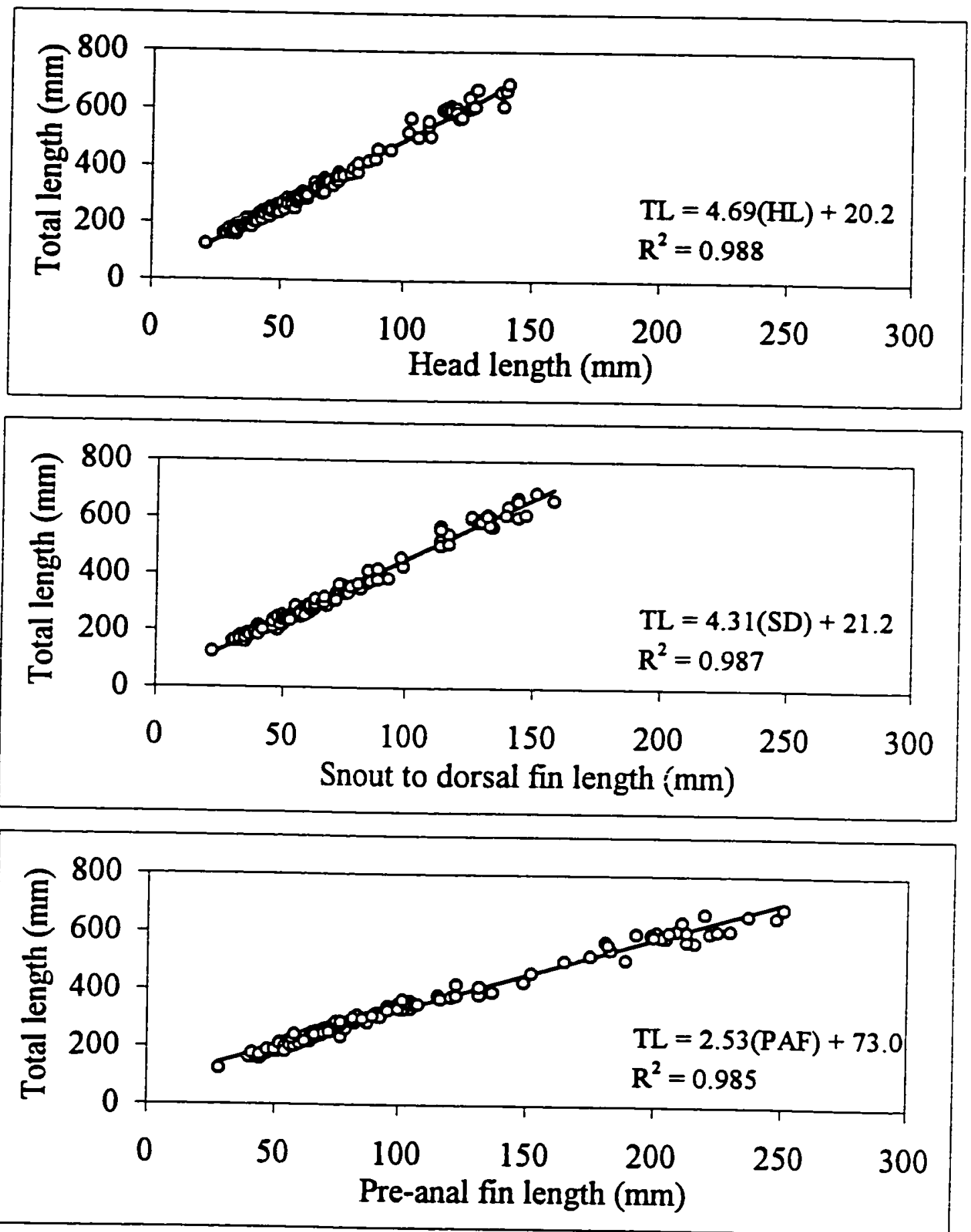


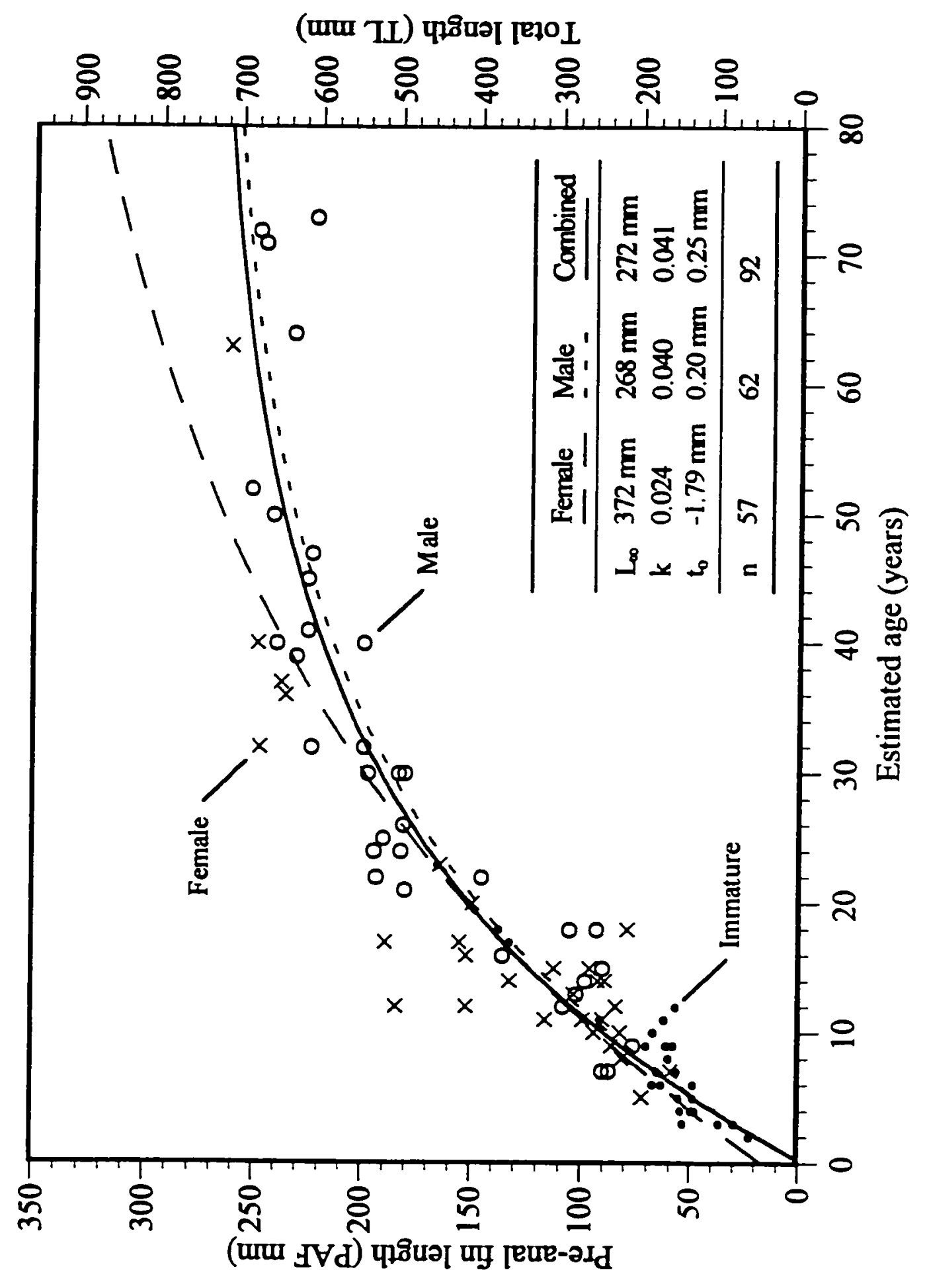




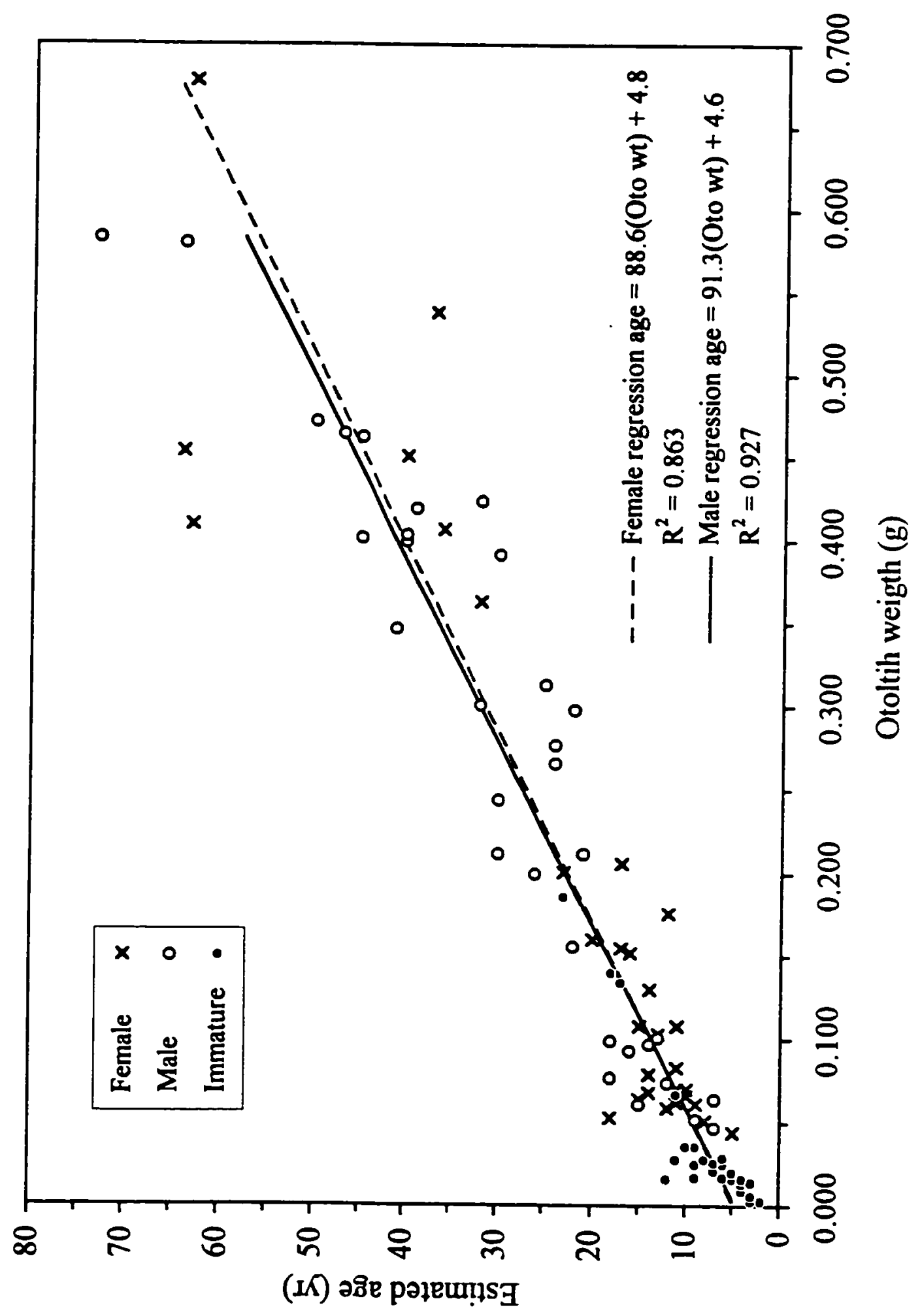




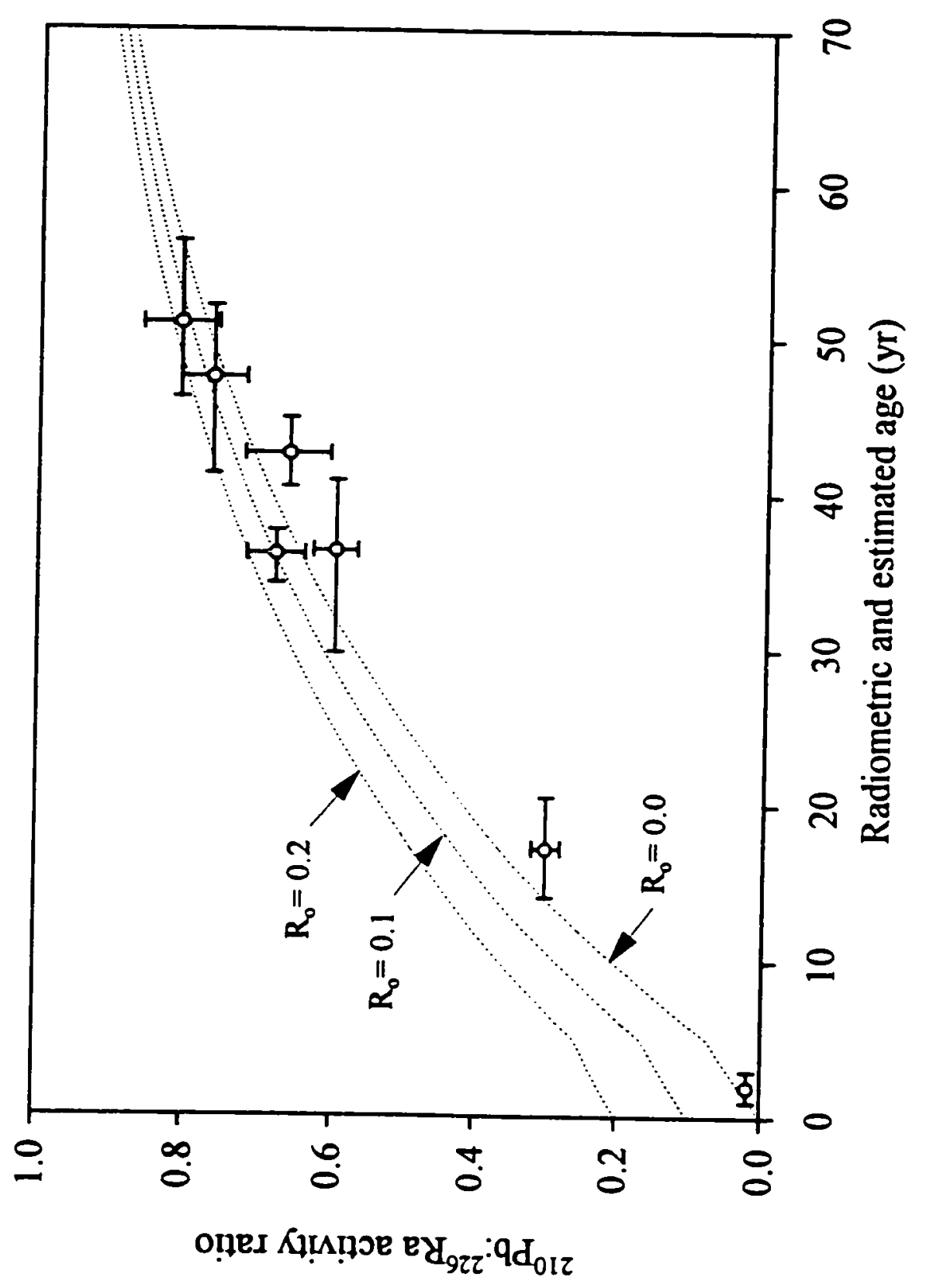




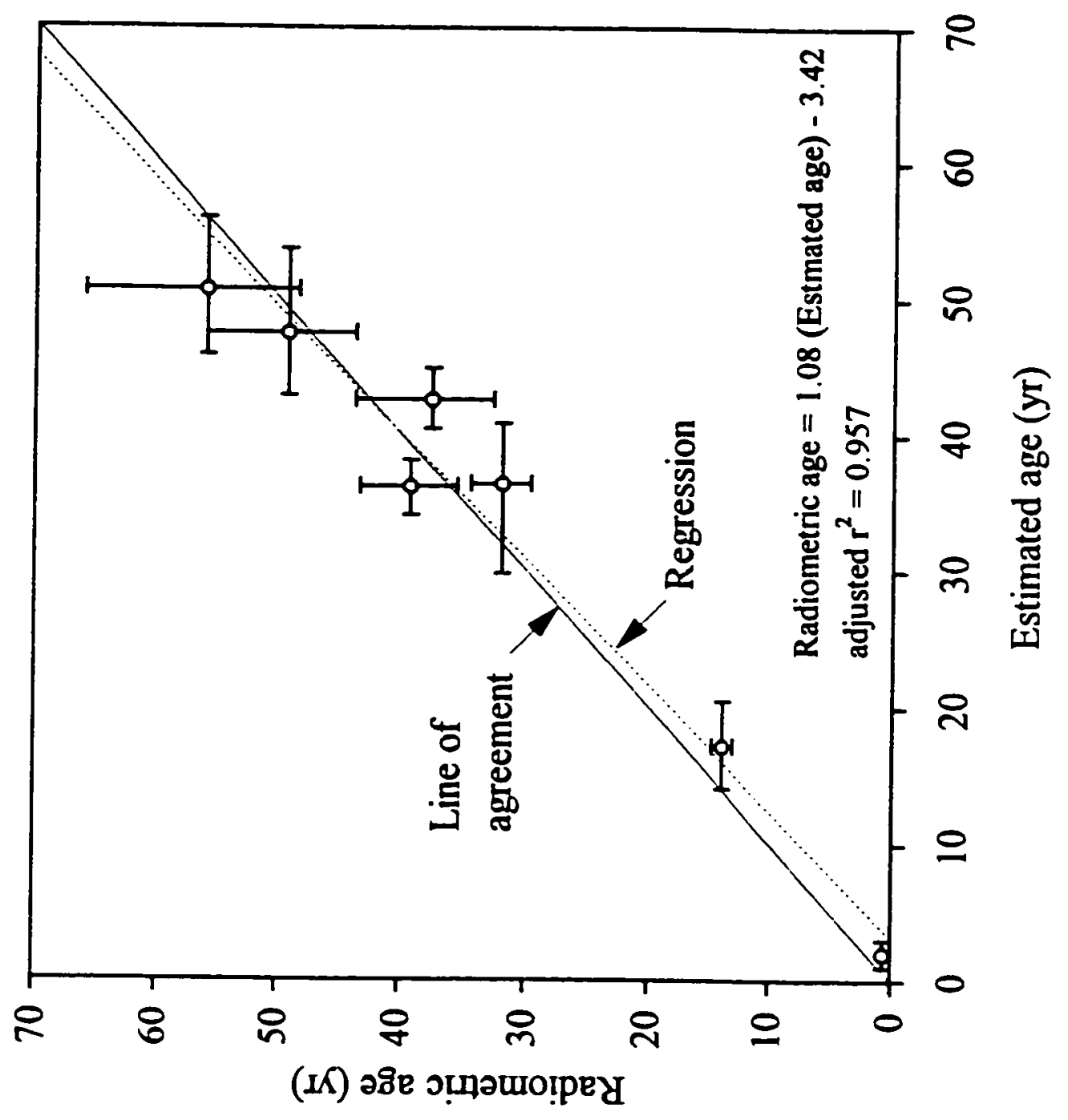




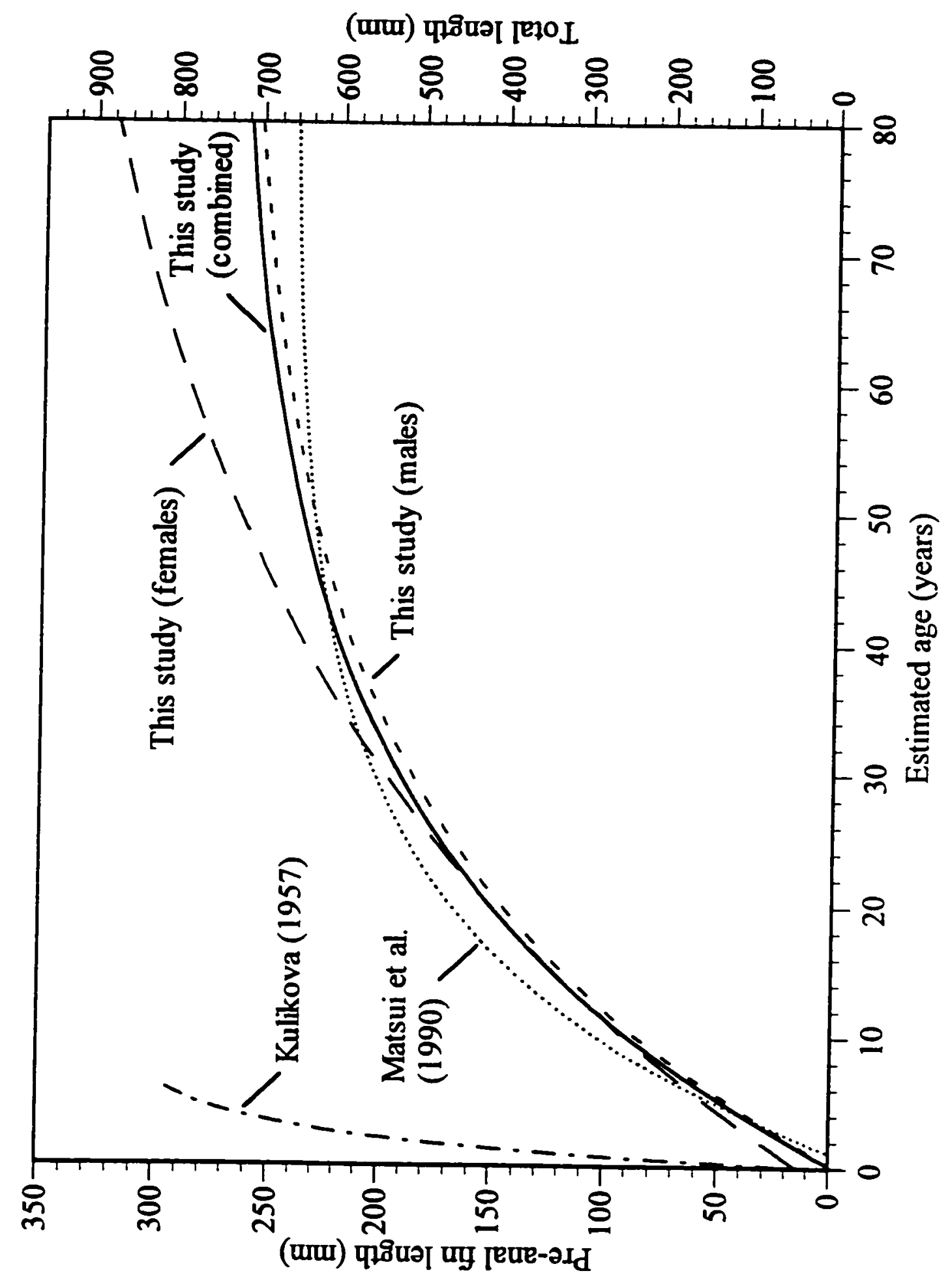




\section{CHAPTER 4}

\section{Conclusions and recommendations}


Isotope-dilution thermal ionization mass spectrometry

Isotope-dilution thermal ionization mass spectrometry is an effective tool for measuring ${ }^{226} \mathrm{Ra}$ in otolith material. The three column ion-exchange separation technique effectively isolates radium from interfering quantities of calcium and barium. Because thermal ionization mass spectrometry counts ionized radium atoms directly, determination of ${ }^{226} \mathrm{Ra}$ activity is no longer dependent upon activity or decay. This significantly improves detection limits and analysis time relative to existing techniques (Chapter 2, Table 2). Smaller samples than previously attempted with lower analytical uncertainty have improved the error associated with radiometric age determination. Because of these advances, the most significant source of error is measurement of ${ }^{210} \mathrm{~Pb}$ activity by $\alpha$ spectrometry (Chapter 3, Table 3). In this study, uncertainty in ${ }^{210} \mathrm{~Pb}$ activity contributes $7.8 \%$ of the error where counts are very low (juvenile samples) and decreases to approximately $5 \%$ as age and counts increase. Recovery of ${ }^{226} \mathrm{Ra}$ can still be optimized by tracing radium through the full separation procedure. Experimentation with new ionexchange resins may also provide increased efficiency and recovery (Dietz et al. 1997).

\section{Clarifying assumptions}

The radiometric ageing technique requires several assumptions depending on the analytical circumstances. The typical assumptions are as follows: 1) the otolith is a closed system with no loss or migration of post-formational nuclides in the ${ }^{226} \mathrm{Ra}$ decay series through to ${ }^{210} \mathrm{Po}$; this is necessary because loss of nuclides would result in lower ${ }^{210} \mathrm{~Pb}$ 
activity and subsequently underestimated age, 2) uptake of exogenous nuclides in the ${ }^{226} \mathrm{Ra}$ decay series is negligible relative to ingrowth from ${ }^{226} \mathrm{Ra}$; this is necessary in order to attribute ${ }^{210} \mathrm{~Pb}$ activity in the otolith to the decay of $\left.{ }^{226} \mathrm{Ra}, 3\right)$ uptake of ${ }^{226} \mathrm{Ra}$ is in constant proportion to the otolith mass growth-rate; this assumption is only necessary when whole otoliths are used. These assumptions can be more closely scrutinized with some background research and the increased accuracy of the radiometric ageing technique using isotope-dilution TMS (Chapter 2).

The assumption that an otolith is a closed system is well supported by studies of coraline carbonate properties (a much less controlled matrix than the otolith) and of otolith structure and formation. A proposed violation of this assumption is the loss of ${ }^{222} \mathrm{Rn}$, the daughter of ${ }^{226} \mathrm{Ra}$, from the otolith via diffusion as a noble gas (West and Gauldie 1994). While loss of ${ }^{222} \mathrm{Rn}$ seems possible because it is a non-reactive gas that can enter the interstitial lamellar spaces via alpha-recoil (Moazed et al. 1973, Fleischer et al. 1975) and diffuse out of the otolith, there is strong evidence that indicates this does not occur in the invivo otolith. Any ${ }^{222} \mathrm{Rn}$ that enters the lamellar spaces is entering a matrix of water and otolin, a secreted neuroprotein (Gauldie and Nelson 1988, Panella 1980). A recent study of the sorption characteristics of ${ }^{222} \mathrm{Rn}$ in the presence of organic matter indicate the ${ }^{222} \mathrm{Rn}$ would tend to remain in the sorbent otolin (Wong et al. 1992, Morawska and Phillips 1993). The nature of coraline carbonates also supports the closed system assumption by finding little or no loss of ${ }^{222} \mathrm{Rn}$ from the carbonate matrix (Bender 1973, Moore et al. 1973, Dodge and Thompson 1974). 
The lack of Ostwald ripening and cementation in otoliths support the assumption that there is no post-formational migration of nuclides. Ostwald ripening, a process in which small crystals (more soluble than larger ones) dissolve and reprecipitate onto larger crystals (Parker 1984), has been demonstrated not to occur in corals and otoliths. Studies using ${ }^{45} \mathrm{Ca}$ indicate that once calcium is incorporated it will not exchange with sea water in corals (Goreau and Goreau 1960) and is taken up and remains immobilized in otoliths (Mugiya 1974, Simkiss 1974, Campana 1983, Ichii and Mugiya 1983, Yoklavich and Boehlert 1987, Mugiya 1993). Cementation, precipitation of binding material, may occur in corals (Benninger and Dodge 1986), but probably does not occur in otoliths because porosity is conserved with increasing size, as is indicated by dye penetration (Richter and McDermott 1990). This suggests that the otolith is a well regulated structure, which is supported by the existence of polyanions in the organic matrix, called nucleation barriers, which create directional growth by inhibiting crystal growth to one direction (Wheeler 1993).

The assumption that uptake of exogenous nuclides in the ${ }^{226} \mathrm{Ra}$ decay series is negligible is only necessary for ${ }^{210} \mathrm{~Pb}$. All nuclides from ${ }^{226} \mathrm{Ra}$ through to ${ }^{210} \mathrm{~Pb}$ are very short lived (seconds to minutes) Therefore, incorporation of these isotopes is highly improbable. Because ${ }^{210} \mathrm{~Pb}$ exists in the natural environment, it must be assessed as a potential contaminant. Measuring ${ }^{210} \mathrm{~Pb}$ in juvenile otoliths is currently the most applicable technique for assessing the possibility of direct incorporation. Epipelagic and inshore fishes may encounter the same problem as with corals, where uptake of ${ }^{210} \mathrm{~Pb}$ varies more than ${ }^{226} \mathrm{Ra}$ due to precipitation and runoff (Moore and Krishnaswami 1972, Moore et al. 
1973, Dodge and Thompson 1974, Veeh and Green 1977, Benninger and Dodge 1986).

For deepwater fishes, however, the potential for uptake is far less because dissolved ${ }^{210} \mathrm{~Pb}$ is depleted relative to ${ }^{206} \mathrm{Ra}$ with increasing depth (Nozaki and Tsumogai 1976, Thomson and Turekian 1976, Chung 1987).

West and Gauldie (1994) propose that ${ }^{210} \mathrm{~Pb}$ and ${ }^{210} \mathrm{Po}$ may diffuse into the otolith through the pore structure. Migration of these nuclides into the otolith is very improbable because these species are extremely particle reactive and readily adsorb onto surfaces. The most probable location for either species to be deposited, if they are biologically transported this far, is the actively accreting surface. Therefore, ${ }^{210} \mathrm{Po}$ would not be a factor because of its short half life (138.4 d) and ${ }^{210} \mathrm{~Pb}$ can be assessed in juvenile otoliths.

The assumption that ${ }^{226} \mathrm{Ra}$ uptake is in constant proportion to mass growth-rate is only necessary when whole otoliths and an otolith mass growth-model are used (Bennett et al. 1982). A violation of this assumption was documented for the blue grenadier (Gadidae: Macruronus novaezelandiae; Fenton et al. 1990). The radiometric ageing technique could not be used on whole otoliths because the activity of ${ }^{226} \mathrm{Ra}$ decreased in otoliths from juveniles to adults. This was attributed to an ontogenetic movement from estuarine and inshore waters, where environmental ${ }^{226} \mathrm{Ra}$ can be significantly higher (Fanning et al. 1982, Moore 1996), to deeper, offshore waters. A radiometric analysis of otolith cores from this species, however, was successful (Fenton and Short 1995).

In further support of the effectiveness of the radiometric ageing technique, it has been applied successfully to 13 fish species, including the Pacific grenadier (Bennett et al. 1982, Campana et al. 1990, Fenton et al. 1991, Kastelle et al. 1994, Fenton and Short 
1995, Milton et al. 1995, Stewart et al. 1995, Watters 1995, Kline 1996). In each of these studies, radiometric age determinations are in close agreement with age estimates derived from traditional ageing techniques. It was said, however, that concerns about the assumptions are so significant that the radiometric ageing technique is "invalid" (West and Gauldie 1994). This perspective was biased because much of what was written in the manuscript did not consider all possibilities. The radiometric analysis results for the Pacific grenadier are the most accurate thus far and further supports the validity of this technique.

Pacific grenadier age and growth

The Pacific grenadier is confirmed as a long-lived fish that needs special attention because of the rapidly developing fishery (Chapter 3, Figures $1 \& 2$ ). According to radiometric age determinations, the Pacific grenadier can attain an age of at least $56 \mathrm{yr}$ and may have a longevity greater than 73 yr based on growth increments (Chapter 3, Figures 4 \& 7). Because the Pacific grenadier matures late in life at a large size and population distribution and abundance is unknown, conservative regulatory measures need to be taken.

The depth distribution of the Pacific grenadier may provide a viable management strategy. Because size and abundance appear to increase to a depth of approximately $1500 \mathrm{~m}$ (Stein and Pearcy 1982), it may be possible to implement a size refuge for the Pacific grenadier by limiting fishing to a depth range (i.e. 1200 to $1800 \mathrm{~m}$ ). By fishing in this depth range, juvenile and old adults could be protected in a strategy comparable to 
that of white sturgeon (Acipenser transmontanus) in California, where small and large fish are released. With this strategy, recruitment and growth of immature fish on the upper slope could be more protected, and larger, older fish at depth could provide an undisturbed source of productivity for the population. In addition to this limitation, a seasonal restriction should be implemented to reduce to impact on individuals during spawning season. A moratorium on fishing for the early fall (August) to late winter (February) would encompass the period where reproduction appears to hit a peak (Matsui et al. 1990).

Much remains unknown about the Pacific grenadier that is necessary to develop a sustainable fishery. Population size and distribution, and the movement of individuals in the population, are probably the most important aspects of this fishery that need research. Population size and individual movement may be assessed using recently developed acoustical techniques (Priede et al. 1990). Catch per unit effort information needs to be compiled and analyzed for abundance estimates in areas already being fished. Other studies including tag and recapture coupled with deep trawling and submersible transects could be used to estimate population characteristics at depths greater than current commercial fishing depths. 


\section{References}

Bender, M.L. 1973. Helium-uranium dating of corals. Geochim. Cosmochim. Acta. 37:1229-1247.

Bennett, J.T., Boehlert, G.W., and Turekian, K.K.. 1982. Confirmation of longevity in Sebastes diploproa (Pisces: Scorpaenidae) from ${ }^{210} \mathrm{~Pb} /{ }^{226} \mathrm{Ra}$ measurements in otoliths. Mar. Biol. 71:209-215.

Benninger, L.K. and Dodge, R.E. 1986. Fallout plutonium and natural radionuclides in annual bands of the coral Montastrea annularis, St. Croix, U.S. Virgin Islands. Geochim. Cosmochim. Acta. 50:2785-2797.

Campana, S.E. 1983. Calcium deposition and otolith check formation during periods of stress in coho salmon, Oncorhynchus kisutch. Comp. Biochem. Physiol. 75A:215220.

Campana, S.E., Zwanenburg, K.C.T., and Smith, J.N.. $1990 .{ }^{210} \mathrm{~Pb} /{ }^{226} \mathrm{Ra}$ determination of longevity in redfish. Can. J. Fish. Aquat. Sci. 47:163-165.

Chung, $\mathrm{Y} .1987 .210-\mathrm{Pb}$ in the western Indian Ocean: distribution, disequilibrium and partitioning between dissolved and particulate phases. Earth Planet. Sci. Lett. 85:28-40.

Dietz, M.L., Chiarizia, R., Horwitz, E.P., Bartsch, R.A., and Talanov, V. 1997. Effect of crown ethers on the ion-exchange behavior of alkaline earth metals. Toward improved ion-exchange methods for the separation and preconcentration of radium. Anal. Chem. 69:3028-3037. 
Dodge, R.E. and Thomson, J. 1974. The natural radiochemical and growth records in contemporary hermatypic corals from the Atlantic and Caribbean. Earth Planet. Sci. Lett. 23:313-322.

Fanning, K.A., Breland, J.A., and Byrne, R.H. 1982. Radium-226 and Radon-222 in the coastal waters of west Florida: high concentrations and atmospheric degassing. Science 215:667-670.

Fenton, G.E., Ritz, D.A., and Short, S.A. $1990 .{ }^{210} \mathrm{~Pb} /{ }^{226} \mathrm{Ra}$ disequilibria in otoliths of blue grenadier, Macruronus novaezelandiae; problems associated with radiometric ageing. Aust. J. Mar. Freshwater Res. 41:467-473.

Fenton, G.E., Short, S.A., and Ritz, D.A. 1991. Age determination of orange roughy, Hoplostethus atlanticus (Pisces: Trachichthyidae) using ${ }^{210} \mathrm{~Pb}:{ }^{226} \mathrm{Ra}$ disequilibria. Mar. Biol. 109:197-202.

Fenton, G.E. and Short, S.A. 1995. Radiometric analysis of blue grenadier, Macruronus novaezelandiae, otolith cores. Fish. Bull. 93:391-396.

Fleischer, R.L., Price, P.B., and Walker, R.M. 1975. Nuclear tracks in solids. University of California Press, Berkeley.

Gauldie, R.W., and Nelson, D.G.A. Aragonite twinning and neuroprotein secretion are the cause of daily growth rings in fish otoliths. Comp. Biochem. Physiol. 90A(3):501 509. 
Goreau, T.F. and Goreau, N.I. 1960. The physiology of skeleton formation in corals.

IV. On isotopic equilibrium exchanges of calcium between corallum and environment in living and dead reef-building corals. Biol. Bull. Mar. Biol. Lab., Woods Hole. 119:416-427.

Ichii, T. and Mugiya, Y. 1983. Comparative aspects of calcium dynamics in calcified tissues in the goldfish Carassius auratus. Bull. Japan. Soc. Sci. Fish. Manag. 49:1039-1044.

Kastelle, C.R., Kimura, D.K., Nevissi, A.E., and Gunderson, D.R. 1994. Using Pb210/Ra-226 disequilibria for sablefish, Anoplopoma fimbra, age validation. Fish. Bull. 92:292-301.

Kline, D.E. 1996. Radiometric age verification for two deep-sea rockfish (Sebastolobus altivelis and Sebastolobus alascamus). M.S. thesis, California State University, San Jose, Moss Landing Marine Laboratories.

Matsui, T., Kato, S., and Smith, S.E. 1990. Biology and potential use of Pacific grenadier, Coryphaenoides acrolepis, off California. Mar. Fish. Rev. 52(3):1-17.

Milton, D.A., Short, S.A., ONeill, M.F., Blaber, S.J.M. 1995. Ageing of three species of tropical snapper (Lutjanidae) from the Gulf of Carpentaria, Australia, using radiometry and otolith ring counts. Fish. Bull. 93:103-115.

Moazed, C., Spector, R.M., and Ward, R.F. 1973. Polonium radiohalos: an aiternate interpretation. Science. 180:1272-1274.

Moore, W.S. and Krishnaswami, S.. 1972. Coral growth rates using 228-Ra and 210-Pb. Earth Planet. Sci. Lett. 15:187-190. 
Moore, W.S., Krishnaswami, S., and Bhat, S.G. 1973. Radiometric determinations of coral growth rates. Bull. Mar. Sci. 23:157-176.

Moore, W.S. 1996. Large groundwater inputs to coastal waters revealed by ${ }^{226} \mathrm{Ra}$ enrichments. Nature 380:612-614.

Morawska, L., and Phillips, C.R. 1993. Dependence of the radon emanation coefficient on radium distribution and internal structure of the material. Geochim. Cosmochim. Acta. 57:1783-1797.

Mugiya, Y. 1974. Calcium-45 behavior at the level of the otolithic organs of rainbow trout. Bull. Jpn. Soc. Sci. Fish. 40:457-463.

Mugiya, Y. 1993. Calcium and strontium metabolism in fish otoliths. Abstract. International Otolith Symposium: Fish Otolith Research and Application. Hilton Head, South Carolina, U.S.A.

Nozaki, Y. and Tsunogai, S. 1976. 226-Ra, 210-Pb, 210-Po disequilibria is the western North Pacific. Earth Planet. Sci. Lett. 32:313-321.

Parker, S.P. (ed.) 1984. McGraw-Hill dictionary of scientific and technical terms. 3rd ed. McGraw-Hill Book Co.

Pannella, G. Growth patterns in fish sagittae. 1980. In Skeletal growth of aquatic organisms. Edited by Rhoades, D.C., and Lutz, R.A. Plenum Publishing Corp. pp. 519-560.

Priede, I.G., Smith, K.L. Jr., and Armstrong, J.D. Foraging behavior of abyssal grenadier fish: inferences from acoustic tagging and tracking in the North Pacific Ocean. Deep-Sea Res. 37(1):81-101. 
Richter, H. and McDermott, J.G. 1990. The staining of fish otoliths for age determiriztion. J. Fish. Biol. 36:773-779.

Simkiss, K. 1974. Calcium metabolism of fish in relation to ageing. In The proseedings of an international symposium on ageing of fish. Edited by T.B. Bagenal. Unwin Brothers Limited, The Gresham Press, Old Woking, Surrey, England.

Stein, D.L., and Pearcy, W.G. 1982. Aspects of reproduction, early life history, and biology of macrourid fishes of Oregon, USA. Deep-Sea Res. 29(11A):1373-1379.

Stewart, B.D., Fenton, G.E., Smith, D.C., and Short, S.A.. 1995. Validation of otolithincrement age estimates for a deepwater fish species, the warty oreo Allocyttus verrucosus, by radiometric analysis. Mar. Biol. 123:29-38.

Thomson, J. and Turekian, K.K.. 1976. 210-Po and 210-Pb distributions in the ocean water profiles from the eastem South Pacific. Earth Planet. Sci. Lett. 32:297-303.

Veeh, H.H. and Green, D.C.. 1977. Radiometric geochronology of coral reefs. In Jones, O.A. and Endean, R. (eds.) Biology and Geology of coral reefs. Academic Press, New York. 4:183-2Co.

Watters, D.L. 1995. Age determination and confirmation from otoliths of the bank rockfish, Sebastes rufus (Scorpaenidae). M.S. thesis, Califomia State University, San Jose, Moss Landing Marine Laboratories.

West, I.F., and Gauldie, R.W. 1994. Perspective: Determination of fish age using ${ }^{210} \mathrm{~Pb}:{ }^{226} \mathrm{Ra}$ disequilibrium methods. Can. J. Fish. Aquat. Sci. 51:2333-2340. 
Wheeler, A.P. 1993. Regulation of carbonate biomineralization. Abstract. International Otolith Symposium: Fish Otolith Research and Application. Hilton Head, South Carolina, U.S.A.

Wong, C.S., Chin, Y., and Gschwend, P.M. 1992. Sorption of radon-222 to natural sediments. Geochim. Cosmochim. Acta. 56:3923-3932.

Yoklavich, M.M. and G.W. Boehlert. 1987. Daily growth increments in otoliths of juvenile black rockfish, Sebastes melanops : an evaluation of autoradiography as a new method of validation. Fish. Bull. 85(4):826-832. 